Correspondence to:

Professor Mark G. Humphrey

Research School of Chemistry

Australian National University

Canberra, ACT 2601, Australia

T: +61261252927

E: Mark.Humphrey@anu.edu.au 


\title{
Computational Studies of the Nonlinear Optical Properties of Organometallic Complexes
}

Mahesh S. Kodikara, Robert Stranger, and Mark G. Humphrey*

Research School of Chemistry, Australian National University

Canberra, ACT 2601 (Australia)

\begin{abstract}
Computational methods for calculating the molecular nonlinear optical (NLO) properties of molecules are reviewed, with an emphasis on clarifying the strengths and weaknesses of the various approaches. A brief introduction to the theory of NLO effects is provided, and a summary of the key experimental techniques for the determination of molecular first hyperpolarizabilities is included, with discussion of their advantages and disadvantages. Applications of semi-empirical methods and density functional theory in developing structure - quadratic NLO property relationships for organometallic complexes (and particularly metal alkynyl complexes) are reviewed.
\end{abstract}

Abbreviations (footnote on first published page)

AC alternating current or asymptotically correct 
ADF Amsterdam density functional

AM1 Austin model 1 semi-empirical method

au atomic units

BBO $\beta$-barium borate

CC coupled-cluster

CHF coupled Hartree-Fock

CI configuration interaction

CNDO complete neglect of differential overlap

CPHF coupled-perturbed Hartree-Fock

CPKS coupled-perturbed Kohn-Sham

CT charge transfer

DC direct current

DFT density functional theory

DZ double $\varsigma$

DZP double $\varsigma$ plus polarized

EFISH electric field-induced second-harmonic generation

EOM-CC equation-of-motion CC

DFG difference-frequency generation

ERM external reference method

FF finite-field

GGA generalized gradient approximation

HRS hyper-Rayleigh scattering

ICT intramolecular charge transfer

INDO intermediate neglect of differential overlap method

INDO/S INDO/spectroscopic approximation 
IRM internal reference method

KDP potassium dihydrogen phosphate

KTP potassium titanyl phosphate

LBO lithium triborate

LDA local-density approximation

LLCT ligand-to-ligand charge transfer

LMCT ligand-to-metal charge transfer

LR long-range

LRC LR corrected

MBPT or MP many-body perturbation theory

MCSCF, TDMCSCF, MCTDHF, MCRPA (time-dependent) multiconfiguration selfconsistent field

MLCT metal-to-ligand charge transfer

MNA 2-methyl-4-nitroaniline

MP2 second-order Møller-Plesset perturbation theory

NLO nonlinear optical

OR optical rectification

PA parametric amplification

PNA $p$-nitroaniline

PPP Pariser-Parr-Pople method

QZ4P core triple- $\varsigma$, valence quadruple- $\varsigma$ plus quadruply polarized

RPA random-phase approximation

RS range-separated

SFG sum-frequency generation

SHG second-harmonic generation 
SIE self-interaction error

SOPPA second-order polarization propagator approximation

SOS sum-over-states

SR short-range

TDCHF or TDCPHF time-dependent coupled (perturbed) Hartree-Fock

TDDFT time-dependent DFT

TDHF time-dependent Hartree-Fock

THG third-harmonic generation

TLM two-level model

TPA two-photon absorption

TZP core double- $\varsigma$, valence triple- $\varsigma$ plus polarized

TZ2P core double- $\varsigma$, valence triple- $\varsigma$ plus doubly polarized

ZINDO Zerner's intermediate neglect of differential overlap method

\section{Keywords}

Density functional theory; computational methods; nonlinear optics; hyperpolarizabilities; alkynyl complexes

\section{Contents}

\section{Introduction}

\subsection{Material considerations}


1.2. Theory of nonlinear optics

1.2.1. Second-order NLO processes

1.2.2. Third-order NLO processes

\section{Determination of molecular first hyperpolarizability}

2.1. Experimental techniques

2.1.1. Electric field-induced second-harmonic generation (EFISH)

2.1.2. Hyper-Rayleigh scattering (HRS)

2.2. Quantum mechanical methods and corrections

2.2.1. Sum-over-states (SOS) method

2.2.2. Derivatives method

2.2.3. Electron correlation

2.2.4. Density functional theory

2.2.5. Time-dependent density functional theory

2.2.6. Exchange-correlation functionals

2.2.7. Basis set effects

3. Molecular first hyperpolarizability of organometallic complexes

3.1. Ferrocenyl complexes

3.2. Chromium arene derivatives

3.3. Group 8 metal alkynyl complexes

3.4. Effect of co-ligands

3.5. Optimizing the alkynyl $\pi$-bridge

3.6. Group 10 and 11 metal alkynyl complexes

4. Conclusion

5. Acknowledgement

6. References 


\section{Introduction}

Nonlinear optics deals with phenomena arising from light-induced changes in the optical properties of materials. The interaction of light with a nonlinear optical (NLO) material gives rise to new optical fields with altered properties (e.g. phase, frequency, amplitude, polarization, path, etc.) [1-4]. The high-intensity electromagnetic fields required are usually supplied by lasers, so routine observation of NLO phenomena was only possible after the advent of the laser in 1960 [5]. Modern nonlinear optics began with the first demonstration of second-harmonic generation shortly thereafter [6], but several NLO effects had been proposed or demonstrated beforehand (e.g. the Kerr or quadratic electro-optic effect, the Pockels or linear electro-optic effect [7], Raman scattering, two-photon absorption (TPA) [8], two-photon excitation [9], etc.). Following demonstration of the first working laser $[5,10]$ and the first demonstration of second-harmonic generation [6], several other nonlinear optical effects (e.g. third-harmonic generation (THG), sum-frequency generation (SFG), differencefrequency generation (DFG), optical rectification, etc.) and the theoretical framework to describe the NLO phenomena were developed and demonstrated in quick succession $[11,12]$.

NLO-efficient materials continue to be of intense interest, the research being given strong impetus by a plethora of applications. Organometallic complexes are of particular interest for reasons summarized below. The experimental studies have been complemented by computational approaches because the latter can not only post-rationalize the outcomes of experimental studies, but can also suggest fruitful experimental targets, and in addition can 
probe structural modifications accessible with difficulty experimentally. This review summarizes computational studies of the NLO properties of organometallic complexes, and includes a discussion of some materials considerations, a summary of the theoretical background to NLO phenomena, and a description of the experimental and computational methods that have been employed to investigate organometallics.

\subsection{Material considerations}

Nonlinear effects arise from the interaction of intense electric fields with nonlinear optical media. Materials with significant NLO properties have various technological applications such as data storage, optical computing, optical communication, optical switches, frequency generation, etc. $[2,4,13,14]$. Materials which provide large as well as fast NLO responses are desirable for practical devices, and the search for novel, efficient, photon-manipulating materials continues unabated because there is no material thus far which is suitable for all types of NLO applications.

Inorganic materials are usually robust with excellent thermal stability, and inorganic crystals were the initial choice for NLO materials, Franken et al. [6] observing the first example of second-harmonic generation when a ruby laser was directed at a quartz crystal. Subsequently, KTP (potassium titanyl phosphate), $\mathrm{LiNbO}_{3}$, and $\mathrm{LiTaO}_{3}$ were used for frequency conversions. Borate crystals have a high damage threshold and a broad transparency region, two critical material requirements for NLO device applications; LBO (lithium triborate) and BBO ( $\beta$-barium borate) are the two most popular NLO crystalline materials from the borate family. LBO, BBO and KDP (potassium dihydrogen phosphate) crystals have found applications in third-harmonic generation of Nd:YAG lasers. Some chalcopyrite crystals such 
as $\mathrm{AgGaS}_{2}, \mathrm{AgGaSe}_{2}$, and $\mathrm{ZnGeP}_{2}$ have been shown to be applicable for NLO uses in the infrared [15]. However, many NLO applications require fast responses and, in general, inorganic NLO crystals suffer from slow response times (usually of the order of nanoseconds) and little architectural flexibility [16].

Organic crystals represent another interesting class of NLO materials $[4,17,18]$. Bulk nonlinearities of organic crystals can be directly related to the optical nonlinearity of the molecular constituents, and the molecular structure can be used to optimize the nonlinearity, which is mostly derived from $\pi$-electron redistribution. As a result, organic crystals generally exhibit faster response times (of the order of femtoseconds) than inorganic crystals, for which lattice distortions or the dynamics of charge carriers lead to slower nonlinear responses $[17,19,20]$. In addition to fast response times, the advantages of organic crystals over inorganics include ease of fabrication, exceptionally large NLO responses, and ease of processing to films $[21,22]$.

Organic molecules with electron releasing and withdrawing groups linked through a $\pi$ conjugated system have been found to exhibit strong quadratic NLO responses. However, most organic molecules crystallize in centrosymmetric space groups for which bulk secondorder NLO effects (e.g. second-harmonic generation) vanish, although the molecular secondorder response may be non-zero, e.g. p-nitroaniline (PNA) [22]. In contrast, 2-methyl-4nitroaniline (MNA), for example, has a very large bulk material second-harmonic coefficient $\left(d_{i j k}\right)$ because the methyl groups of the aromatic ring lead to crystallization in the acentric monoclinic space group $C \mathrm{c}[23,24]$. Translating strong molecular NLO responses into efficient NLO-active bulk materials is a major crystal engineering challenge. Lower thermal stability than inorganic crystals and transparency/NLO efficiency tradeoff are drawbacks associated with organic materials. 
Organometallics possess the advantages of organics but offer additional design flexibility, e.g. the possibility of varying the metal (and its oxidation state), co-ligands, and coordination geometry. Moreover, the NLO merit of organic fragments (e.g. carbenes) with little or no independent stability can be determined via complexation to metals. As a result, organometallic complexes have commanded significant attention [22,25-27]. The metal center can introduce electronic asymmetry to the molecule because it can act as an extremely strong donor or acceptor, thereby resulting in second-order nonlinearity. The two most intensively studied classes of organometallic complexes to date are metallocenyl and metal alkynyl complexes (Figures 1 and 2). In metal alkynyl complexes, the metal center is in the plane of the organic $\pi$-system and so, compared to metallocenyl complexes, a better coupling between the donor (ligated metal) and bridge-acceptor groups is expected, which should improve NLO performance for the metal alkynyl complexes [28,29]. For organometallic complexes, metal-to-ligand charge transfer (MLCT) or ligand-to-metal charge transfer (LMCT) transitions in the visible region usually dictate the molecular second-order NLO response [22,27]. In the case of dipolar metal alkynyl complexes (Figure 2), the CT transition from $\mathrm{d}(\mathrm{M})$ to $\pi^{*}$ (bridge-acceptor) is usually responsible for the quadratic NLO response. Structure-NLO property relationships for dipolar metal alkynyls that have considered the effect of varying the ligated metal center and co-ligands, bridge lengthening, and bridge composition have been developed [16,25,30-33].

(Insert Figure 1)

(Insert Figure 2)

\subsection{Theory of nonlinear optics}


A brief introduction to various nonlinear optical effects is provided here to clarify the subsequent discussion. For weak fields, the induced polarization, $\mathrm{P}$, in a bulk material is proportional to the strength of the external oscillating electric field E:

$\mathrm{P}=\chi^{(1)} \cdot \mathrm{E}$

where the proportionality constant $\chi^{(1)}$ is the linear susceptibility (a second-rank tensor, $\chi_{\mathrm{ij}}{ }^{(1)}$ ). The polarization is linearly dependent on the applied field. When an intense electromagnetic field (such as that from a laser) propagates through a nonlinear optical medium, Eq. 1 should be modified as follows:

$\mathrm{P}=\chi^{(1)} \cdot \mathrm{E}+\chi^{(2)} \cdot \mathrm{E} \cdot \mathrm{E}+\chi^{(3)} \cdot \mathrm{E} \cdot \mathrm{E} \cdot \mathrm{E}+\ldots$

The coefficients $\chi^{(2)}$ and $\chi^{(3)}$ are bulk NLO susceptibilities (or more precisely second- and third-order nonlinear susceptibilities), leading to second- and third-order NLO processes (discussed next). For convenience, indices of susceptibilities have been dropped, but it should be noted that $\chi_{\mathrm{ijk}}{ }^{(2)}$ and $\chi_{\mathrm{ijkl}}{ }^{(3)}$ are tensors of third- and fourth-order, respectively. For most materials, the higher-order effects which result from the higher-order terms in Eq. 2 are extremely difficult to observe [4].

\subsubsection{Second-order NLO processes}

The total polarization, including nonlinear polarization, corresponds to:

$\mathrm{P}=\mathrm{P}_{\mathrm{L}}+\mathrm{P}_{\mathrm{NL}}$ 
The electric field of a plane wave travelling along the $\mathrm{z}$-direction can be expressed within an arbitrary phase factor as:

$\mathrm{E}=\mathrm{E}_{0} \cos (\mathrm{kz}-\omega \mathrm{t})$

where $E_{0}$ is the amplitude of the electric field and $\mathrm{k}$ is the propagation constant. From Eq. 2, the nonlinear polarization created by the first nonlinear term is:

$\mathrm{P}_{\mathrm{NL}}^{(2)}=\chi^{(2)} \mathrm{E}^{2}$

Substituting Eq. 4 into Eq. 5 gives:

$\mathrm{P}_{\mathrm{NL}}^{(2)}=\chi^{(2)} \mathrm{E}_{0}^{2} \cos ^{2}(\mathrm{kz}-\omega \mathrm{t})$

Applying the trigonometric identity for $\cos ^{2} \theta$, Eq. 6 can be rewritten as:

$\mathrm{P}_{\mathrm{NL}}^{(2)}=(1 / 2) \chi^{(2)} \mathrm{E}_{0}^{2}+(1 / 2) \chi^{(2)} \mathrm{E}_{0}^{2} \cos 2(\mathrm{kz}-\omega \mathrm{t})$

From Eq. 7, $\mathrm{P}_{\mathrm{NL}}{ }^{(2)}$ consists of two components: a frequency independent component (the first term) and a component oscillating at frequency $2 \omega$ (the second term). The former, a time independent polarization, is called optical rectification (OR), while the latter leads to secondharmonic generation (SHG) (Figure 3). The nonlinear polarization oscillating at $2 \omega$ emits new radiation with frequency $2 \omega$. When the external electric field contains two distinct frequency components $\left(\omega_{1}\right.$ and $\left.\omega_{2}\right)$, e.g. two light beams with different frequencies, Eq. 4 can be expressed in the form:

$E=E_{1} \cos \left(k_{1} z-\omega_{1} t\right)+E_{2} \cos \left(k_{2} z-\omega_{2} t\right)$ 
The $\mathrm{P}_{\mathrm{NL}}{ }^{(2)}$ resulting from the above field, Eq. 8, is:

$\mathrm{P}_{\mathrm{NL}}^{(2)}=\chi^{(2)} \mathrm{E}_{1}^{2} \cos ^{2}\left(\mathrm{k}_{1} \mathrm{Z}-\omega_{1} \mathrm{t}\right)+\chi^{(2)} \mathrm{E}_{2}^{2} \cos ^{2}\left(\mathrm{k}_{2} \mathrm{Z}-\omega_{2} \mathrm{t}\right)+\chi^{(2)} 2 \mathrm{E}_{1} \mathrm{E}_{2} \cos \left(\mathrm{k}_{1} \mathrm{Z}-\omega_{1} \mathrm{t}\right) \cos \left(\mathrm{k}_{2} \mathrm{Z}-\omega_{2} \mathrm{t}\right)$

Using the trigonometric identity for $\cos \theta \cos \varphi$, the third term of Eq. 9 can be rewritten as:

$\chi^{(2)} 2 \mathrm{E}_{1} \mathrm{E}_{2} \cos \left(\mathrm{k}_{1} \mathrm{z}-\omega_{1} \mathrm{t}\right) \cos \left(\mathrm{k}_{2} \mathrm{z}-\omega_{2} \mathrm{t}\right)=\chi^{(2)} \mathrm{E}_{1} \mathrm{E}_{2} \cos \left[\left(\mathrm{k}_{1}+\mathrm{k}_{2}\right) \mathrm{z}-\left(\omega_{1}+\omega_{2}\right) \mathrm{t}\right]+\chi^{(2)} \mathrm{E}_{1} \mathrm{E}_{2} \cos \left[\left(\mathrm{k}_{1}\right.\right.$

$\left.\left.-\mathrm{k}_{2}\right) \mathrm{z}-\left(\omega_{1}-\omega_{2}\right) \mathrm{t}\right]$

According to Eq. 9 and Eq. 10 , in addition to $2 \omega_{1}, 2 \omega_{2}$, and $\omega=0$ components (the first and second terms of Eq. 9), the polarization contains two frequency components, the sum $\left(\omega_{1}+\right.$ $\left.\omega_{2}\right)$ and the difference $\left(\omega_{1}-\omega_{2}\right)$, the former leading to SFG, while the latter is responsible for DFG (Figure 3). Although several new fields are generated when the beam passes through the crystal (Eq. 10), only one process is usually targeted because different processes require different phase-matching conditions.

(Insert Figure 3)

SHG is just a special case of SFG (in which $\omega_{1}=\omega_{2}=\omega$ ). In the case of DFG, the frequency of the output, $\omega_{3}$, is equal to the difference of those of the incident beams, i.e. $\omega_{3}=\omega_{1}-\omega_{2}$. Typically, the input field at frequency $\omega_{1}$ is the strongest (and is known as the pump beam). In the process of generating the output at $\omega_{3}$, the pump photons decay into two photons of frequencies $\omega_{2}$ and $\omega_{3}$ to satisfy conservation of energy (Figure 3). The signal at $\omega_{2}$ (the other input field) is amplified during this process, which is known as parametric amplification (PA). In this case, the output at $\omega_{3}$ is called the idler. If the only incident field used is the 
pump wave $\left(\omega_{1}\right)$, the interaction with the NLO crystal still generates two output waves at frequencies $\omega_{2}$ and $\omega_{3}$ such that $\omega_{1}=\omega_{2}+\omega_{3}$ but the new signals are very weak. The efficiency of generating the signal and/or idler beams (two output waves) can be enhanced by placing the NLO crystal in a cavity. The frequency of the signal beam, the desired output, can be tuned by adjusting the phase-matching condition. This is often achieved by changing temperature, orientation of the crystal, or by applying an external potential.

In $\mathrm{SHG}$, two photons at frequency $\omega$ combine to form a photon at frequency $2 \omega$. In other words, SHG (and other NLO phenomena) conserve energy. For a general situation, this is:

$\omega_{3}=\omega_{1}+\omega_{2} \quad(11)$

where $\omega_{1}$ and $\omega_{2}$ are the frequency of the input waves and $\omega_{3}$ is the frequency of the output wave. Frequency mixing processes generally have low efficiency, unless the phase matching condition is satisfied. If satisfied, the intensity of the second-harmonic wave will grow as the light propagates through the crystal. If not met, the intensity periodically oscillates as the light travels through the medium. The phase mismatch for SHG is shown in Figure 4 using a vector diagram.

\section{(Insert Figure 4)}

If the phase matching condition is obeyed, then:

$\mathrm{k}_{2}=\mathrm{k}_{1}+\mathrm{k}_{1}=2 \mathrm{k}_{1}$

Because: 
$\mathrm{k}=\mathrm{n}(\omega) \omega / \mathrm{c}$

where $n(\omega)$ is the refractive index of the wave of frequency $\omega$ and $c$ is the speed of light, we can rewrite Eq. 12 as:

$\mathrm{n}(2 \omega)=\mathrm{n}(\omega) \quad(14)$

Eq. 14 implies that both waves must travel with equal velocities for efficient SHG. This can be achieved with birefringent phase matching [3].

The electro-optic effect is the change in the refractive index caused by a DC or lowfrequency electric field. This modified refractive index leads to changes in amplitude, phase, or path of light travelling through a medium. In other words, the field applied to a medium modulates the light travelling through it. The total electric field within the media subjected to a DC (or low-frequency) electric field with an amplitude of $\mathrm{E}_{0}$ is given by:

$\mathrm{E}=\mathrm{E}_{0}+\mathrm{E}_{1} \cos (\mathrm{kz}-\omega \mathrm{t})$

The total polarization due to the contributions of the first and second terms is:

$\mathrm{P}=\chi^{(1)} \cdot \mathrm{E}+\chi^{(2)} \cdot \mathrm{E} \cdot \mathrm{E} \quad(16)$

Substituting Eq. 15 into Eq. 16 gives:

$\mathrm{P}=\chi^{(1)}\left[\mathrm{E}_{0}+\mathrm{E}_{1} \cos (\mathrm{kz}-\omega \mathrm{t})\right]+\chi^{(2)}\left[\mathrm{E}_{0}+\mathrm{E}_{1} \cos (\mathrm{kz}-\omega \mathrm{t})\right]^{2}$

Collecting polarization contributions with $\omega$ gives:

$P(\omega)=\left(\chi^{(1)}+2 \chi^{(2)} \mathrm{E}_{0}\right) \mathrm{E}_{1} \cos (\mathrm{kz}-\omega \mathrm{t})(18)$ 
Eq. 18 is similar to the linear relationship between the polarization and the electric field $\omega$, but now the susceptibility $\left(\chi^{(1)}+2 \chi^{(2)} \mathrm{E}_{0}\right)$ has an additional second-order NLO susceptibility term which depends linearly on the external electric field strength. The DC field thus modifies the linear susceptibility and refractive index of the medium (refractive index is related to the linear susceptibility). This change in the refractive index is known as the linear electro-optic effect (or the Pockels effect) - the change in the refractive index is proportional to the amplitude of the external electric field.

\subsubsection{Third-order NLO processes}

Third-order nonlinear optical effects arise from the third term in Eq. 2. It should be noted that $\chi^{(2)}$ vanishes for materials with a centre of symmetry, while odd terms, including $\chi^{(3)}$, are non-zero for all media. The polarization contribution of the first three terms in Eq. 2 for a material with a centre of symmetry is:

$\mathrm{P}=\chi^{(1)} \cdot \mathrm{E}+\chi^{(3)} \cdot$ E.E.E (19)

For a monochromatic field,

$\mathrm{P}=\chi^{(1)} \mathrm{E}_{1} \cos (\mathrm{kz}-\omega \mathrm{t})+\chi^{(3)}\left[\mathrm{E}_{1} \cos (\mathrm{kz}-\omega \mathrm{t})\right]^{3}$

Applying the trigonometry identity for $\cos ^{3} \theta$ gives:

$\mathrm{P}=\chi^{(1)} \mathrm{E}_{1} \cos (\mathrm{kz}-\omega \mathrm{t})+\chi^{(3)} \mathrm{E}_{1}^{3}(1 / 4) \cos 3(\mathrm{kz}-\omega \mathrm{t})+\chi^{(3)} \mathrm{E}_{1}^{3}(3 / 4) \cos (\mathrm{kz}-\omega \mathrm{t})=\mathrm{E}_{1}\left[\chi^{(1)}+\right.$

$\left.(3 / 4) \chi^{(3)} \mathrm{E}_{1}^{2}\right] \cos (\mathrm{kz}-\omega \mathrm{t})+\chi^{(3)} \mathrm{E}_{1}^{3}(1 / 4) \cos 3(\mathrm{kz}-\omega \mathrm{t})(21)$ 
The first and second terms of Eq. 21 give the polarization waves at the frequencies $\omega$ and $3 \omega$, respectively. The former is very similar to the term that leads to the linear electro-optic effect in Eq. 18, but with the nonlinear susceptibility term depending quadratically on the amplitude of the fundamental field. However, since the fundamental wave itself provides the electric field, this effect is referred to as the AC Kerr effect or optical Kerr effect. Change in the refractive index of a third-order NLO material by the application of a DC field is known as the DC Kerr effect.

The second term in Eq. 21 leads to the generation of new fields of frequency $3 \omega$ as the incident light $(\omega)$ travels through the NLO medium. This process is known as third-harmonic generation (THG) (Figure 5), where three photons at frequency $\omega$ combine to form a photon at frequency $3 \omega$. More details on various NLO phenomena, including third-order effects when the input wave consists of three different frequencies, and nonlinear absorption, can be found in Ref. [1].

\section{(Insert Figure 5)}

Eq. 2 describes the polarization response of a bulk medium when it is subjected to an intense light beam. A similar expression can be written for the dipole moment $\left(\mu_{\mathrm{i}}\right)$ of a molecule induced by a laser:

$\mu_{\mathrm{i}}=\mu_{0}+\alpha_{\mathrm{ij}} \mathrm{E}_{\mathrm{j}}+\beta_{\mathrm{ijk}} \mathrm{E}_{\mathrm{j}} \mathrm{E}_{\mathrm{k}}+\gamma_{\mathrm{ijk} l} \mathrm{E}_{\mathrm{j}} \mathrm{E}_{\mathrm{k}} \mathrm{E}_{1}+\ldots$

In this equation, $\mu_{0}$ is the permanent dipole moment, $\alpha_{\mathrm{ij}}$ is the linear polarizability, and $\beta_{\mathrm{ijk}}$ and $\gamma_{\mathrm{ijkl}}$ are the first (or quadratic) and second (or cubic) hyperpolarizabilities, respectively. $\alpha_{\mathrm{ij}}, \beta_{\mathrm{ijk}}$, and $\gamma_{\mathrm{ijkl}}$ are tensors of first, second and third order, respectively, akin to their bulk susceptibilities. $\beta_{\mathrm{ijk}}$ and $\gamma_{\mathrm{ijkl}}$ are responsible for molecular second- and third-order NLO 
effects. Similar to $\chi^{(2)}, \beta$ vanishes for a system with a centre of symmetry, but $\alpha$ and $\gamma$ are non-zero for all molecules. Note that even though $\beta \neq 0, \chi^{(2)}$ can vanish; this is a common situation for organic materials as a result of crystallization in centrosymmetric space groups [22]. Further, $\beta_{\mathrm{ijk}}$ is a third order tensor and thus contains 27 components. Fortunately, due to various symmetry properties of the tensor, only a few components are independent. Common second- and third-order nonlinear processes, including their frequency arguments, are listed in Table 1. The first frequency in an argument describes the resultant polarization wave while the other frequencies refer to the incident waves.

Table 1. Common second- and third-order NLO processes with relevant frequency arguments

$$
\text { Second-order NLO processes }\left(\beta_{\mathrm{ijk}}, \chi_{\mathrm{IJK}}^{(2)}\right)
$$

\begin{tabular}{lc}
\hline Static & $(0 ; 0,0)$ \\
Second-harmonic generation (SHG) & $(-2 \omega ; \omega, \omega)$ \\
Two-wave mixing & $\left(-\left(\omega_{1}+\omega_{2}\right) ; \omega_{1}, \omega_{2}\right)$ \\
DC Pockels effect & $(-\omega ; \omega, 0)$ \\
Optical rectification (OR) & $(0 ; \omega,-\omega)$
\end{tabular}

Third-order NLO process $\left(\gamma_{\mathrm{ijkl}}, \chi_{\mathrm{IJKL}}^{(3)}\right)$

Static $(0 ; 0,0,0)$

Third-harmonic generation (THG) $(-3 \omega ; \omega, \omega, \omega)$

DC Kerr effect

$$
(-\omega ; \omega, 0,0)
$$

AC Kerr effect

$\left(-\omega_{2} ; \omega_{1},-\omega_{1}, \omega_{2}\right)$

DC-induced second-harmonic generation $(-2 \omega ; 0, \omega, \omega)$ 
Three-wave mixing

$\left(-\omega_{\sigma} ; \omega_{1}, \omega_{2}, \omega_{3}\right)$

DC-induced optical rectification

$$
(0 ; \omega,-\omega, 0)
$$

\section{Determination of molecular first hyperpolarizability}

Some microscopic second-order NLO phenomena at different frequency inputs are listed in

Table 1. Amongst these, second-harmonic generation, the process that converts the $\omega$ input beam to a $2 \omega$ output beam, is the most widely studied NLO process. The efficiency of this conversion or SHG-activity of a molecule depends on the first hyperpolarizability coefficient $\beta(-2 \omega ; \omega, \omega)$; reliable measurements of $\beta(-2 \omega ; \omega, \omega)$ are thus required to study the SHGactivity. Attention is first given to commonly used experimental techniques for the determination of molecular first hyperpolarizability. Following this, quantum chemical methods which have been developed to calculate response properties and play an important role in understanding the origin of NLO effects at the molecular level are discussed.

\subsection{Experimental techniques}

Electric field-induced second-harmonic generation and hyper-Rayleigh scattering are the techniques that have been widely used to extract $\beta(-2 \omega ; \omega, \omega)$ for organometallics. This section covers the fundamentals of each technique and their limitations. 


\subsubsection{Electric field-induced second-harmonic generation (EFISH)}

As mentioned earlier, the first hyperpolarizability coefficient vanishes for centrosymmetric media such as gases and liquids. Thus, second-order NLO processes such as secondharmonic generation (SHG) are forbidden in liquids [34]. In a typical EFISH experiment, a strong DC electric field is applied to break the symmetry of a liquid or solution. The molecules partially orient in the solution due to the interaction of the molecular dipoles with the applied field $[4,35]$. This in turn leads to a nonzero $\chi^{(2)}$, thereby rendering the observation of SHG (i.e. DC-SHG) possible. Field-induced doubling was first observed in a solid [36] and subsequently in a number of gases [37]. Levine and Bethea first used this technique to determine the hyperpolarizabilities $(\beta$ and $\gamma$ ) in organic liquids $[38,39]$.

Since EFISH involves the interaction of four waves to generate the SHG signal, two waves from the laser with a frequency of $\omega$ and one from the DC field, DC-SHG can be viewed as a third-order NLO process, i.e. $\chi^{(3)}(-2 \omega ; \omega, \omega, 0)$ [40]. In EFISH, the macroscopic second hyperpolarizability $\Gamma_{L}$ of the medium of interest, a shorthand for $\chi^{(3)}(-2 \omega ; \omega, \omega, 0)$, is actually measured. In a pure liquid, $\Gamma_{\mathrm{L}}$ is related to the microscopic second hyperpolarizability through [39]:

$$
\Gamma_{\mathrm{L}}=\mathrm{N} \gamma \mathrm{f}_{0} \mathrm{f}_{\omega}^{2} \mathrm{f}_{2 \omega}
$$

where $\mathrm{N}$ is the number density and $\mathrm{f}_{0}, \mathrm{f}_{\omega}^{2}$, and $\mathrm{f}_{2 \omega}$ are local field factors at the indicated optical frequencies. When the molecular z-axis is parallel to the direction of the permanent dipole moment, the second hyperpolarizability can be expressed as: 


$$
\gamma=\gamma^{\mathrm{e}}+\frac{\mu_{\mathrm{z}} \beta_{\mathrm{z}}}{5 \mathrm{kT}}
$$

Here, the first term $\gamma^{\mathrm{e}}$ is the purely electronic contribution to $\gamma$ and the temperature dependent term is the rotational contribution [41]. The $\beta_{\mathrm{z}}$ in the second term is the vector component of the molecular first hyperpolarizability tensor $\beta$ along the permanent dipole moment (or z-axis in this case). Assuming Kleinman symmetry [42], $\gamma^{\mathrm{e}}$ and $\beta_{\mathrm{z}}$ can be written in tensor elements as:

$$
\begin{gathered}
\gamma^{\mathrm{e}}=\frac{1}{5}\left(\gamma_{\mathrm{xxxx}}+\gamma_{\mathrm{yyyy}}+\gamma_{\mathrm{zzzz}}+2 \gamma_{\mathrm{xxyy}}+2 \gamma_{\mathrm{xxzz}}+2 \gamma_{\mathrm{yyzz}}\right) \\
\beta_{\mathrm{z}}=\beta_{\mathrm{zxx}}+\beta_{\mathrm{zyy}}+\beta_{\mathrm{zzz}}
\end{gathered}
$$

$\Gamma_{\mathrm{L}}\left(\Gamma_{\text {mix }}\right)$ is determined from measuring SHG in the liquid (or in the solution) relative to that of a reference (e.g. a quartz crystal). In smaller NLO chromophores for which NLO responses are dictated by a low-lying CT state, the contribution from $\gamma^{\mathrm{e}}$ can be ignored; $\mu \beta / 5 \mathrm{kT} \gg \gamma^{\mathrm{e}}$ $[43,44]$. This gives:

$$
\mu_{\mathrm{z}} \beta_{\mathrm{z}}=5 \mathrm{kT} \gamma
$$

Using Eq. 23 and Eq. 27, the $\mu_{z} \beta_{z}$ product can be extracted for a pure liquid. In a solution of NLO chromophores (c) dissolved in solvent (s), the macroscopic nonlinearity $\Gamma_{\mathrm{L}}$ is given by:

$$
\Gamma_{\mathrm{L}}=\mathrm{N}_{\mathrm{c}} \mathrm{f}_{\mathrm{c}} \gamma_{\mathrm{c}}+\mathrm{N}_{\mathrm{s}} \mathrm{f}_{\mathrm{s}} \gamma_{\mathrm{s}}
$$

Here, $f$ is the product of local-field factors for the chromophore and solvent and $f_{I}=f_{0} f_{\omega}^{2} f_{2 \omega}$, where I may be either $\mathrm{c}$ or $\mathrm{s}$. From the measurement of $\Gamma_{\text {mix }}$ as a function of the 
chromophore concentration, the $\beta_{\mathrm{z}}$ can be determined with the aid of Eq. 24 and Eq. 28 , neglecting the contribution from the $\gamma^{\mathrm{e}}[44,45]$. Because EFISH samples the product $\mu_{z} \beta_{z}$, the permanent dipole moment must be determined in a separate experiment to obtain $\beta_{\mathrm{z}}$. In addition, a number of physical and optical measurements, such as refractive indices, dielectric constants, and coherence lengths, are also required to determine $\beta$ (or $\gamma$ ) $[39,46-$ 48]. EFISH is a relatively difficult experiment to perform compared with techniques such as hyper-Rayleigh scattering (HRS) [49,50], and limited to certain types of chromophores.

\subsubsection{Hyper-Rayleigh scattering (HRS)}

In early studies, second-order nonlinear scattering was observed in $\mathrm{H}_{2} \mathrm{O}$, fused quartz, $\mathrm{CCl}_{4}$, and $\mathrm{CH}_{3} \mathrm{CN}$ [51], while in another study [52], second-harmonic scattering was seen in solutions containing molecules with a center of inversion. The theory of hyper-Rayleigh scattering (HRS) was developed primarily by Cyvin et al. [53] and Bersohn et al. [54], while the practical implementation was demonstrated by Persoons and co-workers $[49,50]$. This simple technique has become increasingly popular over the last twenty-five years; this is because no knowledge of third-order polarizability $\gamma$ and ground-state dipole moment $\mu$ of the chromophore of interest is required in the HRS experiment $[27,35,46]$. EFISH cannot be employed with non-dipolar neutral and ionic species because of the strong DC-electric field used to break the solution symmetry to generate second-harmonic scattering, but HRS is applicable to a wide range of chromophores, including octupolar systems [55-58] and ionic species [59-62]. Not only does HRS directly measure the $\beta$ value, but it can also be used to estimate the individual tensor components by depolarized HRS [63] or by parametric light 
scattering [64]. In contrast, in the EFISH experiment, one measures the vector projection of $\beta$ along the ground-state dipole moment.

\section{(Insert Figure 6)}

In the experimental HRS space-fixed coordinate system (Figure 6), the incident beam with (in this case) a wavelength of $1064 \mathrm{~nm}$ travels in the $\mathrm{X}$ direction and is linearly polarized in the $\mathrm{Z}$ direction while the scattered signal is detected in the $\mathrm{Y}$ direction. The intensities of the scattered light polarized along the $\mathrm{Z}$ and $\mathrm{X}$ axes, $\mathrm{I}_{\mathrm{Z}}$ and $\mathrm{I}_{\mathrm{X}}$, are proportional to the observable macroscopic second-order susceptibility components $\left\langle\beta_{\mathrm{ZZZ}}^{2}\right\rangle$ and $\left\langle\beta_{\mathrm{XZZ}}^{2}\right\rangle$, respectively:

$$
\begin{aligned}
& \mathrm{I}_{\mathrm{X}} \propto\left\langle\beta_{\mathrm{XzZ}}^{2}\right\rangle \\
& \mathrm{I}_{\mathrm{Z}} \propto\left\langle\beta_{\mathrm{ZZZ}}^{2}\right\rangle
\end{aligned}
$$

The total intensity of the second-harmonic scattered light $\mathrm{I}_{2 \omega} \propto\left\langle\beta_{\mathrm{HRS}}^{2}\right\rangle$, observed in the direction of $\mathrm{Y}$, is proportional to the sum of $\mathrm{I}_{\mathrm{X}}$ and $\mathrm{I}_{\mathrm{Z}}$. Hence,

$$
\left\langle\beta_{\mathrm{HRS}}^{2}\right\rangle=\left\langle\beta_{\mathrm{ZZZ}}^{2}\right\rangle+\left\langle\beta_{\mathrm{XZZ}}^{2}\right\rangle
$$

The relationship between the first hyperpolarizability calculated with respect to the laboratory frame (i.e. $\beta_{z z Z}$ ) and the $\beta$ calculated with respect to the molecular frame (i.e. $\beta_{z z z}$ ) can be expressed as follows $[65,66]$ :

$$
\begin{gathered}
\left\langle\beta_{\mathrm{ZZZ}}^{2}\right\rangle=\frac{1}{7} \sum_{\mathrm{i}} \beta_{\mathrm{iii}}^{2}+\frac{6}{35} \sum_{\mathrm{i} \neq \mathrm{j}} \beta_{\mathrm{iii}} \beta_{\mathrm{ijj}}+\frac{9}{35} \sum_{\mathrm{i} \neq \mathrm{j}} \beta_{\mathrm{ijj}}^{2}+\frac{6}{35} \sum_{\mathrm{i} \neq \mathrm{j} \neq \mathrm{k}} \beta_{\mathrm{ijj}} \beta_{\mathrm{ikk}} \\
+\frac{12}{35} \beta_{\mathrm{ijk}}
\end{gathered}
$$




$$
\begin{gathered}
\left\langle\beta_{\mathrm{XzZ}}^{2}\right\rangle=\frac{1}{35} \sum_{\mathrm{i}} \beta_{\mathrm{iii}}^{2}-\frac{2}{105} \sum_{\mathrm{i} \neq \mathrm{j}} \beta_{\mathrm{iii}} \beta_{\mathrm{ijj}}+\frac{11}{105} \sum_{\mathrm{i} \neq \mathrm{j}} \beta_{\mathrm{ijj}}^{2}-\frac{2}{105} \sum_{\mathrm{i} \neq \mathrm{j} \neq \mathrm{k}} \beta_{\mathrm{ijj}} \beta_{\mathrm{ikk}} \\
+\frac{8}{35} \beta_{\mathrm{ijk}}
\end{gathered}
$$

where $\mathrm{i}, \mathrm{j}$, and $\mathrm{k}$ extend over the molecular Cartesian directions $\mathrm{x}, \mathrm{y}$, and $\mathrm{z}$. The total intensity of the second-harmonic signal $\mathrm{I}_{2 \omega}$ scattered by chromophores (c) in a solvent (s) is given by $[49,50,67]:$

$$
\mathrm{I}_{2 \omega}=\mathrm{G}\left[\mathrm{N}_{\mathrm{s}}\left\langle\beta_{\mathrm{HRS}}^{2}\right\rangle_{\mathrm{s}}+\mathrm{N}_{\mathrm{c}}\left\langle\beta_{\mathrm{HRS}}^{2}\right\rangle_{\mathrm{c}}\right] \mathrm{I}_{\omega}^{2}
$$

where $\mathrm{G}$ is the proportionality constant containing geometrical, electrical and instrumental factors, and $\mathrm{N}_{\mathrm{S}}$ and $\mathrm{N}_{\mathrm{c}}$ are the concentrations of the solvent and solute, respectively. Diluted solutions of the chromophore are used in the HRS experiment, and so the concentration of the solvent $\left(\mathrm{N}_{\mathrm{S}}\right)$ is effectively constant. The orientational average hyperpolarizability of the chromophore $\left\langle\beta_{\mathrm{HRS}}^{2}\right\rangle_{\mathrm{c}}$ can be extracted using the slope and intercept of a linear plot of $\mathrm{I}_{2 \omega} / \mathrm{I}_{\omega}^{2}$ versus $\mathrm{N}_{\mathrm{c}}$ if the $\left\langle\beta_{\mathrm{HRS}}^{2}\right\rangle_{\mathrm{s}}$ are known. This method is known as the internal reference method (IRM). No knowledge of local field factors at optical frequencies is required when using the IRM to calculate the hyperpolarizability of the chromophore.

Another approach to calculating the $\left\langle\beta_{\mathrm{HRS}}^{2}\right\rangle_{\mathrm{c}}$ is the external reference method (ERM), which is more reliable than the IRM [67-69]. In the ERM, a chromophore with known $\beta$ is used as a reference and plots of $\mathrm{I}_{2 \omega} / \mathrm{I}_{\omega}^{2}$ versus $\mathrm{N}_{\mathrm{c}}$ for both chromophore concentrations in the same solvent are obtained. Slopes of the linear graphs give the unknown $\left\langle\beta_{\mathrm{HRS}}^{2}\right\rangle_{\mathrm{c}}$. 


\subsection{Quantum mechanical methods and corrections}

There are a number of computational methods available for the determination of molecular linear optical and nonlinear optical properties, the two basic approaches being the sum-overstates (SOS) expressions from perturbation theory and derivative methods. The derivative methods are further divided based on the numerical and analytical procedures used in the differentiations. For example, in finite-field calculations, the derivatives are evaluated numerically, whilst analytical procedures are used in the coupled-perturbed Hartree-Fock approach. The SOS and derivative approaches are briefly described below, but more details can be found in the original references. Additionally, practical considerations such as the level of electron correlation and basis set used in the calculation of response properties are also discussed in this section.

\subsubsection{Sum-over-states (SOS) method}

The NLO responses $\alpha_{\mathrm{ij}}, \beta_{\mathrm{ijk}}$, and $\gamma_{\mathrm{ijkl}}$ can be calculated using time-dependent perturbation theory. Polarization induced by an electric field can be viewed as a mixing of the ground and excited states of the unperturbed system, since the electron distribution of the unperturbed excited state is different from that of the unperturbed ground state [3]. The expression for (hyper)polarizabilities derived from time-dependent perturbation theory can be expressed as infinite sums over various excited states, known as sum-over-states (SOS) perturbation expressions $[70,71]$. For instance, in the non-resonant case, the SOS perturbation expression for the first hyperpolarizability, defined by the Taylor convention, is given by [72]: 


$$
\begin{aligned}
\beta_{\mathrm{ijk}}\left(-\omega_{\sigma} ; \omega_{1}, \omega_{2}\right) \\
=\frac{1}{\hbar^{2}} \mathrm{P}\left(\mathrm{i}, \mathrm{j}, \mathrm{k} ;-\omega_{\sigma}, \omega_{1}, \omega_{2}\right) \\
\times \sum_{1 \neq 0} \sum_{\mathrm{m} \neq 0} \frac{\left\langle 0\left|\mu_{\mathrm{i}}\right| \mathrm{l}\right\rangle\left\langle\mathrm{l}\left|\bar{\mu}_{\mathrm{j}}\right| \mathrm{m}\right\rangle\left\langle\mathrm{m}\left|\mu_{\mathrm{k}}\right| 0\right\rangle}{\left(\omega_{0 \mathrm{l}}-\omega_{\sigma}\right)\left(\omega_{0 \mathrm{~m}}-\omega_{2}\right)}
\end{aligned}
$$

Here, the matrix element $\left\langle 1\left|\bar{\mu}_{\mathrm{j}}\right| \mathrm{m}\right\rangle=\left\langle\mathrm{l}\left|\mu_{\mathrm{j}}\right| \mathrm{m}\right\rangle-\left\langle 0\left|\mu_{\mathrm{j}}\right| 0\right\rangle \delta_{\mathrm{Im}}$, where $\delta_{\mathrm{Im}}$ is the Kronecker delta function, $\langle q|\mu| r\rangle$ is the transition dipole moment between states $q$ and $r, \hbar \omega_{0 r}$ is the excitation energy between the ground state (g) and an excited state (r), i, j, and k correspond to the molecular axes $\mathrm{x}, \mathrm{y}$, and $\mathrm{z}$, and $\mathrm{P}\left(\mathrm{i}, \mathrm{j}, \mathrm{k} ;-\omega_{\sigma}, \omega_{1}, \omega_{2}\right)$ is a permutation operator, which leads to six terms in Eq. 33 for each 1 and $m$ pair [72].

From Eq. 33 it is clear that a complete set of transition moments, excitation energies, and excited-state dipole moments is required to extract the tensor components. However, in a typical SOS calculation, the infinite sum is truncated after the desired property converges $[4,73]$. The SOS procedure is often employed with semi-empirical methods. Kanis et al. [74] used the ZINDO formalism for studying the second-order NLO behavior of organometallics for the first time (various ferrocenyl and (arene)chromium tricarbonyl derivatives). They showed that the calculated $\beta$ agreed well with the experimental data and converged rapidly, with less than 100 excited configurations. An excellent historical account of the application of the SOS semi-empirical methods (e.g. PPP, CNDO, INDO, ZINDO, and AM1) for the calculation of first hyperpolarizabilities of various NLO chromophores is provided in Ref. [73]. Quadratic NLO property calculations were performed for metal alkynyl complexes with the ZINDO code (including 150-250 excited configurations) by Humphrey and co-workers $[31,75-80]$ to obtain better insights into structure-property relationships. They found that the semi-empirical calculations usually reproduce the experimental hyperpolarizability trend, 
although the predicted absolute values are poor; this is less important in the process of screening the potential NLO candidates. Quantitative disagreement may arise because the calculations were carried out in vacuo (rather than in solvent) as well as at a different fundamental wave frequency compared to experiment (usually $1907 \mathrm{~nm}$ in the computational studies and $1064 \mathrm{~nm}$ in the experiment: $1064 \mathrm{~nm}$ is the fundamental wavelength of light from a Nd:YAG laser and is consequently the most common wavelength employed experimentally, while $1907 \mathrm{~nm}$ light is generated from stimulated Raman scattering of the Nd:YAG output in a high-pressure $\mathrm{H}_{2}$ cell; this necessitates a Raman shift cell, but it generally affords off-resonance experimental data).

In recent years, with the rapid growth of computer power as well as efficient algorithms, NLO calculations have been performed using ab initio methods coupled with derivative methods (discussed later), in particular density functional theory (DFT) [81-86]. A detailed discussion of quantum chemical NLO calculations with reference to the metal alkynyl complexes is given in a later section. To the best of our knowledge, NLO calculations involving the SOS-ab initio approach are not extant in the literature for metal alkynyl complexes, and in general for transition metal-containing chromophores.

For the SHG process $\left(\omega_{\sigma}=2 \omega\right.$ and $\left.\omega_{1}=\omega_{2}=\omega\right)$, Eq. 33 can be rewritten as

$$
\beta_{\mathrm{ijk}}(-2 \omega ; \omega, \omega)=\frac{1}{\hbar^{2}} \mathrm{P} \times \sum_{\mathrm{l} \neq 0} \sum_{\mathrm{m} \neq 0} \frac{\left\langle 0\left|\mu_{\mathrm{i}}\right| \mathrm{l}\right\rangle\left\langle\mathrm{l}\left|\bar{\mu}_{\mathrm{j}}\right| \mathrm{m}\right\rangle\left\langle\mathrm{m}\left|\mu_{\mathrm{k}}\right| 0\right\rangle}{\left(\omega_{01^{-}}-2 \omega\right)\left(\omega_{0 \mathrm{~m}^{-}}-\omega\right)}
$$

Eqs 33 and 34 show the effects of dispersion on $\beta$. For example, Eq. 34 diverges when $\omega_{01}=$ $\omega$ and $\omega_{01}=2 \omega$, and thus near resonance, the $\beta_{\mathrm{ijk}}(-2 \omega ; \omega, \omega)$ are considerably resonance enhanced. Oudar and Chemla $[87,88]$ suggested that for an intramolecular charge-transfer (ICT) molecule, e.g. p-nitroaniline, the low-lying CT state dictates the first 
hyperpolarizability $\beta$; the contribution of this low-energy CT state is more than $85 \%$ of the total value. If the infinite sum in Eq. 34 is reduced to two states, the ground state and an excited state $(\mathrm{l}=\mathrm{m}=1)$, and it is assumed that the $\mathrm{z}$ component $\left(\beta_{\mathrm{zzz}}\right)$ dominates the $\beta$ (i.e. the CT process is along the z-axis), then $\beta_{\mathrm{zzz}}(-2 \omega ; \omega, \omega)$ is given by:

$$
\beta_{\mathrm{zzz}}(-2 \omega ; \omega, \omega)=\frac{6 \omega_{01}^{2}\left\langle 0\left|\mu_{\mathrm{z}}\right| 1\right\rangle\left(\left\langle 1\left|\mu_{\mathrm{z}}\right| 1\right\rangle-\left\langle 0\left|\mu_{\mathrm{z}}\right| 0\right\rangle\right)\left\langle 1\left|\mu_{\mathrm{z}}\right| 0\right\rangle}{\hbar^{2}\left(\omega_{01}^{2}-\omega^{2}\right)\left(\omega_{01}^{2}-4 \omega^{2}\right)}
$$

Note that the numerical factor on the right-hand side depends on the choice of convention for the $\beta$ [72]. This is consistent with the two-level model of Oudar and Chemla:

$$
\beta_{\mathrm{CT}}=\frac{3 \mathrm{e}^{2} \hbar^{2}}{2 \mathrm{~m}} \frac{\mathrm{W}}{\left(\mathrm{W}^{2}-(2 \hbar \omega)^{2}\right)\left(\mathrm{W}^{2}-(\hbar \omega)^{2}\right)} \mathrm{f}_{10} \Delta \mu_{10}
$$

Here, $\mathrm{W}\left(=\hbar \omega_{01}\right)$ is the energy of the CT transition, $\mathrm{f}_{01}\left(=\frac{2 \mathrm{~m}}{\hbar^{2}} \mathrm{~W} \mu_{01}^{2}\right)$ is the oscillator strength, and $\Delta \mu_{10}$ is the difference in the dipole moment between the ground state $(0)$ and the excited state (1). One can rewrite Eq. 36 as:

$$
\beta_{2 \omega}=\beta_{0} D_{\omega}
$$

where $\beta_{0}$ is the intrinsic first hyperpolarizability $(\omega=0.0 \mathrm{au})$ and $\mathrm{D}_{\omega}$ is a dispersion factor. $\beta_{0}$ and $\mathrm{D}_{\omega}$ are given by:

$$
\begin{gathered}
\beta_{0}=\left[\frac{3 \Delta \mu_{01} \mu_{01}^{2}}{\hbar^{2} \omega_{01}^{2}}\right] \\
D_{\omega}=\frac{1}{\left[1-\left(2 \omega / \omega_{g n}\right)^{2}\right]\left[1-\left(\omega / \omega_{g n}\right)^{2}\right]}
\end{gathered}
$$


The dispersion factor $\mathrm{D}_{\omega}$ describes frequency dependence of the first hyperpolarizability. The two-level expression (Eq. 35) indicates that as the frequency of the fundamental wave ( $\omega)$ or the frequency of the second-harmonic wave $(2 \omega)$ approaches and reaches the optical resonance frequency $\left(\omega_{01}\right)$, the $\beta_{\mathrm{CT}}$ is considerably resonance enhanced. In general, the intrinsic hyperpolarizability $\beta_{0}, \beta$ in the static limit, is simply obtained by dividing experimental $\beta_{2 \omega}$ by an appropriate dispersion factor [79,82,89-91]. However, the neglect of contributions from other potential excited states is an inherent problem of the simple twolevel model. Further, it cannot be applied in the resonant regime, where the effects of damping and vibronic structure of the excited states should also be taken into account [9294]. The adequacy of the two-level model of Oudar and Chemla is uncertain for numerous NLO chromophores $[29,84,94-97]$, so two-level corrected data $\left(\beta_{0}\right)$ should be used with great care.

For the static case $(\omega=0.0)$, Eq. 35 becomes:

$$
\beta_{\mathrm{zzz}}(-0 ; 0,0)=\frac{6\left\langle 0\left|\mu_{\mathrm{z}}\right| 1\right\rangle\left(\left\langle 1\left|\mu_{\mathrm{z}}\right| 1\right\rangle-\left\langle 0\left|\mu_{\mathrm{z}}\right| 0\right\rangle\right)\left\langle 1\left|\mu_{\mathrm{z}}\right| 0\right\rangle}{\hbar^{2} \omega_{01}^{2}}
$$

Because $\left\langle 0\left|\mu_{\mathrm{z}}\right| 1\right\rangle=\left\langle 1\left|\mu_{\mathrm{z}}\right| 0\right\rangle=\mu_{01}$ and $\left\langle 1\left|\mu_{\mathrm{z}}\right| 1\right\rangle-\left\langle 0\left|\mu_{\mathrm{z}}\right| 0\right\rangle=\mu_{11}-\mu_{00}=\Delta \mu_{01}$, Eq. 40 can be rewritten as:

$$
\beta_{\mathrm{zzz}}(0 ; 0,0)=\frac{6 \Delta \mu_{01} \mu_{01}^{2}}{\hbar^{2} \omega_{01}^{2}}
$$

Note that the numerical factors in Eq. 38 and 41 are different as a result of different conventions being used [72]; perturbation and Taylor conventions were chosen for the $\beta_{0}$ in Eq. 38 and 41, respectively. 
Notwithstanding the limitations of the two-level model, it is very useful in describing structure- $\beta$ relationships and optimizing $\beta$; for example, $\beta$ and transition energy are inversely related. Note, however, that large charge separations between the two states (large $\left.\Delta \mu_{01}\right)$ do not necessarily enhance $\beta$. Figure 7 shows that as $\Delta \mu_{01}$ increases (left to right), $\mu_{01}^{2}$ decreases (the wave function overlap of the two states decreases) [98]. Because $\beta \propto \Delta \mu_{01} \mu_{01}^{2}$ (Eq. 41), both $\Delta \mu_{01}$ and $\mu_{01}^{2}$ should be optimized simultaneously to improve the $\beta$ value.

\section{(Insert Figure 7)}

\subsubsection{Derivatives method}

The dipole moment in the presence of an electric field $\mathrm{F}$ (where $\mathrm{F}$ is used instead of $\mathrm{E}$ in the following discussion to represent the field, so as to avoid confusion with energy E) can be written in a Taylor series expansion as follows:

$$
\mu_{i}(F)=\mu_{i}^{0}+\alpha_{i j} F_{j}+\frac{1}{2 !} \beta_{i j k} F_{j} F_{k}+\frac{1}{3 !} \gamma_{i j k l} F_{j} F_{k} F_{1}+\cdots
$$

Eq. 42 differs from Eq. 22 (the perturbation series expansion) because the numerical factor in Eq. 22 has been moved into the coefficient of the electric field. Similarly, the energy E of the system perturbed by the external field can be given by:

$$
E(F)=E(0)-\mu_{i} F_{i}-\frac{1}{2 !} \alpha_{i j} F_{i} F_{j}-\frac{1}{3 !} \beta_{i j k} F_{i} F_{j} F_{k}-\frac{1}{4 !} \gamma_{i j k l} F_{i} F_{j} F_{k} F_{l}+\cdots
$$


where $E(0)$ is the energy of the unperturbed molecule. From Eqs 42 and 43, it is clear that the $\alpha_{\mathrm{ij}}, \beta_{\mathrm{ijk}}$, and $\gamma_{\mathrm{ijkl}}$ values can be obtained by differentiating $\mu(\mathrm{F})$ and $\mathrm{E}(\mathrm{F})$ with respect to the external field.

\begin{tabular}{|l|l|}
\hline Derivatives of $\mu(F)$ & Derivatives of E(F) \\
\hline$\alpha_{i j}=\left.\frac{\partial \mu_{\mathrm{i}}}{\partial \mathrm{F}_{\mathrm{j}}}\right|_{\mathrm{F}=0}$ & $\alpha_{\mathrm{ij}}=-\left.\frac{\partial^{2} \mathrm{E}}{\partial \mathrm{F}_{\mathrm{i}} \partial \mathrm{F}_{\mathrm{j}}}\right|_{\mathrm{F}=0}$ \\
$\beta_{\mathrm{ijk}}=\left.\frac{\partial^{2} \mu_{\mathrm{i}}}{\partial \mathrm{F}_{\mathrm{j}} \partial \mathrm{F}_{\mathrm{k}}}\right|_{\mathrm{F}=0}$ & $\beta_{\mathrm{ijk}}=-\left.\frac{\partial^{3} \mathrm{E}}{\partial \mathrm{F}_{\mathrm{i}} \partial \mathrm{F}_{\mathrm{j}} \partial \mathrm{F}_{\mathrm{k}}}\right|_{\mathrm{F}=0}$ \\
$\gamma_{\mathrm{ijkl}}=\left.\frac{\partial^{3} \mu_{\mathrm{i}}}{\partial \mathrm{F}_{\mathrm{j}} \partial \mathrm{F}_{\mathrm{k}} \partial \mathrm{F}_{\mathrm{l}}}\right|_{\mathrm{F}=0}$ & $\gamma_{\mathrm{ijkl}}=-\frac{\partial^{4} \mathrm{E}}{\left.\partial \mathrm{F}_{\mathrm{i}} \partial \mathrm{F}_{\mathrm{j}} \partial \mathrm{F}_{\mathrm{k}} \partial \mathrm{F}_{\mathrm{l}}\right|_{\mathrm{F}=0}}$ \\
\hline
\end{tabular}

Partial derivatives are evaluated at zero to give the (hyper)polarizability tensors in the presence of static fields. Note that the nonlinear optical coefficients in Eqs 42 and 43 are equivalent only if the computational technique satisfies the Hellman-Feynman theorem (i.e. $\mathrm{dE} / \mathrm{dF}=\langle\partial \mathrm{H} / \partial \mathrm{F}\rangle=-\langle\mu\rangle)$

The simplest approach to obtain the linear optical and nonlinear optical tensor elements is the Finite-Field (FF) technique (also known as coupled Hartree-Fock (CHF) when coupling with Hartree-Fock theory) in the static fields [99]. In the FF calculation, the energy of the perturbed system is calculated at various field strengths (and directions), followed by numerical evaluation of the energy derivatives. Although the finite field technique is very easy to implement and can be applied with a variety of wave functions, it has several drawbacks. For example, the FF calculations may produce meaningless results if one does not use appropriate field strengths $[100,101]$. Another problem is many energy calculations are required for the higher order tensors. This is not computationally efficient when electron correlation is taken into account in the FF calculations [102,103]. Further, the FF method 
cannot be extended to derive frequency-dependent response properties, thus making direct comparison with the experimental data, which is always measured at non-zero frequency $(\omega \neq 0.0)$, difficult. However, some of the dynamic properties, e.g. $\gamma(-\omega ; \omega, 0,0)$ and $\gamma(0 ; 0$, $-\omega, 0)$, can be obtained from a mixed numerical-analytical method (Finite-Difference method) $[104,105]$ where an analytically derived (discussed next) lower-order response property is modified numerically by the presence of an additional static field to obtain the properties. Alternatively, (hyper)polarizability tensors can be obtained by solving the aforementioned derivatives analytically [106-109]. This approach is frequently known as the coupled-perturbed HF (CPHF) method, which is much more computationally convenient compared to the numerically equivalent CHF method $[103,110]$.

The perturbed Hamiltonian H(F) in the presence of the electric field for the static case is

$$
H(F)=H_{0}-F . \sum_{i} r_{i}
$$

where the second term represents the interaction between the field and electrons, and the field dependent dipole moment $\mu(F)$ and energy $E(F)$ are given by:

$$
\begin{gathered}
\mu(F)=\left\langle\psi(F)\left|\sum_{i} q_{i} \cdot r_{i}\right| \psi(F)\right\rangle \\
E(F)=\langle\psi(F)|H(F)| \psi(F)\rangle
\end{gathered}
$$

In Eq. 45, $\mathrm{q}_{\mathrm{i}}$ and $\mathrm{r}_{\mathrm{i}}$ are the charge and position, respectively, for the ith particle and the summation runs over all electrons and nuclei. Appropriate derivatizations of the $\mu(\mathrm{F})$ or $\mathrm{E}(\mathrm{F})$ with respect to the field are then performed either numerically or analytically. As alluded to before, (hyper)polarizabilities from Eqs 42 and 43 are equivalent if the wavefunction satisfies the Hellmann-Feynman theorem, although in the case of a FF calculation, numerical 
derivatives of the dipole moment usually give better results [100]. However, many E(F) (or $\mu(\mathrm{F}))$ calculations are required to derive the desired property in the FF approach, whereas in the analytical approach, a single calculation is sufficient to obtain the property. Another advantage of the analytical expressions over the FF method is that the former can be extended to obtain frequency-dependent properties, permitting direct comparison with experimental data.

The time-dependent Hartree-Fock (TDHF) theory is another quantum mechanical method for evaluating the (hyper)polarizabilities when the electric field is time-dependent. Using the TDHF scheme, Sekino and Bartlett [111] developed formulas applicable for any order. This approach is also known as time-dependent coupled (perturbed) Hartree-Fock (TDCHF or TDCPHF), equivalent to the random-phase approximation (RPA). Later, their procedure was further improved by Rice et al. [112] and by Karna and Dupuis [113]. Sekino and Bartlett [114] also introduced a MO-based approach which is more efficient than the original AObased TDHF method as well as closer to the usual RPA equations. In addition to the evaluation of the dipole derivatives in the above methods, energy-like derivative methods (i.e. pseudo-energy derivatives) are also used to evaluate time-dependent properties [115117]. Straightforward extension of the energy derivative approach is impossible for the timedependent case. Alternatively, if the wavefunction is fully variational, one can use dipole derivatives. Rice and Handy [115,116] introduced analytical expressions for dynamic (hyper)polarizabilities as derivatives of pseudo-energy $\mathrm{W}(\mathrm{t})$. This procedure is applicable for all quantum chemistry methods, including Møller-Plesset perturbation theory, that do not obey the Hellmann-Feynman theorem (dipole moment cannot be clearly defined as an expectation value with Møller-Plesset perturbation theory). The pseudo-energy $\mathrm{W}(\mathrm{t})$ is expressed by: 


$$
\mathrm{W}(\mathrm{t})=\left\langle\phi(\mathrm{t})\left|\mathrm{H}(\mathrm{t})-\mathrm{i}\left(\frac{\partial}{\partial \mathrm{t}}\right)\right| \phi(\mathrm{t})\right\rangle
$$

For example, the $\alpha_{\mathrm{ij}}(-\omega ; \omega)$ is given by the following derivative of $\mathrm{W}(\mathrm{t})$ with respect to one static field $F(0)$ and one dynamic field $F(\omega)$.

$\alpha_{i j}(-\omega ; \omega)=-\frac{\partial^{2} W}{\partial F_{i}(0) \partial F_{j}(\omega)}=\frac{\partial^{2} W}{\partial F_{j}(\omega) \partial F_{i}(0)}$

\subsubsection{Electron correlation}

In the preceding section, two methods that are widely employed to calculate the molecular (hyper)polarizability tensors were discussed: sum-over-states expressions and derivative techniques (numerical and analytical). Both techniques have the ability to predict frequencydependent properties. Additionally, there are two important corrections that one needs to consider: electron correlation and basis sets effects. In the following sections, these two effects are discussed. Other corrections such as vibrational effects are important in some NLO processes (particularly in the static limit), although negligible for SHG [101,118-121], but this review will focus on the electronic contributions only.

Both SOS and derivative approaches can be coupled with ab initio and semi-empirical methods to evaluate (hyper)polarizabilities. HF theory assumes that an electron moves in an average field created by the rest of the $(\mathrm{N}-1)$ electrons, and thus fails to describe the instantaneous repulsion between the electrons. An important consequence of this treatment is that HF theory ignores electron correlation, which has been found, according to numerous studies [122-135], to have a significant effect on the computed NLO properties regardless of 
the molecular size. Better agreement with the relevant experimental data was found after incorporating correlation effects in the calculations for small molecules $[128,136,137]$. In the hyperpolarizability calculations, many-body perturbation theory (MBPT or MP) $[115,116]$ and the coupled-cluster (CC) approach are frequently employed to account for electron correlation [73,101,103]. In addition, multiconfiguration self-consistent field (MCSCF, TDMCSCF, MCTDHF, MCRPA) [138-140], second-order polarization propagator approximation (SOPPA) [141,142], full configuration interaction (CI) [143,144], and equation-of-motion CC (EOM-CC) [145,146] methods are also used to include correlation effects.

In a study involving finite-field calculations on $p$-nitroaniline (a prototypical example of a donor-bridge-acceptor molecule), Sim et al. [147] reported that the computed values of the first hyperpolarizability $(\beta)$ and second hyperpolarizability $(\gamma)$ increased by $88 \%$ and $100 \%$, respectively, when proceeding from SCF to MP2 (second-order Möller-Plesset perturbation theory). This was confirmed by Davis et al. [148]. Wergifosse and Champagne [149] studied the correction effects on the $\beta$ value of a set of relatively larger push-pull chromophores using several correlated methods (MP2, SCS-MP2, MP4, SDQ-MP4, CCSD, and CCSD(T)), with $\operatorname{CCSD}(\mathrm{T})$ used as the reference method. Their FF hyperpolarizability calculations showed that HF theory underestimates the $\beta$ values, whilst MP2 yields values that are close to the $\operatorname{CSD}(\mathrm{T})$ reference $\beta$ values. Diffuse basis sets were found to decrease the discrepancy between the values from MP2 and $\operatorname{CCSD}(\mathrm{T})$ correlated methods.

Semi-empirical calculations involving truncated SOS expressions were discussed in the preceding section. They can also be used with the derivative approach to obtain (hyper)polarizabilities [73,150-152]. Due to the parameterization, semi-empirical methods may recover the correlation effects in part, but the correlation cannot be developed 
systematically as in ab initio (correlated) schemes. Such correlated methods (e.g. CC) are often employed with extended basis sets but this limits their applicability to relatively small systems [153]. Semi-empirical methods, on the other hand, are more efficient and can be applied to the larger $\pi$-systems. Combining the features of both the CC and PPP semiempirical methods, Ivanov and co-workers have successfully calculated the NLO properties of various $\pi$-conjugated systems [154-156]. Because the semi-empirical methods depend on the parameterizations, their applicability to certain systems and properties can be problematic.

\subsubsection{Density functional theory}

Approximate methods are needed to solve the many-electron problem in quantum chemistry, as the electronic Schrödinger equation (Eq. 49) cannot be solved exactly (except for some special cases); the main difficulty is the electron-electron repulsion term (Eq. 50).

$\widehat{\mathrm{H}}_{\mathrm{elec}} \psi_{\text {elec }}=\mathrm{E}_{\text {elec }} \psi_{\text {elec }}$

where the electronic Hamiltonian $\widehat{\mathrm{H}}_{\text {elec }}$ for a N-electron system is

$\widehat{\mathrm{H}}_{\text {elec }}=-\sum_{\mathrm{i}=1}^{\mathrm{N}} \frac{1}{2} \nabla_{\mathrm{i}}^{2}-\sum_{\mathrm{i}=1}^{\mathrm{N}} \sum_{\mathrm{A}=1}^{\mathrm{M}} \frac{\mathrm{Z}_{\mathrm{A}}}{\mathrm{r}_{\mathrm{i}} \mathrm{A}}+\sum_{\mathrm{i}=1}^{\mathrm{N}} \sum_{\mathrm{j}>\mathrm{i}}^{\mathrm{N}} \frac{1}{\mathrm{r}_{\mathrm{ij}}}$

The first term in Eq. 50 is the kinetic energy operator, while the second and third terms correspond to the electron-nuclei attraction and electron-electron interaction, respectively. The simplest wave function based approach to solve the many-electron problem is the 
Hartree-Fock (HF) approximation. This approximation reduces the interacting many-electron problem to a one-electron problem in which the electron-electron repulsion is treated in an average way; each electron moves in the field of all other electrons. In the HF method, the ground-state wave function is a single Slater determinant involving spin orbitals. This is a very crude approximation to the true ground-state wave function. Further, HF theory neglects the electron correlation which is essential for high-accuracy correlated methods such as CI, CC, and Møller-Plesset Perturbation Theory (MPPT). However, for large molecules, these calculations are computationally intractable.

An alternative approach that is computationally feasible for large molecules and also incorporates electron correlation is density functional theory (DFT) which is built on the Hohenberg and Kohn theorems [157]. In contrast to the HF wave function, which depends on 3N spatial coordinates, in DFT, the electron density, $n(r)$, which depends only on three spatial coordinates, is used as the fundamental quantity. The properties of any many-electron system, including the energy $\mathrm{E}[\mathrm{n}(\mathrm{r})]$, can thus be obtained from its ground-state density [157]. The minimum energy, $E_{0}$, is given only if the true ground-state density $n_{o}(r)$ is provided. The total energy, E[n], of an interacting system can be expressed as follows.

$E[n]=T_{s}[n]+J[n]+E_{X C}[n]+E_{N e}[n]$

where $T_{S}[n]$ is the kinetic energy of the non-interacting reference system, the fictitious KohnSham (KS) system [158], J[n] is the classical electrostatic electron-electron repulsion energy, $\mathrm{E}_{\mathrm{XC}}[\mathrm{n}]$ includes the exchange-correlation energy and the kinetic energy difference between the true and non-interacting systems, and $\mathrm{E}_{\mathrm{Ne}}[\mathrm{n}]$ is the energy due to the nuclei. Except for $\mathrm{E}_{\mathrm{XC}}$, all terms can be given in the form of Kohn-Sham orbitals which are determined by solving the KS one-electron equations iteratively. Details can be found in Refs [159] and 
[160]. The exact form of the $E_{X C}[n]$ functional is, however, unknown and must be approximated in practice. The accuracy of approximate functionals is thus responsible for the quality of the DFT approach, which has become the main method for treating ground-state properties of large molecules. The exponential growth in the number of publications involving DFT calculations over the years speaks for its popularity in quantum chemistry.

\subsubsection{Time-dependent density functional theory}

The KS-DFT formalism is not appropriate for treating time-dependent problems because it is a static ground state theory, although a number of alternative approaches to calculate the excitation energies have been proposed within the time-independent DFT scheme [161,162]. The foundations for the time-dependent version of ground state DFT, the so-called timedependent DFT (TDDFT), were laid by Runge and Gross (RG) [163] 20 years after the formulation of its ground state analogue by Hohenberg and Kohn in 1964 [157]. TDDFT has become increasingly popular in recent years as an inexpensive, but accurate quantum mechanical tool for modelling the excited state properties of medium-sized and large molecules. As a result, it is often compared to correlated methods such as CI and MCSCF, which are in general computationally costly procedures for large molecules, and regarded as a better choice than the less expensive CI singles (CIS) and TDHF methods [164]. Note that there are known failures associated with the conventional TDDFT formalism, which are discussed later.

The RG theorem is the time-dependent analogue of the ground state Hohenberg and Kohn theorem. For an interacting system, there is a one-to-one correspondence between time dependent density $n(r, t)$ and time dependent external potential $v_{\text {ext }}(r, t)$, and thus all properties of the system are a function of $n(r, t)$. Analogous to ground state DFT, this density 
is obtained by solving the time-dependent $\mathrm{KS}$ equations. Excitation energies and oscillator strengths can be derived with the help of the linear response theory of TDDFT (LR-TDDFT) [162]. In principle, TDDFT is an exact theory, but the exchange-correlation (xc) kernel in the TD-KS formula is approximated in practice (analogous to ground state DFT in which $\mathrm{E}_{\mathrm{XC}}[\mathrm{n}]$ needs to be approximated). In adiabatic TDDFT, ground state xc functionals are utilized $[162,164]$. The accuracy of DFT and TDDFT formalism depends on the quality of the approximated xc functionals. Thus, finding a better approximation has become an active area of research.

\subsubsection{Exchange-correlation functionals}

The simplest approximation is the local-density approximation (LDA) which is usually applicable to systems with slowly-varying densities [165]. Thus, its accuracy is insufficient for most applications in chemistry as the electron densities in molecular systems are not typically uniform. The extension to the LDA, the generalized gradient approximation (GGA), has become very popular in chemistry. These approximations, however, exhibit selfinteraction errors (SIEs); unlike in HF theory (which is SIE free) there is no guarantee that the non-physical error given by the $J[\rho]$ term in Eq. 51 is completely cancelled by the approximated $\mathrm{E}_{\mathrm{XC}}[\rho]$ in LDA and GGA (see the discussion in Ref. [159]). In the asymptotic region for the atom or molecule, traditional exchange-correlation potentials decay exponentially rather than exhibiting the correct $-1 / \mathrm{r}$ behaviour, leading to severe SIEs. This is partly corrected in hybrid DFT functionals by including a fixed amount of exact HF exchange, which yields $-\mathrm{n} / \mathrm{r}$ asymptotic behavior ( $\mathrm{n}$ is the fraction of HF exchange in the functional). Due to the incorrect behavior in the asymptotic region, conventional DFT functionals $E_{X C}[\rho]$ have been found to yield errors for properties such as (hyper)polarizabilities, Rydberg excitation energies, and charge-transfer excitation energies 
$[164,166-171]$

Asymptotically correct (AC) SAOP [172] and AC-LB94 [173] potentials also failed to improve the overestimated hyperpolarizabilities obtained from the pure DFT functionals in push-pull $\pi$-conjugated molecules. The recent development of long-range corrected (LRC) DFT methods are known to improve the errors associated with the conventional $\mathrm{XC}$ functionals [166,174-181]. In the LRC-DFT functionals, the two-electron operator for the exchange functional $E_{X}$ splits into two regions: short-range (SR) and long-range (LR). The SR part is defined by a modified DFT functional and the HF exchange is employed for the LR part. With many exchange-correlation functionals to choose from, finding the most appropriate functional is a crucial step in any application [81,177, 182-185].

Response properties can be expressed in terms of energy derivatives. For instance, the first hyperpolarizability $\beta_{\mathrm{ijk}}$ is the third energy derivative with respect to the electric field. These derivatives are evaluated numerically (FF method) or analytically (CPHF method). The latter (analytical approach) in DFT is known as the coupled-perturbed Kohn-Sham (CPKS) approach [186,187], which is numerically more stable than the FF method. A plethora of applications of numerical [188-196], analytical [81,83,84,197-204], and mixed (e.g. the $\beta$ is obtained by numerical differentiation of the analytic polarizability) [205] approaches with DFT for a broad range of compounds have been reported, while the former approach (FF) cannot be used to calculate time-dependent properties. Note that the CPKS (DFT) approach is exact when $E_{X C}[\rho]$ is exact but, unfortunately, the unknown $E_{X C}[\rho]$ is usually approximated. To calculate the dynamic responses, DFT should be extended to the time-dependent domain. Nonlinear responses to an oscillating electric field are generally treated by the timedependent DFT (TDDFT) approach [110,163,206-210]. Using TDDFT (CP-TDDFT) equations, studies involving dynamic (hyper)polarizability calculations for larger molecular 
systems have been reported in recent years [203,211-215].

\subsubsection{Basis set effects}

The choice of basis set is crucial in the calculation of (hyper)polarizabilities with ab initio methods, as it affects both quality and cost of the NLO calculations [100,216]. Basis sets augmented with diffuse and polarization functions are usually required [146,147]. Kanis et al. [73] showed that, for $p$-nitroaniline, supplementing the split-valence 6-31G(d) with a set of diffuse functions on heavy elements, e.g. $6-31+\mathrm{G}(\mathrm{d})$, leads to a greater than $20 \%$ increase in the CPHF first hyperpolarizability responses. The choice of basis set is much more important for small molecules than for large molecules because, in the latter, the basis set requirements of a given centre can diminish with overlap of functions on adjacent centres [149,217,218]. Jacquemin et al. [219] have reported that for large $\alpha, \omega$-nitroaminopolyene oligomers, a relatively small $6-31 \mathrm{G}$ basis set is adequate to reproduce the static $\beta$ obtained from extended basis sets such as 6-31G+pd [218] and cc-pVDZ [220].

However, such studies on the basis set effect may not be feasible with currently available resources for large organometallics. Kulasekera [221] carried out analytic $\beta$ calculations for a series of metal alkynyl complexes using the RESPONSE module [208] implemented in the Amsterdam density functional (ADF) program [222,223] with various all electron Slater-type orbital basis sets: DZ (double $\varsigma$ ), DZP (double $\varsigma$ plus polarized), TZP (core double- $\varsigma$, valence triple- $\varsigma$ plus polarized), TZ2P (core double- $\varsigma$, valence triple- $\varsigma$ plus doubly polarized), and QZ4P (core triple- $\varsigma$, valence quadruple- $\varsigma$ plus quadruply polarized). The data indicated that the performance of TZP, TZ2P, and QZ4P basis sets are very similar, while the data derived from the DZ and DZP basis sets were found to be inconsistent between different exchangecorrelation functionals as well as between different structures. Unfortunately, diffuse 
functions were not included in the calculations. Very recently, the basis set effect on the first hyperpolarizability $(\mathrm{CPKS})$ for $\mathrm{Ru}\left(\mathrm{C} \equiv \mathrm{C}-4-\mathrm{C}_{6} \mathrm{H}_{4}-1-\mathrm{NO}_{2}\right)\left(\kappa^{2}-\mathrm{dppe}\right)\left(\eta^{5}-\mathrm{C}_{5} \mathrm{H}_{5}\right)$ and $\mathrm{Ru}(\mathrm{C} \equiv \mathrm{C}-4-$ $\left.\mathrm{C}_{6} \mathrm{H}_{4}-1-\mathrm{NO}_{2}\right) \mathrm{Cl}\left(\kappa^{2}-\mathrm{dppm}\right)_{2}$ has been studied by us [185]. Figure 8 shows the resulting data computed with three different DFT functionals, and indicates the importance of including diffuse functions in the calculations if one requires quantitative data. We found that the hyperpolarizability trend for a series of related complexes is unaffected by the presence or absence of diffuse functions. Thus, screening potential NLO molecules among a series of related chromophores can be achieved without performing calculations involving resource intensive diffuse basis sets. Augmentation of $6-31 \mathrm{G}(\mathrm{d}, \mathrm{p})$ with a set of diffuse functions, e.g. $6-31+\mathrm{G}(\mathrm{d}, \mathrm{p})$, increases the static $\beta$ values by more than $35 \%$ for a given method, while addition of a set of valence functions and polarization functions was found to have little impact.

(Insert Figure 8)

\section{Molecular first hyperpolarizability of organometallic complexes}

(Hyper)polarizability coefficients are tensors. For instance, the first hyperpolarizability $\beta_{\mathrm{ijk}}$ is

a third-rank tensor with 27 components. However, only a few components are usually relevant due to the symmetry properties of the tensor (in the case of SHG, for example, permutation of the last two indices has no effect, thereby reducing the number of independent tensor elements from 27 to 18 for $\beta_{\mathrm{ijk}}$. Further, in the static limit, $\lambda=\infty$, and the Kleinman symmetry condition [42] (i.e. $\beta_{\mathrm{ijj}}=\beta_{\mathrm{jij}}=\beta_{\mathrm{jji}}$ ) is a valid assumption, so the number of independent elements can reduce to 10).

Comparisons between data derived from computational and experimental techniques must be 
made with great care. This is mainly because the convention adopted to define (hyper)polarizabilities is often unspecified (see Ref. [72] for more details), whereas theoreticians usually employ the Taylor expansion convention (Eq. 43). SI and esu are two common unit systems used for describing NLO properties. The computed results are often given in atomic units (au) and Table 2 shows conversion factors to SI and esu [100].

The vector component along the dipole moment axis $\left(\beta_{\mathrm{vec}}\right)$ can be given by [73]:

$$
\beta_{\mathrm{vec}}(-2 \omega ; \omega, \omega)=\sum_{\mathrm{i}=1}^{3} \frac{\mu_{\mathrm{i}} \beta_{\mathrm{i}}}{|\mu|}
$$

Here, $\mu$ is the ground-state dipole moment and:

$$
\beta_{\mathrm{i}}=\beta_{\mathrm{iii}}+\frac{1}{3} \sum_{\mathrm{j} \neq \mathrm{i}}\left(\beta_{\mathrm{ijj}}+\beta_{\mathrm{jij}}+\beta_{\mathrm{jji}}\right)
$$

where $\mathrm{i}$ and $\mathrm{j}$ run over the molecular Cartesian directions $\mathrm{x}, \mathrm{y}$, and $\mathrm{z}$. The $\beta$ quantity measured in the EFISH experiment $(\beta \|)$ is different by a factor of $3 / 5$, i.e. $\beta \|=(3 / 5) \beta_{\text {vec }}$.

Table 2. Conversion factors for atomic units (au)

\begin{tabular}{cccc}
\hline & & SI & esu \\
\hline$\alpha$ & $1 \mathrm{au}$ & $1.6488 \times 10^{-41} \mathrm{C}^{2} \mathrm{~m}^{2} \mathrm{~J}^{-1}$ & $1.4819 \times 10^{-25} \mathrm{esu}$ \\
$\beta$ & $1 \mathrm{au}$ & $3.20636 \times 10^{-53} \mathrm{C}^{3} \mathrm{~m}^{3} \mathrm{~J}^{-2}$ & $8.63922 \times 10^{-33} \mathrm{esu}$ \\
$\gamma$ & $1 \mathrm{au}$ & $6.23538 \times 10^{-65} \mathrm{C}^{4} \mathrm{~m}^{4} \mathrm{~J}^{-3}$ & $5.03670 \times 10^{-40} \mathrm{esu}$
\end{tabular}

The total first hyperpolarizability $\left(\beta_{\text {tot }}\right)$ is another parameter that is commonly used by theoreticians: 


$$
\beta_{\text {tot }}=\sqrt{\beta_{\mathrm{x}}+\beta_{\mathrm{y}}+\beta_{\mathrm{z}}}
$$

where components $\beta_{\mathrm{x}}, \beta_{\mathrm{y}}$, and $\beta_{\mathrm{z}}$ are defined as in Eq. 53 .

One can also write an expression for the HRS experiment using Eqs 30 and 31. If Kleinman symmetry is obeyed, $\left\langle\beta_{\mathrm{HRS}}^{2}\right\rangle$ is given by:

$$
\begin{gathered}
\left\langle\beta_{\mathrm{HRS}}^{2}\right\rangle=\frac{18}{105} \sum_{\mathrm{i}} \beta_{\mathrm{iii}}^{2}+\frac{16}{105} \sum_{\mathrm{i} \neq \mathrm{j}} \beta_{\mathrm{iii}} \beta_{\mathrm{ijj}}+\frac{38}{105} \sum_{\mathrm{i} \neq \mathrm{j}} \beta_{\mathrm{ijj}}^{2}+\frac{34}{105} \sum_{\mathrm{i} \neq \mathrm{j} \neq \mathrm{k}} \beta_{\mathrm{ijj}} \beta_{\mathrm{ikk}} \\
+\frac{60}{105} \beta_{\mathrm{ijk}}
\end{gathered}
$$

Depending on the molecular symmetry, Eq. 55 can be further reduced. For instance, if the $\beta_{z z z}$ tensor component dominates the other components, Eq. 55 becomes:

$$
\beta_{\mathrm{HRS}} \approx \sqrt{\frac{18}{105}} \beta_{\mathrm{zzz}}
$$

Material suitable for practical applications must possess very large $\chi_{\mathrm{IJK}}^{(2)}$ (we limit our discussion to the second-order properties). The macroscopic second-order susceptibility is directly related to the $\beta_{\mathrm{ijk}}$. Thus, optimising the molecular first hyperpolarizability can lead to large $\chi^{(2)}$. For centrosymmetric systems, both $\chi_{\mathrm{IJK}}^{(2)}$ and $\beta_{\mathrm{ijk}}$ vanish. Due to unfavourable crystal packing, $\chi_{\mathrm{IJK}}^{(2)}$ can be zero even though $\beta_{\mathrm{ijk}} \neq 0$, which is usually the case for dipolar molecules. The goal is, however, developing molecular systems with very large $\beta$, so understanding structure- $\beta$ relationships is therefore essential. Reliable quantum chemical calculations can be very useful for this purpose as they allow one to not only rationalize the experimental observations, but also to study the structure- $\beta$ relationships that are inaccessible 
by experimental methods, thereby guiding experimentalists in designing chromophores with optimum NLO-activity. The use of quantum chemical methods in the calculation of linear optical and quadratic nonlinear optical properties of organometallic complexes, particularly of metal alkynyl complexes, has been an active field of research $[73,75-78,80-$ $82,84,90,91,221,224-230]$.

\subsection{Ferrocenyl complexes}

In the first theoretical investigation of the second-order NLO properties of organometallic complexes, Kanis et al. reported INDO/S semi-empirical calculations of quadratic nonlinear optical properties of several organometallic complexes [224]. Amongst these, the calculated $\beta_{\text {vec }}$ and $\beta_{\text {tot }}$ values of a series of ferrocenyl derivatives are shown in Table 3 , together with the relevant experimental data.

As shown in Table 3, the ZINDO calculated values are in very good agreement with the EFISH data; the calculations not only successfully reproduce the magnitude but also the sign of the data ( $\beta_{\text {tot }}$ is always positive: Eq. 54). The authors showed that, for 2 , the quadratic response is dictated by relatively high-energy MLCT and $\pi$ to $\pi^{*}$ (LLCT) transitions, while the low-energy ligand-field $\mathrm{d}$-d transitions contribute little to $\beta_{\text {vec. }}$ The dominant $\mathrm{CT}$ essentially lies along the dipole axis; consequently, $\beta_{\text {vec }} \approx \beta_{\text {tot. }}$ However, a year later, with the aid of extended Hückel molecular orbital calculations, Calabrese et al. [28] argued that, for 2, the lowest-energy transition is MLCT in character, whereas the high-energy transition is predominantly a $\pi$ to $\pi^{*}$ ligand transition with some metal character. Further, they showed that the low-energy band is sensitive to the variation in the metal centre, while the high- 
energy transition is sensitive to variation in the $\pi$-system. For instance, replacement of the cyclopentadienyl group with a pentamethylcyclopentadienyl group on proceeding from $\mathbf{2}$ to $\mathbf{4}$ leads to a red-shift of $36 \mathrm{~nm}$ and $10 \mathrm{~nm}$ in the respective high-energy and low-energy bands (Table 3). On the other hand, replacing iron in 2 with less oxidizable ruthenium leads to a significant blue-shift in the lower energy band. A year later, Kanis et al. [225] reported a detailed analysis of the electronic origin of quadratic nonlinearities in several organometallics, including the aforementioned ferrocenyls (Table 3). $\beta_{\text {vec values in refs [224] }}$ and [225] differ slightly due to the discrepancies in the initial geometries used in the calculations. From their semi-empirical studies, they claimed that the lower energy transitions in the ferrocenyl derivatives are mainly ligand-field based (this was assigned to MLCT by Calabrese et al.), and therefore have a minor impact on $\beta$ (i.e. small $\Delta \mu$ and $\mathrm{f}$ values associated with the d-d transition lead to a small $\beta$, according to the two-level model, Eq. 36, although the energy $\hbar \omega$ is relatively small). On the basis of frontier orbital analysis, the highenergy transitions are MLCT in character, and these are responsible for the quadratic NLO response. The simple two-level model is thus a valid assumption for these types of systems (i.e. contributions from the low-lying ligand-field-based transitions are small) but, according to Calabrese et al., the two-level model is inapplicable as both CT (low-lying MLCT and high-lying LLCT) contribute to the $\beta$. Calabrese et al. also reported that the experimental $\beta_{\text {vec }}$ of 2 is comparable to that of the methoxyphenyl analogue, a traditional organic push-pull system, thereby indicating the effective electron donating ability of the ferrocenyl moiety. The INDO/S calculations of several ferrocenyl complexes and their methoxyphenyl analogues are shown in Table 4 [225]. As can be seen, the replacement of the ferrocenyl moiety with a methoxyphenyl donor seems to have a minor impact on the $\beta_{\text {vec. The authors }}$ inferred, from a detailed molecular orbital analysis of $\mathbf{2}$ and $\mathbf{1 0}$, that the electronic origin of $\beta$ is similar for the two systems due to the similarities in the dominant CT transitions in $\mathbf{2}$ and 
10 and hence that low-lying $d-d$ transitions are not responsible for the $\beta$ in the former. Thus, it appears that the two-level model can be used to explain the quadratic NLO responses observed for the ferrocenyl derivatives [225].

Several structure- $\beta$ relationships for the ferrocenyl complexes can be identified from the $\beta_{\text {vec }}$ data in Table 3. The increase in donor strength via methylation of the cyclopentadienyl ring, on proceeding from 2 to 4 , results in a considerable increase in the $\beta_{\text {vec }}$ value. The $\beta_{\text {vec values }}$ from EFISH and ZINDO studies increase when a stronger acceptor is introduced, e.g. CHO $(11) \approx \mathrm{CN}(10)<\mathrm{NO}_{2}(2)$. Moreover, the increase in the number of ethylenic units (n) in moving from $\mathbf{2}$ to $\mathbf{7}$ to $\mathbf{8}$ results in a significant increase in the calculated $\beta_{\text {vec }}$ values. The nonlinear optical activity of $\mathbf{2}$ ( $E$ isomer) is much greater than that of $\mathbf{1}$ ( $Z$ isomer). The same holds for compounds $\mathbf{9}$ and $\mathbf{1 0}$, according to the calculations. 
Table 3. Comparison of experimental and calculated linear optical and quadratic nonlinear optical data (at $\lambda=1.91 \mu \mathrm{m}$ ) for a series of ferrocenyl complexes: ZINDO-derived data. ${ }^{\mathrm{a}}$

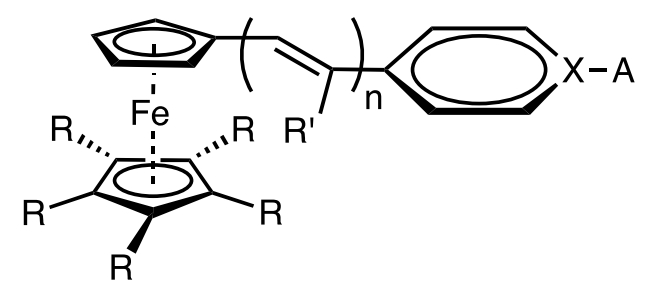

\begin{tabular}{|c|c|c|c|c|c|c|c|c|c|c|c|c|}
\hline \multirow[b]{2}{*}{ Complex } & \multirow[b]{2}{*}{$\mathrm{R}$} & \multirow[b]{2}{*}{$\mathrm{R}^{\prime}$ (isomer) } & \multirow[b]{2}{*}{$\mathrm{n}$} & \multirow[b]{2}{*}{$\mathrm{X}-\mathrm{A}$} & \multicolumn{3}{|c|}{ Ref. [224] } & \multicolumn{5}{|c|}{ Ref. [225] } \\
\hline & & & & & $\beta_{\mathrm{vec}}^{\exp }$ & $\beta_{\text {vec }}^{\text {calc }}$ & $\beta_{\text {tot }}^{\text {cal }}$ & $\beta_{\mathrm{vec}}^{\exp }$ & $\beta_{\text {vec }}^{\text {calc }}$ & $\beta_{\text {tot }}^{\text {cal }}$ & $\lambda_{1} / \lambda_{2}(\exp )$ & $\lambda_{1} / \lambda_{2}($ calc $)$ \\
\hline 1 & $\mathrm{H}$ & $\mathrm{H}(Z)$ & 1 & $\mathrm{C}-\mathrm{NO}_{2}$ & 14 & 29.0 & 29.1 & 13 & 20.7 & 21.0 & $480 / 325$ & $363 / 350$ \\
\hline 2 & $\mathrm{H}$ & $\mathrm{H}(E)$ & 1 & $\mathrm{C}-\mathrm{NO}_{2}$ & 34 & 41.0 & 41.0 & 31 & 30.8 & 30.8 & $496 / 356$ & $381 / 354$ \\
\hline 3 & $\mathrm{H}$ & $\mathrm{CN}(E)$ & 1 & $\mathrm{C}-\mathrm{NO}_{2}$ & 22 & 31.9 & 37.1 & 21 & 25.6 & 29.0 & $526 / 348$ & $473 / 359$ \\
\hline 4 & $\mathrm{CH}_{3}$ & $\mathrm{H}(E)$ & 1 & $\mathrm{C}-\mathrm{NO}_{2}$ & 40 & 45.4 & 45.5 & 40 & 34.7 & 34.7 & $533 / 366$ & $468 / 357$ \\
\hline 5 & $\mathrm{CH}_{3}$ & $\mathrm{CN}(E)$ & 1 & $\mathrm{C}-\mathrm{NO}_{2}$ & 35 & 35.3 & 40.4 & 35 & 28.4 & 31.9 & $560 / 366$ & $460 / 363$ \\
\hline 6 & $\mathrm{H}$ & $\mathrm{H}(E)$ & 1 & $\begin{array}{l}\mathrm{C}-2,4- \\
\left(\mathrm{NO}_{2}\right)_{2}\end{array}$ & 21 & 51.0 & 56.4 & 23 & 40.0 & 44.8 & $536 / 366$ & $455 / 413 / 355^{\mathrm{b}}$ \\
\hline
\end{tabular}




$\begin{array}{lllllllllllrr}\mathbf{7} & \mathrm{H} & \mathrm{H}(E, E) & 2 & \mathrm{C}-\mathrm{NO}_{2} & 52 & 73.7 & 73.8 & 66 & 47.4 & 47.5 & 500 / 382 \\ \mathbf{8} & \mathrm{H} & \mathrm{H}(E, E, E) & 3 & \mathrm{C}-\mathrm{NO}_{2} & \mathrm{c} & \mathrm{c} & \mathrm{c} & \mathrm{c} & 66.6 & 66.8 & 510 / 377 \\ \mathbf{9} & \mathrm{H} & \mathrm{H}(Z) & 1 & \mathrm{C}-\mathrm{CN} & \mathrm{c} & \mathrm{c} & \mathrm{c} & 4.0 & 5.49 & 5.92 & 460 / 308 \\ \mathbf{1 0} & \mathrm{H} & \mathrm{H}(E) & 1 & \mathrm{C}-\mathrm{CN} & \mathrm{c} & \mathrm{c} & \mathrm{c} & 10 & 9.72 & 9.76 & 466 / 324 & 386 / 311 \\ \mathbf{1 1} & \mathrm{H} & \mathrm{H}(E) & 1 & \mathrm{C}-\mathrm{CHO} & \mathrm{c} & \mathrm{c} & \mathrm{c} & 12 & 15.1 & 17.2 & 474 / 338 \\ \mathbf{1 2} & \mathrm{H} & \mathrm{H}(E) & 1 & \mathrm{~N}-\mathrm{CH}_{3}{ }^{+} & \mathrm{c} & \mathrm{c} & \mathrm{c} & \mathrm{c} & 67.6 & 68.9 & 5502 / 317 \\ \end{array}$

${ }^{\mathrm{a}}$ See original references for the experimental and computational details. $\beta_{\mathrm{vec}}$ values are in $10^{-30}$ esu. $\lambda_{1} / \lambda_{2}$ : wavelength of first

transition/second transition in $\mathrm{nm}$. The calculated $\beta$ values are slightly different in the two reports as they used different geometries in the calculations. ${ }^{\mathrm{b}}$ Three transitions were found computationally. ${ }^{\mathrm{c}}$ Not reported. 
Table 4. Comparison of calculated $\beta_{\mathrm{vec}}$ values of ferrocenyl complexes and their methoxyphenyl analogues at $\lambda=1.91 \mu \mathrm{m}$. ZINDO-derived data (Ref. [225]).

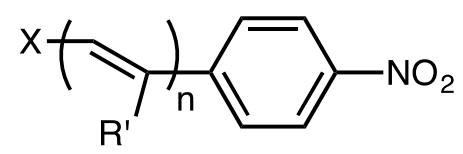

\begin{tabular}{|c|c|c|c|c|}
\hline \multirow[b]{3}{*}{$\mathrm{R}^{\prime}$} & \multirow[b]{3}{*}{$\mathrm{n}$} & \multirow[b]{3}{*}{ isomer } & \multicolumn{2}{|c|}{$\beta_{\text {vec }}^{\text {calc }}\left(10^{-30}\right.$ esu $)$} \\
\hline & & & $X=$ & $X=$ \\
\hline & & & $\mathrm{Fe}\left(\eta^{5}-\mathrm{C}_{5} \mathrm{H}_{5}\right)\left(\eta^{5}-\right.$ & 1-MeOC $6 \mathrm{H}_{4}-4-$ \\
\hline & & & $\left.\mathrm{C}_{5} \mathrm{H}_{4}\right)$ & \\
\hline $\mathrm{H}$ & 1 & $Z$ & $20.7(1)$ & 19.8 \\
\hline $\mathrm{H}$ & 1 & $E$ & $30.8(2)$ & $34.2(\mathbf{1 0})$ \\
\hline $\mathrm{CN}$ & 1 & $E$ & $25.6(3)$ & 26.8 \\
\hline $\mathrm{H}$ & 2 & $E, E$ & $47.4(7)$ & 50.5 \\
\hline $\mathrm{H}$ & 3 & $E, E, E$ & $66.6(8)$ & 68.0 \\
\hline
\end{tabular}

\subsection{Chromium arene derivatives}

Additionally, Kanis et al. [225] reported semi-empirical studies of linear optical and quadratic nonlinear optical properties of a series of chromium arene derivatives (e.g. 13-18 in Table 5). Their $\beta_{\text {vec }}$ values (both experimental and calculated) were considerably smaller than those of the ferrocenyl derivatives as well as those of the most efficient organic push-pull chromophores. According to the ZINDO calculations, this is mainly because of the modest $\Delta \mu$ (dipole moment difference between the ground and excited state) associated with the MLCT transition contributing to the $\beta_{\mathrm{vec}}$, due to the electronic pseudo-symmetry about the metal (i.e. the CT density almost equally distributes between the carbonyl and arene ligands). For instance, the two-level parameters $\left(\lambda_{\max }, \mathrm{f}, \Delta \mu\right)$ for the MLCT band for $\mathbf{2}$ and $\mathbf{1 3}$ are (354 
$\mathrm{nm}, 0.90,14.1 \mathrm{D})$ and $(225 \mathrm{~nm}, 0.60,1.9 \mathrm{D})$, respectively. Thus, the $\Delta \mu$ of $\mathbf{1 3}$ is significantly smaller than that of $\mathbf{2}$. The authors showed that the electronic pseudo-symmetry in the aforementioned arene complexes can be removed by increasing the $\pi$-conjugation length of the arene ligand (e.g. 19 in Table 6). This in turn increases the dipole component along the xaxis (and has a minor impact on the $\mu_{z}$ ) and changes the CT axis to the x-axis. Since the dominant CT direction is not parallel with the ground state dipole moment for the hypothetical complexes, EFISH will sample only a part of the intrinsic $\beta$, i.e. $\beta_{\mathrm{vec}}^{\text {calc }}<\beta_{\text {tot }}^{\text {calc }}$. The $\Delta \mu$ associated with the dominant MLCT band is modest, and so the calculated $\beta$ values of the chromium arene complexes are smaller than those of their organic analogues (e.g. 19 vs 20). It was suggested that $\Delta \mu$ can be enhanced by replacing the three $\pi$-accepting $C O$ ligands with electron releasing $\mathrm{NH}_{3}$ groups. 
Table 5. Comparison of experimental and calculated linear optical and quadratic nonlinear optical data (at $\lambda=1.91 \mu \mathrm{m})$ for a series of chromium arene derivatives: ZINDO-derived data (Ref. [225])

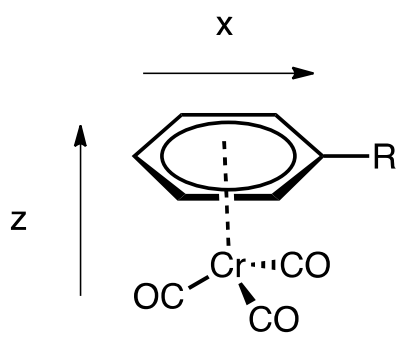

\begin{tabular}{|c|c|c|c|c|c|c|c|c|c|}
\hline \multirow[b]{2}{*}{ Complex } & \multirow[b]{2}{*}{$\mathrm{R}$} & \multirow[b]{2}{*}{$\beta_{\mathrm{vec}}^{\exp }$} & \multirow[b]{2}{*}{$\beta_{\mathrm{vec}}^{\text {calc }}$} & \multirow[b]{2}{*}{$\beta_{\text {tot }}^{\text {calc }}$} & \multirow[b]{2}{*}{$\mu_{\mathrm{x}}^{\text {calc }}$} & \multirow[b]{2}{*}{$\mu_{\mathrm{z}}^{\text {calc }}$} & \multicolumn{3}{|c|}{ MLCT transition } \\
\hline & & & & & & & $\lambda^{\text {calc }}$ & $\mathrm{f}$ & $\Delta \mu$ \\
\hline 13 & $\mathrm{H}$ & -0.8 & -1.30 & 1.30 & 0.0 & 8.6 & 225 & 0.60 & 1.9 \\
\hline 14 & $\mathrm{OCH}_{3}$ & -0.9 & -1.36 & 1.50 & 0.6 & 8.6 & 227 & 0.64 & 1.60 \\
\hline 15 & $\mathrm{NH}_{2}$ & -0.6 & -1.27 & 1.42 & 1.1 & 8.8 & 230 & 0.52 & 0.8 \\
\hline 16 & $\mathrm{~N}\left(\mathrm{CH}_{3}\right)_{2}$ & -0.4 & -0.91 & 1.12 & 1.4 & 8.9 & 237 & 0.11 & 2.7 \\
\hline 17 & $\mathrm{COOCH}_{3}$ & -0.7 & -1.79 & 4.28 & -4.5 & 8.1 & 241 & 0.15 & 2.4 \\
\hline 18 & trans-styrenyl & -2.2 & -3.93 & 4.80 & 0.8 & 8.6 & 337 & 0.14 & 6.1 \\
\hline
\end{tabular}

${ }^{\mathrm{a}} \beta$ values in $10^{-30}$ esu. Dipole moments $(\mu)$ in Debyes. Wavelengths $(\lambda)$ in $\mathrm{nm}$. 
Table 6. Calculated linear optical and quadratic nonlinear optical (at $\lambda=1.91 \mu \mathrm{m})$ ZINDO-derived data (Ref. [225]).

$\beta_{\mathrm{vec}}^{\mathrm{calc}} \quad \beta_{\mathrm{tot}}^{\mathrm{cal}}$

19

15.6

34.5

$-6.8$

8.6

393

1.45

8.2

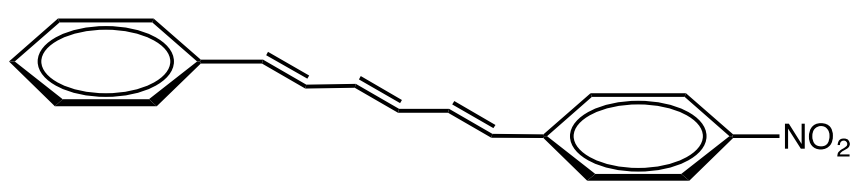

20

57.6 57.9

$-8.1$

0.0

398

1.86

12.6

\subsection{Group 8 metal alkynyl complexes}

Calabrese et al. [28] pointed out that the organic $\pi$-system is weakly coupled with the metal in the ferrocenyl complexes. In contrast, Kanis et al. [225] have inferred that the organic-like NLO properties shown by the ferrocenyls, as well as their large $\beta$ values compared to the chromium arene complexes, are due to the successful coupling between the metal and $\pi$ system. In this respect, metal alkynyl complexes represent an interesting class of organometallics; the ligated metal is in the plane of the organic $\pi$-framework and there is some $\pi$-bonding between the metal and the alkynyl ligand, favouring large NLO properties 
[26,231]. The better coupling between the metal centre and the alkynyl ligand should enhance the charge delocalization between the termini through the alkynyl $\pi$-network. The interaction between the metal centre and the alkynyl linker, and the effect of alkynyl substitution on the bonding properties, have been extensively studied for several (group 8) metal alkynyl complexes such as $\mathrm{Ru}(\mathrm{C} \equiv \mathrm{CX})\left(\mathrm{PH}_{3}\right)_{2}\left(\eta^{5}-\mathrm{C}_{5} \mathrm{H}_{5}\right)\left(\mathrm{X}=\mathrm{H}, \mathrm{Ph},-4-\mathrm{C}_{6} \mathrm{H}_{4}-1-\mathrm{NO}_{2}\right)$ [229], trans$\left[\mathrm{M}(\mathrm{C} \equiv \mathrm{CX}) \mathrm{Cl}\left(\mathrm{PH}_{3}\right)_{4}\right]\left(\mathrm{M}=\mathrm{Fe}, \mathrm{Ru}, \mathrm{Os} ; \mathrm{X}=\mathrm{H}, \mathrm{Ph},-4-\mathrm{C}_{6} \mathrm{H}_{4}-1-\mathrm{NO}_{2}\right)[230]$, and $\left[\mathrm{M}\left(\mathrm{C} \equiv \mathrm{CC}_{6} \mathrm{H}_{4}-\right.\right.$ $\mathrm{X})\left(\kappa^{2}\right.$-dppe $\left.)\left(\eta^{5}-\mathrm{C}_{5} \mathrm{Me}_{5}\right)\right]^{\mathrm{n}}\left(\mathrm{n}=0,1+; \mathrm{M}=\mathrm{Fe}\right.$ and $\mathrm{X}=\mathrm{NO}_{2}, \mathrm{CN}, \mathrm{CF}_{3}, \mathrm{Br}, \mathrm{F}, \mathrm{H}, \mathrm{Me},{ }^{\mathrm{t}} \mathrm{Bu}$, OMe, $\mathrm{NH}_{2} ; \mathrm{M}=\mathrm{Ru}$ and $\mathrm{X}=\mathrm{NO}_{2}, \mathrm{CN}, \mathrm{F}, \mathrm{H}, \mathrm{OMe}, \mathrm{NH}_{2}$ ) [232-234]. From these studies, an increase in the acceptor strength of the alkynyl ligand (e.g. via nitration) was found to improve the M-C back-bonding interaction, although the $\pi$-interactions (forward-bonding between the metal $\mathrm{d} \pi$ and $\pi$ orbitals of the alkynyl fragment and back-bonding between the $\mathrm{d} \pi$ and $\pi^{*}$ orbitals) are relatively weak compared to the dominant M-C $\sigma$ interaction. Bonding properties of these complexes, and thus ionization potentials, are sensitive to the electronic nature of the alkynyl ligand. Delfs et al. [230] studied the effect of metal variation on the $\mathrm{M}-\mathrm{C}$ back-bonding interaction in $\left[\mathrm{M}(\mathrm{C} \equiv \mathrm{CX}) \mathrm{Cl}\left(\mathrm{PH}_{3}\right)_{4}\right]$ where $\mathrm{M}=\mathrm{Fe}, \mathrm{Ru}$, and Os. Their findings showed that the replacement of $\mathrm{Fe}$ with $\mathrm{Ru}$ has a minor impact on the magnitude of the $\mathrm{d} \pi-\pi^{*}$ interaction, which was corroborated by Paul and co-workers [234] for closely related alkynyl complexes. However, $\pi$-back-bonding energy increases when Fe or $\mathrm{Ru}$ is replaced by $\mathrm{Os}$ (when the relativistic corrections are included in the calculations) [230]. The trend in the back-bonding energy $(\mathrm{Fe} \approx \mathrm{Ru}<\mathrm{Os})$ agrees with the observed $\beta$ trend of the $\left[\mathrm{M}\left(\mathrm{C} \equiv \mathrm{C}-4-\mathrm{C}_{6} \mathrm{H}_{4}-1-\mathrm{NO}_{2}\right) \mathrm{Cl}\left(\kappa^{2}-\mathrm{dppe}\right)_{2}\right]$ [90], although some studies have shown that for related alkynyl complexes, the $\mathrm{Fe}(\mathrm{II})$ centre is more efficient than $\mathrm{Ru}(\mathrm{II})$ for $\beta$ (Table 6) $[235,236]$. For example, varying the ligated metal on proceeding from 21a $(\mathrm{Fe})$ to $\mathbf{2 1 b}(\mathrm{Ru})$ to 21c (Os) leads to an increase in the experimental quadratic NLO response $\left(\beta_{\text {exp }}\right)$. In 
contrast, the two-level corrected data $\left(\beta_{\mathrm{TLM}}\right)$ indicates that $\mathrm{Ru}(\mathrm{II})$ is more efficient than

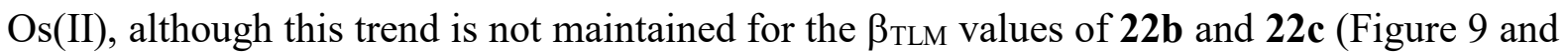
Table 7). The HRS values of 22a $(\mathrm{Fe})$ and $22 \mathbf{b}(\mathrm{Ru})$ are comparable, with the resonance contribution being pronounced in the former (the $\lambda_{\max }$ of $\mathbf{2 2 a}$ is closer to the second harmonic at $532 \mathrm{~nm}$ than are those of $\mathbf{2 2 b}$ and $\mathbf{2 2 c}$ ). From the hyperpolarizability data of $\mathbf{2 2 a - c}$, it is clear that $\pi$-back-bonding is important for NLO behaviour [90]. In contrast, Paul and coworkers [236] have extracted $\beta_{\exp }$ values for 23a-d using the EFISH technique and their data suggest that the $\mathrm{Fe}(\mathrm{II})$ centre is more effective than $\mathrm{Ru}(\mathrm{II})$. They employed a fundamental wavelength of $1910 \mathrm{~nm}$ (as opposed to $1064 \mathrm{~nm}$ in the previous studies), and thus their data is essentially free from resonance effects, although they used computationally-derived dipole moments to calculate $\beta$ from the measured $\mu \beta$ product. For longer alkynyl ligands, Garcia et al. showed that the replacement of $\mathrm{Ru}$ with Fe has no significant effect on the HRS $\beta$ values (24a vs 24b) [235]. For thiophene-based alkynyl complexes, e.g. 25a and 25b, both HRS (at $1500 \mathrm{~nm}$ ) and two-level corrected data in Table 7 show that the $\beta$ response of the Ru complex is better than that of its Fe homologue, although the calculated response for the model complexes (with $\mathrm{H}$ atoms substituting for phenyl groups in the dppe ligand) was less profound [84]. Overall, although there is some ambiguity for $\beta$ values of the $\mathrm{Fe}(\mathrm{II})$ and $\mathrm{Ru}(\mathrm{II})$ homologues, the Os(II) centre is demonstrably superior to the Fe and Ru centres with the same coordination.

(Insert Figure 9) 
Table 7. Experimental linear optical and quadratic nonlinear optical data for selected group 8, 10, and 11 metal alkynyl complexes.

\begin{tabular}{|c|c|c|c|c|c|c|c|}
\hline Complex & Solvent & $\begin{array}{l}\lambda_{\max } \\
(\mathrm{nm})\end{array}$ & $\begin{array}{l}\beta_{\exp } \\
\left(10^{-30}\right.\end{array}$ & $\begin{array}{l}\beta_{\text {TLM }}\left(10^{-30}\right. \\
\text { esu) }\end{array}$ & Technique & $\begin{array}{l}\text { Fundamental } \\
(\mathrm{nm})\end{array}$ & Ref. \\
\hline & & & esu) & & & & \\
\hline$\left[\mathrm{Fe}\left(\mathrm{C} \equiv \mathrm{C}-4-\mathrm{C}_{6} \mathrm{H}_{4}-1-\mathrm{NO}_{2}\right) \mathrm{Cl}\left\{\kappa^{2}-(R, R)-\operatorname{diph}\right\}_{2}\right](\mathbf{2 1 a})$ & THF & 543 & 440 & -14 & HRS & 1064 & [237] \\
\hline \multirow[t]{2}{*}[\mathrm{Fe}(\mathrm{C}\equiv\mathrm{C}-4-\mathrm{C}_{6}\mathrm{H}_{4}-1-\mathrm{NO}_{2})(\kappa^{2}-\mathrm{dppe})(\eta^{5}-\mathrm{C}_{5}\mathrm{H}_{5})]{$(\mathbf{2 2 a})$} & THF & 498 & 665 & 64 & HRS & 1064 & [90] \\
\hline & $\mathrm{CHCl}_{3}$ & 504 & 1160 & na & HRS & 1064 & [235] \\
\hline$\left[\mathrm{Fe}\left(\mathrm{C} \equiv \mathrm{C}-4-\mathrm{C}_{6} \mathrm{H}_{4}-1-\mathrm{NO}_{2}\right)\left(\kappa^{2}-\right.\right.$ dppe $\left.)\left(\eta^{5}-\mathrm{C}_{5} \mathrm{Me}_{5}\right)\right](\mathbf{2 3 a})$ & $\mathrm{CH}_{2} \mathrm{Cl}_{2}$ & 595 & 168.9 & 93.0 & EFISH & 1910 & [236] \\
\hline$\left[\mathrm{Fe}\left(\mathrm{C} \equiv \mathrm{C}-4-\mathrm{C}_{6} \mathrm{H}_{4}-1-\mathrm{CN}\right)\left(\kappa^{2}-\mathrm{dppe}\right)\left(\eta^{5}-\mathrm{C}_{5} \mathrm{Me}_{5}\right)\right](\mathbf{2 3 b})$ & $\mathrm{CH}_{2} \mathrm{Cl}_{2}$ & 445 & 69.8 & 51.0 & EFISH & 1910 & [236] \\
\hline$\left[\mathrm{Fe}\left(\mathrm{C} \equiv \mathrm{C}-4-\mathrm{C}_{6} \mathrm{H}_{4}-1-(E)-\mathrm{CH}=\mathrm{CH}-1-\mathrm{C}_{6} \mathrm{H}_{4}-4-\mathrm{NO}_{2}\right)\left(\kappa^{2}-\mathrm{dppe}\right)\left(\eta^{5}-\mathrm{C}_{5} \mathrm{H}_{5}\right)\right](\mathbf{2 4 a})$ & $\mathrm{CHCl}_{3}$ & 506 & 2315 & na & HRS & 1064 & [235] \\
\hline$\left[\mathrm{Fe}\left\{\mathrm{C} \equiv \mathrm{C}-5-\mathrm{C}_{4} \mathrm{H}_{2} \mathrm{~S}-2-\mathrm{NO}_{2}\right\}\left(\kappa^{2}-\mathrm{dppe}\right)\left(\eta^{5}-\mathrm{C}_{5} \mathrm{H}_{5}\right)(\mathbf{2 5 a})\right.$ & $\mathrm{CHCl}_{3}$ & 578 & 232 & 80 & HRS & 1500 & [84] \\
\hline$\left[\mathrm{Fe}\left(\mathrm{C} \equiv \mathrm{C}-4-\mathrm{C}_{6} \mathrm{H}_{4}-1-\mathrm{NO}_{2}\right)(\mathrm{CO})_{2}\left(\eta^{5}-\mathrm{C}_{5} \mathrm{H}_{5}\right)\right]$ (26a) & THF & 370 & 49 & 22 & HRS & 1064 & [90] \\
\hline$\left[\mathrm{Ru}\left(\mathrm{C} \equiv \mathrm{C}-4-\mathrm{C}_{6} \mathrm{H}_{4}-1-\mathrm{NO}_{2}\right) \mathrm{Cl}\left\{\kappa^{2}-(R, R)-\mathrm{diph}\right\}_{2}\right](\mathbf{2 1} \mathbf{b})$ & THF & 467 & 530 & 97 & HRS & 1064 & [237] \\
\hline$\left[\mathrm{Ru}\left(\mathrm{C} \equiv \mathrm{C}-4-\mathrm{C}_{6} \mathrm{H}_{4}-1-\mathrm{NO}_{2}\right)\left(\kappa^{2}-\mathrm{dppe}\right)\left(\eta^{5}-\mathrm{C}_{5} \mathrm{H}_{5}\right)\right](\mathbf{2 2} \mathbf{b})$ & THF & 447 & 664 & 161 & HRS & 1064 & [90] \\
\hline$\left[\mathrm{Ru}\left(\mathrm{C} \equiv \mathrm{C}-4-\mathrm{C}_{6} \mathrm{H}_{4}-1-\mathrm{NO}_{2}\right)\left(\kappa^{2}-\mathrm{dppe}\right)\left(\eta^{5}-\mathrm{C}_{5} \mathrm{Me}_{5}\right)\right](\mathbf{2 3 c})$ & $\mathrm{CH}_{2} \mathrm{Cl}_{2}$ & 500 & 57.9 & 39 & EFISH & 1910 & [236] \\
\hline
\end{tabular}




\begin{tabular}{|c|c|c|c|c|c|c|c|}
\hline$\left[\mathrm{Ru}\left(\mathrm{C} \equiv \mathrm{C}-4-\mathrm{C}_{6} \mathrm{H}_{4}-1-\mathrm{CN}\right)\left(\kappa^{2}-\mathrm{dppe}\right)\left(\eta^{5}-\mathrm{C}_{5} \mathrm{Me}_{5}\right)\right](\mathbf{2 3 d})$ & $\mathrm{CH}_{2} \mathrm{Cl}_{2}$ & 384 & 33.9 & 11 & EFISH & 1910 & [236] \\
\hline$\left[\mathrm{Ru}\left(\mathrm{C} \equiv \mathrm{C}-4-\mathrm{C}_{6} \mathrm{H}_{4}-1-(E)-\mathrm{CH}=\mathrm{CHC}_{6} \mathrm{H}_{4}-4-\mathrm{NO}_{2}\right)\left(\mathrm{PPh}_{3}\right)_{2}\left(\eta^{5}-\mathrm{C}_{5} \mathrm{H}_{5}\right)\right](\mathbf{2 4 b})$ & $\mathrm{CHCl}_{3}$ & 484 & 2270 & na & HRS & 1064 & {$[235]$} \\
\hline$\left[\mathrm{Ru}\left\{\mathrm{C} \equiv \mathrm{C}-5-\mathrm{C}_{4} \mathrm{H}_{2} \mathrm{~S}-2-\mathrm{NO}_{2}\right\}\left(\kappa^{2}-\mathrm{dppe}\right)\left(\eta^{5}-\mathrm{C}_{5} \mathrm{H}_{5}\right)\right](\mathbf{2 5 b})$ & $\mathrm{CHCl}_{3}$ & 517 & 326 & 151 & HRS & 1500 & {$[84]$} \\
\hline$\left[\mathrm{Ru}\left(\mathrm{C} \equiv \mathrm{C}-4-\mathrm{C}_{6} \mathrm{H}_{4}-1-\mathrm{NO}_{2}\right)(\mathrm{CO})_{2}\left(\eta^{5}-\mathrm{C}_{5} \mathrm{H}_{5}\right)\right](\mathbf{2 6} \mathbf{b})$ & THF & 364 & 58 & 27 & HRS & 1064 & {$[90]$} \\
\hline $\mathrm{Ru}(\mathrm{C} \equiv \mathrm{CPh})\left(\mathrm{PPh}_{3}\right)_{2}\left(\eta^{5}-\mathrm{C}_{5} \mathrm{H}_{5}\right)(27)$ & THF & 310 & 16 & 10 & HRS & 1064 & {$[80]$} \\
\hline $\mathrm{Ru}\left(\mathrm{C} \equiv \mathrm{C}-4-\mathrm{C}_{6} \mathrm{H}_{4}-1-\mathrm{NO}_{2}\right)\left(\mathrm{PPh}_{3}\right)_{2}\left(\eta^{5}-\mathrm{C}_{5} \mathrm{H}_{5}\right)(\mathbf{2 8})$ & THF & 460 & 468 & 96 & HRS & 1064 & {$[78]$} \\
\hline $\mathrm{Ru}\left(\mathrm{C} \equiv \mathrm{C}-4-\mathrm{C}_{6} \mathrm{H}_{4}-1-\mathrm{NO}_{2}\right)\left(\mathrm{PMe}_{3}\right)_{2}\left(\eta^{5}-\mathrm{C}_{5} \mathrm{H}_{5}\right)(\mathbf{2 9})$ & THF & 477 & 248 & 39 & HRS & 1064 & {$[78]$} \\
\hline trans $-\left[\mathrm{Ru}(\mathrm{C} \equiv \mathrm{CPh}) \mathrm{Cl}\left(\kappa^{2}-\mathrm{dppm}\right)_{2}\right](\mathbf{3 0})$ & THF & 308 & 20 & 12 & HRS & 1064 & {$[79]$} \\
\hline trans $-\left[\mathrm{Ru}\left(\mathrm{C} \equiv \mathrm{C}-4-\mathrm{C}_{6} \mathrm{H}_{4}-1-\mathrm{NO}_{2}\right) \mathrm{Cl}\left(\kappa^{2}-\mathrm{dppm}\right)_{2}\right](\mathbf{3 1})$ & THF & 473 & 767 & 129 & HRS & 1064 & {$[79]$} \\
\hline trans $-\left[\mathrm{Ru}\left(\mathrm{C} \equiv \mathrm{C}-4-\mathrm{C}_{6} \mathrm{H}_{4}-1-4-\mathrm{C}_{6} \mathrm{H}_{4}-1-\mathrm{NO}_{2}\right) \mathrm{Cl}\left(\kappa^{2}-\mathrm{dppm}\right)_{2}\right](\mathbf{3 2})$ & THF & 465 & 933 & 178 & HRS & 1064 & {$[79]$} \\
\hline trans $-\left[\mathrm{Ru}\left(\mathrm{C} \equiv \mathrm{C}-1-\mathrm{C}_{6} \mathrm{H}_{4}-4-\mathrm{C} \equiv \mathrm{C}-4-\mathrm{C}_{6} \mathrm{H}_{4}-1-\mathrm{NO}_{2}\right) \mathrm{Cl}\left(\kappa^{2}-\mathrm{dppm}\right)_{2}\right](\mathbf{3 3})$ & THF & 464 & 833 & 161 & HRS & 1064 & {$[238]$} \\
\hline trans $-\left[\mathrm{Ru}\left(\mathrm{C} \equiv \mathrm{C}-1-\mathrm{C}_{6} \mathrm{H}_{4}-4-\mathrm{C} \equiv \mathrm{C}-4-\mathrm{C}_{6} \mathrm{H}_{4}-1-\mathrm{C} \equiv \mathrm{C}-4-\mathrm{C}_{6} \mathrm{H}_{4}-1-\mathrm{NO}_{2}\right) \mathrm{Cl}\left(\kappa^{2}-\mathrm{dppm}\right)_{2}\right]$ & THF & 439 & 1379 & 365 & HRS & 1064 & [238] \\
\hline \multicolumn{8}{|l|}{ (34) } \\
\hline$\left[\mathrm{Ru}\left(\mathrm{C} \equiv \mathrm{C}-4-\mathrm{C}_{6} \mathrm{H}_{4}-1-\mathrm{NO}_{2}\right)\left(\kappa^{2}-\mathrm{dppf}\right)\left(\eta^{5}-\mathrm{C}_{5} \mathrm{H}_{5}\right)(\mathbf{3 5})\right.$ & THF & 469 & 770 & 165 & HRS & 1064 & {$[82]$} \\
\hline trans $-\left[\mathrm{Ru}\left(\mathrm{C} \equiv \mathrm{C}-4-\mathrm{C}_{6} \mathrm{H}_{4}-1-\mathrm{NO}_{2}\right) \mathrm{Cl}\left(\kappa^{2}-\mathrm{dppe}\right)_{2}\right](\mathbf{3 6})$ & THF & 477 & 351 & 55 & HRS & 1064 & {$[238]$} \\
\hline trans $-\left[\mathrm{Ru}\left(\mathrm{C} \equiv \mathrm{C}-1-\mathrm{C}_{6} \mathrm{H}_{4}-4-\mathrm{C} \equiv \mathrm{C}-4-\mathrm{C}_{6} \mathrm{H}_{4}-1-\mathrm{NO}_{2}\right) \mathrm{Cl}\left(\kappa^{2}-\mathrm{dppe}\right)_{2}\right](37)$ & THF & 468 & 1240 & 225 & HRS & 1064 & [228] \\
\hline trans $-\left[\mathrm{Ru}\left(\mathrm{C} \equiv \mathrm{C}-1-\mathrm{C}_{6} \mathrm{H}_{4}-4-\mathrm{C} \equiv \mathrm{C}-1-\mathrm{C}_{6} \mathrm{H}_{4}-4-\mathrm{C} \equiv \mathrm{C}-4-\mathrm{C}_{6} \mathrm{H}_{4}-1-\mathrm{NO}_{2}\right) \mathrm{Cl}\left(\kappa^{2}-\mathrm{dppe}\right)_{2}\right]$ (38) & THF & 429 & 1327 & 388 & HRS & 1064 & {$[228]$} \\
\hline trans $-\left[\mathrm{Ru}\left\{(E, E)-\mathrm{C} \equiv \mathrm{C}-4-\mathrm{C}_{6} \mathrm{H}_{4}-1-\mathrm{CH}=\mathrm{CH}-4-\mathrm{C}_{6} \mathrm{H}_{4}-1-\mathrm{CH}=\mathrm{CH}-4-\mathrm{C}_{6} \mathrm{H}_{4}-1-\right.\right.$ & THF & 468 & 2525 & 460 & HRS & 1064 & {$[228]$} \\
\hline
\end{tabular}


$\left.\left.\mathrm{NO}_{2}\right\} \mathrm{Cl}\left(\kappa^{2} \text {-dppe }\right)_{2}\right]$ (39)

$\left[\mathrm{Ru}\left(\mathrm{C} \equiv \mathrm{C}-1-\mathrm{C}_{6} \mathrm{H}_{4}-4-\mathrm{C} \equiv \mathrm{C}-4-\mathrm{C}_{6} \mathrm{H}_{4}-1-\mathrm{NO}_{2}\right)\left(\mathrm{PPh}_{3}\right)_{2}\left(\eta^{5}-\mathrm{C}_{5} \mathrm{H}_{5}\right)\right](\mathbf{4 0})$

$\left[\mathrm{Ru}\left(\mathrm{C} \equiv \mathrm{C}-4-\mathrm{C}_{6} \mathrm{H}_{4}-1-(E)-\mathrm{CH}=\mathrm{CH}-4-\mathrm{C}_{6} \mathrm{H}_{4}-1-\mathrm{NO}_{2}\right)\left(\mathrm{PPh}_{3}\right)_{2}\left(\eta^{5}-\mathrm{C}_{5} \mathrm{H}_{5}\right)\right](\mathbf{4 1})$

$\begin{array}{lcccccc}\text { THF } & 446 & 865 & 212 & \text { HRS } & 1064 & {[80]} \\ \text { THF } & 476 & 1455 & 232 & \text { HRS } & 1064 & {[80]} \\ \text { THF } & 496 & 840 & 86 & \text { HRS } & 1064 & {[78]} \\ \text { THF } & 565 & 1627 & 149 & \text { HRS } & 1064 & {[239]} \\ \text { THF } & 448 & 560 & 134 & \text { HRS } & 1064 & {[80]} \\ \mathrm{CHCl}_{3} & 536 & 192 & 82 & \text { HRS } & 1500 & {[84]}\end{array}$

$\left[\mathrm{Ru}\left\{\mathrm{C} \equiv \mathrm{C}-5-\mathrm{C}_{4} \mathrm{H}_{2} \mathrm{~S}-2-\mathrm{NO}_{2}\right\}\left(\mathrm{PPh}_{3}\right)_{2}\left(\eta^{5}-\mathrm{C}_{5} \mathrm{H}_{5}\right)\right](47)$

$\left[\mathrm{Os}\left(\mathrm{C} \equiv \mathrm{C}-4-\mathrm{C}_{6} \mathrm{H}_{4}-1-\mathrm{NO}_{2}\right) \mathrm{Cl}\left\{\mathrm{K}^{2}-(R, R)-\mathrm{diph}\right\}_{2}\right](\mathbf{2 1} \mathbf{c})$

$\left[\mathrm{Os}\left(\mathrm{C} \equiv \mathrm{C}-4-\mathrm{C}_{6} \mathrm{H}_{4}-1-\mathrm{NO}_{2}\right)\left(\kappa^{2}-\mathrm{dppe}\right)\left(\eta^{5}-\mathrm{C}_{5} \mathrm{H}_{5}\right)\right](\mathbf{2 2 c})$

$\begin{array}{lllllll}\text { THF } & 490 & 620 & 74 & \text { HRS } & 1064 & {[237]} \\ \text { THF } & 461 & 929 & 188 & \text { HRS } & 1064 & {[90]}\end{array}$

$\mathrm{Au}(\mathrm{C} \equiv \mathrm{CPh})\left(\mathrm{PPh}_{3}\right)(\mathbf{4 8})$

$\mathrm{Au}\left(\mathrm{C} \equiv \mathrm{C}-4-\mathrm{C}_{6} \mathrm{H}_{4}-1-\mathrm{NO}_{2}\right)\left(\mathrm{PPh}_{3}\right)(49)$

$\mathrm{Au}\left(\mathrm{C} \equiv \mathrm{C}-4-\mathrm{C}_{6} \mathrm{H}_{4}-1-\mathrm{NO}_{2}\right)\left(\mathrm{PMe}_{3}\right)(\mathbf{5 0})$

$\mathrm{Au}\left(\mathrm{C} \equiv \mathrm{C}-4-\mathrm{C}_{6} \mathrm{H}_{4}-1-4-\mathrm{C}_{6} \mathrm{H}_{4}-1-\mathrm{NO}_{2}\right)\left(\mathrm{PPh}_{3}\right)(\mathbf{5 1})$

$\mathrm{Au}\left(\mathrm{C} \equiv \mathrm{C}-1-\mathrm{C}_{6} \mathrm{H}_{4}-4-\mathrm{C} \equiv \mathrm{C}-4-\mathrm{C}_{6} \mathrm{H}_{4}-1-\mathrm{NO}_{2}\right)\left(\mathrm{PPh}_{3}\right)(\mathbf{5 2})$

$\begin{array}{lcccccc}\text { THF } & 296 & 6 & 4 & \text { HRS } & 1064 & {[240]} \\ \text { THF } & 338 & 22 & 12 & \text { HRS } & 1064 & {[240]} \\ \text { THF } & 339 & 50 & 27 & \text { HRS } & 1064 & {[241]} \\ \text { THF } & 350 & 39 & 20 & \text { HRS } & 1064 & {[240]} \\ \text { THF } & 362 & 59 & 28 & \text { HRS } & 1064 & {[240]}\end{array}$


$\mathrm{Ni}(\mathrm{C} \equiv \mathrm{CPh})\left(\mathrm{PPh}_{3}\right)\left(\eta^{5}-\mathrm{C}_{5} \mathrm{H}_{5}\right)(\mathbf{5 3})$

$\mathrm{Ni}\left(\mathrm{C} \equiv \mathrm{C}-4-\mathrm{C}_{6} \mathrm{H}_{4}-1-\mathrm{NO}_{2}\right)\left(\mathrm{PPh}_{3}\right)\left(\eta^{5}-\mathrm{C}_{5} \mathrm{H}_{5}\right)(\mathbf{5 4})$

$\mathrm{Ni}\left(\mathrm{C} \equiv \mathrm{C}-4-\mathrm{C}_{6} \mathrm{H}_{4}-1-4-\mathrm{C}_{6} \mathrm{H}_{4}-1-\mathrm{NO}_{2}\right)\left(\mathrm{PPh}_{3}\right)\left(\eta^{5}-\mathrm{C}_{5} \mathrm{H}_{5}\right)(\mathbf{5 5})$

$\mathrm{Ni}\left(\mathrm{C} \equiv \mathrm{C}-1-\mathrm{C}_{6} \mathrm{H}_{4}-4-\mathrm{C} \equiv \mathrm{C}-4-\mathrm{C}_{6} \mathrm{H}_{4}-1-\mathrm{NO}_{2}\right)\left(\mathrm{PPh}_{3}\right)\left(\eta^{5}-\mathrm{C}_{5} \mathrm{H}_{5}\right)(\mathbf{5 6})$

$\left[\mathrm{Ni}\left\{\mathrm{C} \equiv \mathrm{C}-5-\mathrm{C}_{4} \mathrm{H}_{2} \mathrm{~S}-2-\mathrm{NO}_{2}\right\}\left(\mathrm{PPh}_{3}\right)\left(\eta^{5}-\mathrm{C}_{5} \mathrm{H}_{5}\right)\right](\mathbf{5 7})$

$\begin{array}{lcccccc}\text { THF } & 307 & 24 & 15 & \text { HRS } & 1064 & {[242]} \\ \text { THF } & 439 & 221 & 59 & \text { HRS } & 1064 & {[242]} \\ \text { THF } & 413 & 193 & 65 & \text { HRS } & 1064 & {[242]} \\ \text { THF } & 417 & 326 & 106 & \text { HRS } & 1064 & {[242]} \\ \mathrm{CHCl}_{3} & 484 / 40 & 331 & 173 & \text { HRS } & 1500 & {[84]}\end{array}$


The quadratic NLO activity of metal alkynyl complexes is usually dictated by low-lying MLCT transitions [243]. The character of the optical transitions in 22a-c was studied with the aid of TD-DFT calculations which showed that the major contribution to $\beta$ is from lowenergy $\mathrm{d}\left(\mathrm{M}^{\mathrm{II}}\right) \rightarrow \pi^{*}$ (MLCT) transitions [90]. Recent CPKS calculations in the static limit with hybrid (B3LYP and PBE0) and range-separated (RS) (CAM-B3LYP, $\omega B 97 X$, and LCBLYP) DFT functionals showed that $\beta$ increased in the order $\mathbf{2 2 a}<\mathbf{2 2 b}<\mathbf{2 2 c}$, which agreed with the two-level corrected data, although the magnitude of $\beta$ is method-dependent. The $\beta$ value is very sensitive to the amount of HF exchange in the functional and decreases dramatically when the HF percentage increases, consistent with the large HOMO-LUMO gap computed for the RS functionals [185]. It should be noted that some pure functionals (e.g. BLYP, PBE, and PB) and functionals with correct asymptotic behaviour (e.g. SAOP, LB94, and GRACLB) have yielded different trends, with qualitatively the wrong trend for $\mathbf{2 2 b}$ and 22c $(\mathbf{2 2 b}>\mathbf{2 2 c})($ Table 8$)$ [81]. Further, Table 8 shows that the effect of solvent corrections is pronounced; the $\beta_{\text {tot }}$ values calculated in THF are more than three times larger than those obtained in the gas phase for BP, SAOP, and GRACLB.

Table 8. DFT (static) first hyperpolarizabilities of 22a-c. Values in $10^{-30}$ esu. Taylor convention used. Refs [81,185].

\begin{tabular}{llcrr}
\hline Method & Type $^{\mathrm{a}}$ & 22a & 22b & 22c \\
\hline $\mathrm{BP}^{\mathrm{b}}$ & GGA & 651.9 & 680.2 & 635.3 \\
$\mathrm{BP}^{\mathrm{b}}$ & GGA & $(157.8)$ & $(155.3)$ & $(149.4)$ \\
$\mathrm{PBE}^{\mathrm{b}}$ & GGA & $(157.7)$ & $(155.0)$ & $(149.0)$ \\
$\mathrm{BLYP}^{\mathrm{b}}$ & GGA & $(160.8)$ & $(158.6)$ & $(152.2)$ \\
$\mathrm{BLYP}^{\mathrm{c}}$ & GGA & 259.4 & 224.4 & 223
\end{tabular}




\begin{tabular}{|c|c|c|c|c|}
\hline B3LYP ${ }^{c}$ & Hybrid & 175.2 & 185.8 & 205 \\
\hline $\mathrm{PBE0}^{\mathrm{c}}$ & Hybrid & 149 & 163.4 & 183.4 \\
\hline CAM-B3LYP & $\mathrm{RS}$ & 80.4 & 102.2 & 123.4 \\
\hline$\omega \mathrm{B} 97 \mathrm{X}^{\mathrm{c}}$ & $\mathrm{RS}$ & 55 & 70.8 & 86.2 \\
\hline LC-BLYP ${ }^{c}$ & $\mathrm{RS}$ & 46.6 & 60.0 & 75.0 \\
\hline \multirow[t]{2}{*}{$\mathrm{SAOP}^{\mathrm{b}}$} & $\mathrm{AC}$ & 609.2 & 666.2 & 599.2 \\
\hline & & $(153.6)$ & $(156.2)$ & (148.9) \\
\hline \multirow[t]{2}{*}{ GRACLB $^{b}$} & $\mathrm{AC}$ & 646.0 & 672.7 & 631.8 \\
\hline & & $(158.7)$ & $(155.8)$ & $(150.6)$ \\
\hline LB9 $4^{\mathrm{b}}$ & $\mathrm{AC}$ & $(153.4)$ & $(167.0)$ & $(153.3)$ \\
\hline \multicolumn{5}{|c|}{${ }^{a}$ RS, range-separated; AC, asymptotically correct. ${ }^{b} \beta_{\text {tot }}$ values from Eq. 54 in } \\
\hline \multicolumn{5}{|c|}{ THF-COSMO (in the gas phase) with all-electron TZP (ADF) basis set. ${ }^{c}$} \\
\hline \multicolumn{5}{|c|}{ Unpublished computational data. $\beta_{\text {HRS }}$ values from Eq. 56 in THF-CPCM with 6- } \\
\hline \multicolumn{5}{|c|}{$311 \mathrm{G}(\mathrm{d}, \mathrm{p})$ basis set (for the ligands) and Stuttgart/Dresden pseudo-potential and } \\
\hline
\end{tabular}

As already mentioned, the M-C bonding in the dipolar, donor-bridge-acceptor alkynyl complexes is central for the charge delocalization from the donor (ligated metal) to acceptor (usually an organic acceptor), and thus for enhancing the NLO properties. Humphrey and coworkers [75] have investigated the effect of $\mathrm{M}-\mathrm{C}$ bond distance, as well as orientation of the arylalkynyl ligand, on the $\beta$ value for $\mathrm{Ru}\left(\mathrm{C} \equiv \mathrm{C}-4-\mathrm{C}_{6} \mathrm{H}_{4}-1-\mathrm{NO}_{2}\right)\left(\mathrm{PH}_{3}\right)_{2}\left(\eta^{5}-\mathrm{C}_{5} \mathrm{H}_{5}\right)$ using ZINDO calculations. They pointed out that a decrease in the metal alkynyl bond distance leads to an increase in $\beta$, whereas the orientation of the alkynyl ligand was found to have little effect on the calculated $\beta$. Although the latter seems to be true for alkynyls with single-phenyl-ring bridges, the first hyperpolarizabilities are adversely affected for complexes with 
oligo(phenyleneethynylene) bridges when the planarity of the alkynyl backbone is distorted (due to the communication between the termini being hampered by the non-planarity of the $\pi$-framework), according to recent DFT calculations $[81,185]$. In fact, such distortions in the aromatic linker have a considerable effect, not only on $\beta$, but also on the low-lying $\beta$ dictating CT transitions [81,91,227,244].

Intramolecular rotation about the molecular axis in such complexes is generally associated with a low energy barrier, permitting a range of rotamers to be in equilibrium in solution $[81,91,185]$. Thus, the average of the $\beta$ values of all the energetically possible conformers in solution must be used in order to compare with the relevant experimental hyperpolarizability data. Similarly, the DFT calculations suggest that the experimental UV-Vis band envelope is made up of overlapping transitions from the different rotamers in solution. Low and coworkers [245-247] have shown that for related binuclear mixed-valence and (bis)alkynyl complexes, some of the experimental UV-vis-NIR data cannot be explained by TD-DFT studies based on a single conformer (i.e. the lowest-energy structure) and that conformational flexibility associated with these systems must be taken into account.

\subsection{Effect of co-ligands}

The donor strength of the metal centre in organometallics can be tuned via co-ligand modification, which is an advantage over organic NLO chromophores [31]. This possibility of tuning quadratic activity in group 8 metal alkynyl complexes has been thoroughly studied by Humphrey and co-workers [78,82,90,238,248]. Some of their findings are provided in Table 7. The replacement of the $\pi$-acceptor CO ligands with the donor bidentate diphosphine dppe leads to a significant increase in the nonlinearity, e.g. 26a vs 22a and 26b vs 22b [90]. 
The $\beta$ value decreases when the $\mathrm{PPh}_{3}$ ligands are replaced with $\mathrm{PMe}_{3}$ ligands (28 vs 29); the greater $\pi$-delocalization possibilities with the $\mathrm{PPh}_{3}$ ligands are presumably a key factor for optimizing the $\beta$ value.

Mulliken charge densities showed that the Ru in the triphenylphosphine complex $\mathbf{2 8}$ is more electron rich than that in $\mathbf{2 9}(+1.40 \mathrm{vs}+1.47)$ [78]. The ZINDO calculations were found to be nearly insensitive to the ligand variation [75]. For the sake of computational expediency, response properties are often predicted for complexes with simplified co-ligands; phenyl groups in bulky (di)phosphines are generally replaced with $\mathrm{H}$ atoms or methyl groups. Kulasekera et al. [81] studied the effect of ligand simplification for 22a-c and found that substituting the phenyls in dppe co-ligands with $\mathrm{H}$ atoms or methyl groups has a minor effect. However, the calculations on larger molecules $(\mathbf{3 0}, \mathbf{3 2}$, and 34) showed some deviation upon modifying the ligands. Recent DFT/TD-DFT calculations on $\mathrm{Ru}\left(\mathrm{C} \equiv \mathrm{C}-4-\mathrm{C}_{6} \mathrm{H}_{4}-1-\right.$ $\left.\mathrm{NO}_{2}\right)\left(\mathrm{L}_{2}\right)\left(\eta^{5}-\mathrm{C}_{5} \mathrm{H}_{5}\right)\left[\mathrm{L}_{2}=\kappa^{2}\right.$-dppe (22b), $\kappa^{2}$-dppf (35)] have shown that the $\beta_{\text {tot }}$ values computed for the dppe complex and its dppf-containing analogue are comparable, consistent with the experimental data, and show very little contribution from the diphosphine ligands to the low-lying CT bands, consistent with the experimental UV-Vis data [82].

\subsection{Optimizing the alkynyl $\pi$-bridge}

Lengthening the alkynyl ligand usually leads to an increase in first hyperpolarizability response $\beta[16,30-32,231]$. For example, for trans $-\left[\mathrm{Ru}\left(\mathrm{C} \equiv \mathrm{C}\left(1,4-\mathrm{C}_{6} \mathrm{H}_{4} \mathrm{C} \equiv \mathrm{C}\right)_{\mathrm{n}}-4-\mathrm{C}_{6} \mathrm{H}_{4}-1-\right.\right.$ $\left.\left.\mathrm{NO}_{2}\right) \mathrm{Cl}\left(\kappa^{2} \text {-dppm }\right)_{2}\right]$, both $\beta_{\exp }$ and $\beta_{\mathrm{TLM}}$ increase significantly as $\mathrm{n}$ increases from 0 (31) to 2 (34), although the first hyperpolarizabilities $\beta_{\exp }$ when $n=0$ and 1 (33) are comparable within experimental error (Table 7) [79,238]. Similarly, for the dppe (instead of dppm) analogues, a 
significant increase in the $\beta$ value was observed upon $n$ increasing from 0 (36) to 2 (38) [228]. For the ruthenium alkynyl complexes with oligo(phenyleneethynylene) bridges, the optimal chain length for $\beta$ has been investigated by Humphrey and co-workers [91]. They revealed that the first hyperpolarizability is invariant (within the experimental error) once the alkynyl ligand contains three phenyleneethynylene units. For the related complex with oligo(phenylenevinylene) units in the $\pi$-bridge, the experimental $\beta$ value reaches the maximum at the same $\pi$-bridge length [249].

For various linkers, e.g. phenyleneethynylene $\left[-\mathrm{C} \equiv \mathrm{CC}_{6} \mathrm{H}_{4}-\right]_{\mathrm{n}}(\mathbf{y n e})$, phenylenevinylene $[-(E)-$ $\left.\mathrm{HC}=\mathrm{CHC}_{6} \mathrm{H}_{4}-\right]_{\mathrm{n}}$ (ene), phenyleneazo $\left[-\mathrm{N}=\mathrm{NC}_{6} \mathrm{H}_{4}-\right]_{\mathrm{n}}$ (azo), and phenyleneimino [- $(E)-$ $\left.\mathrm{N}=\mathrm{CHC}_{6} \mathrm{H}_{4}-\right]_{\mathrm{n}}$ (imino), the effect of lengthening the alkynyl ligand on $\beta$ has been studied by Kulasekera using DFT/TD-DFT calculations (Figure 10) [221]. According to Kulasekera's data, for the yne, ene, and imino series, the computed $\beta$ values reach a maximum at $n=5$ (for yne) and $n=6$ (for ene and imino) in the gas phase, and then decrease dramatically until convergence. In contrast, for the azo-series, the hyperpolarizability increases gradually. For $\mathrm{n}$ $<5$, the $\beta_{\text {tot }}$ values from the DFT calculations decrease as follows: yne $>$ imino $\geq$ ene $>$ azo. However, according to the experimental data for related complexes, the $(E)$-ene linkage was found to be more efficient than the yne linkage for [(38 vs 39) and [40 vs 41 ]) (Table 6).

\section{(Insert Figure 10)}

The calculated UV-Vis data are consistent with the calculated $\beta_{\text {tot }}$ values [221]. $\pi$-Bridge lengthening leads to a red-shift in the crucial lowest-energy band and a reduction in its intensity, on the basis of TD-SAOP/TZP data. By contrast, in the experimental UV-Vis spectra of the related yne [e.g. (31, 33, and 34) and (36-38)] and ene complexes [249], $\lambda_{\max }$ is blue-shifted upon $\pi$-bridge lengthening. This may be due to conformational flexibility 
associated with these long molecules [91,249]. As mentioned before, the energy required to distort the planarity of the $\pi$-network is small and the number of possible rotational isomers increases with molecular size. This might also contribute to the $\beta$ saturation observed in the large complexes. For the coplanar ene series (Figure 10) with $\mathrm{Ru}\left(\kappa^{2}-\mathrm{H}_{2} \mathrm{PCH}_{2} \mathrm{PH}_{2}\right)_{2}$ instead of $\mathrm{Ru}\left(\kappa^{2}-\mathrm{dppm}\right)_{2}($ up to $\mathrm{n}=7)$, recent TD-CAM-B3LYP calculations show that the intense, lowenergy band is red-shifted upon $\pi$-bridge lengthening, but the NLO-inefficient $\pi$ to $\pi^{*}$ transition that occurs within the $\pi$-bridge dominates the band in the larger complexes [249], which impedes the further increase in $\beta$ on proceeding to longer $\pi$-bridge complexes. Indeed, for 44 and 45 (Figure 11), the experimental data was found to be comparable within the margin of error.

\section{(Insert Figure 11)}

\subsection{Group 10 and 11 metal alkynyl complexes}

As already mentioned, experimental measurements of the first hyperpolarizabilities of group 8 metal alkynyl complexes at $1064 \mathrm{~nm}$ usually suffer from resonance effects as a consequence of electronic transitions being close in energy to the second-harmonic frequency. Dispersion-free data can be obtained by extrapolating the HRS/EFISH data at $1064 \mathrm{~nm}$ to the static limit $(\lambda=\infty)$ using the simple two-level model (Eq. 36). An alternative approach to effect a useful comparison of performance is to employ a different fundamental wavelength $\left(\lambda_{0}\right)$ (i.e. a longer wavelength) [84]. However, the longer the $\lambda_{0}$, the lower the HRS scattering signal [35]. Gold alkynyl complexes made by Humphrey and coworkers [30,31,33] have their lowest-energy absorption bands in the UV region, which 
resolves the problems associated with transparency and resonance effects (at $532 \mathrm{~nm}$ ). The experimental linear optical and quadratic NLO properties of a few selected gold alkynyl complexes (48-52) are given in Table 6, together with those of ruthenium $(\mathbf{2 7 - 2 9 , 4 0 , 4 6 )}$ and nickel (53-56) analogues. The nonlinearities for the gold complexes are smaller than those for the ruthenium and nickel complexes, indicating that $\beta$ decreases as the valence electron count decreases; for the alkynyl complexes in Table 6, the valence electron counts are 14 for the $\mathrm{Au}(\mathrm{I})$ and 18 for the $\mathrm{Ru}(\mathrm{II})$ and $\mathrm{Ni}(\mathrm{II})$ complexes. The $\beta_{\mathrm{TLM}}$ values of the ruthenium alkynyl complexes are larger than those of the nickel analogues, with the former being more easily oxidizable and (as a $4 \mathrm{~d}$ vs $3 \mathrm{~d}$ metal) polarizable [30]. Using DFT calculations, the electronic properties of $28(\mathrm{Ru}), \mathbf{4 9}(\mathrm{Au})$, and $54(\mathrm{Ni})$ were studied (Table 8). The DFT static $\beta$ values nicely reproduce the relative hyperpolarizability trend and excellent agreement for $\lambda_{\max }$ between theory and experiment is observed. The calculated $\beta$ value is inversely related to the HOMO-LUMO gap. For 28, the HOMO is considerably destabilized, which is consistent with the ease of oxidation of the ruthenium complex. The CT band for the gold complex is significantly blue-shifted and the DFT/TD-DFT calculations showed that the metal contribution to the crucial transition was relatively weak compared to the ruthenium and nickel analogues. In contrast, Silva et al. have shown that for the thiophene-based alkynyl complexes 47 and 57, the quadratic NLO activity of the nickel(II) complex $\left(\beta_{\exp }=331 \times 10^{-30}\right.$ esu, $\left.\beta_{\mathrm{TLM}}=173 \times 10^{-30} \mathrm{esu}\right)$ is greater than that of ruthenium(II) $\left(\beta_{\exp }=192 \times 10^{-30} \mathrm{esu}, \beta_{\mathrm{TLM}}=82 \times 10^{-30} \mathrm{esu}\right)$ alkynyl complexes [84]. On the basis of the TD-DFT calculations, they claim that, for $\mathbf{5 7}$, the large $\beta$ response arises from two closelying MLCT transitions.

(Insert Figure 12) 
Table 8. Comparison of experimental and calculated linear optical and quadratic nonlinear optical data of $\mathbf{2 8 , 4 9}$, and $\mathbf{5 4} .^{\mathrm{a}}$

\begin{tabular}{llllll}
\hline Complex & $\lambda_{\exp }(\mathrm{nm})$ & $\lambda_{\text {calc }}(\mathrm{nm})$ & $\Delta_{\mathrm{H}-\mathrm{L}}(\mathrm{eV})$ & $\beta_{\mathrm{TLM}}\left(10^{-30}\right.$ & $\beta_{\text {tot }}\left(10^{-30}\right.$ \\
& & & & esu $)$ & esu $)$ \\
\hline $\mathbf{2 8}$ & 460 & 436 & 3.22 & 96 & 138 \\
$\mathbf{4 9}$ & 338 & 348 & 4.04 & 12 & 25 \\
$\mathbf{5 4}$ & 439 & 422 & 3.38 & 59 & 101
\end{tabular}

a Reference [250]. Property calculations were performed in the gas phase using the PBE0 functional. The $6-31+\mathrm{G}(\mathrm{d})$ basis set (for the ligands) and Stuttgart/Dresden pseudo-potential and associated SDD basis set (for $\mathrm{Ru} / \mathrm{Au} / \mathrm{Ni}$ ) were used. In the calculations, the phosphine ligands possessed methyl substituents instead of phenyl groups.

\section{Conclusion}

Materials exhibiting large optical nonlinearities are in demand for many technological applications. Organometallic complexes, and in particular metal alkynyl complexes, have been shown to have large molecular responses, and structure-property relationships have been developed. Progress in this field necessitates input from synthesis, measurement, and theory. Sophisticated laser-based instrumentation needed for measurement and high-level computing power needed for calculations are increasingly available to synthetic chemists, so the present review is timely in summarizing key background theory and practical considerations. In that light, the most common experimental and computational methods used 
to determine the molecular first hyperpolarizabilities have been reviewed, with particular attention given to computational studies of linear optical and quadratic nonlinear optical properties of metal alkynyl complexes.

While the field is poised to exploit the synergy available from combined synthesis/experimental/computational studies, a note of caution is needed. A quantitative comparison between data obtained from computational calculations and experimental methods is affected by a number of factors: (1) The experimental first hyperpolarizabilities are often resonance enhanced (and associated with substantial errors: $\beta$ values are often quoted as $\pm 15 \%$ ), whilst the computational data are generally calculated in the static limit. (2) Dispersion-free experimental data can be obtained by applying the simple two-level model but its adequacy for transition metal complexes is uncertain. (3) Conformational flexibility associated with metal alkynyl complexes, particularly for large complexes in laboratory conditions, must be properly taken into account in the calculations. (4) The computational approaches have limitations, for instance, the reliability of ZINDO calculations depends on the parameterization, whereas the exchange-correlation part must be approximated for DFT. The response calculations are sensitive to the electron correlation and basis set chosen. For larger systems, e.g. many organometallic and coordination complexes, correlated methods with extended basis sets may not be realistic. As a result, DFT has been routinely applied for such large chromophores. However, the most appropriate functional must be chosen following a critical comparison. For push-pull organics, recently introduced range-separated exchange-correlation functionals have been found to improve the (hyper)polarizabilities computed by conventional functionals. However, for organometallics, a detailed assessment of the DFT functionals with regard to the calculation of linear optical and nonlinear optical properties is still limited (one which we and others are currently pursuing). (5) Solvent effects have an undeniable impact on the magnitude of the first hyperpolarizability and should be 
properly accounted for in any calculation. (6) Default hyperpolarizability calculations model only the electronic part, but the experimentally-derived $\beta$ values may contain contributions from the vibrational motion whose effect is, however, negligible in SHG. (7) Comparisons are complicated by the lack of consistency between conventions used in theory and experiment to define the $\beta$.

Using theory to obtain both insight into the origin of NLO properties, and identifying effective NLO chromophores from related but less efficient compounds, is more important than achieving accurate calculation of absolute NLO properties. In this respect, DFT seems promising for studying both the NLO processes in metal alkynyl complexes and for predicting trends in first hyperpolarizabilities for related complexes, and more broadly for making a significant contribution now and in the future to the development of NLO materials.

\section{Acknowledgement}

We thank the Australian Research Council (ARC) for financial support and Dr E. Kulasekera for helpful discussions.

\section{References}

[1] R.W. Boyd, Nonlinear Optics, Academic Press, New York, 2003.

[2] Y.R. Shen, The Principles of Nonlinear Optics, Wiley, New York, 1984. 
[3] G.D. Stucky, S.R. Marder, J.E. Sohn, Linear and Nonlinear Polarizability: A Primer, in: S.R. Marder, J.E. Sohn, G.D. Stucky (Eds.), Mater. Nonlinear Opt., ACS, Washington, D.C., 1991: pp. 2-30.

[4] P.N. Prasad, D.J. Williams, Introduction to Nonlinear Optical Effects in Molecules and Polymers, Wiley, New York, 1991.

[5] T.H. Maiman, Nature 187 (1960) 493.

[6] P.A. Franken, A.E. Hill, C.W. Peters, G. Weinreich, Phys. Rev. Lett. 7 (1961) 118.

[7] B.E.A. Saleh, M.C. Teich, Fundamentals of Photonics, Wiley, New York, 1991: pp. $696-736$.

[8] M. Goeppert-Mayer, Ann. Phys. 9 (1931) 273.

[9] W. Kaiser, C. Garrett, Phys. Rev. Lett. 7 (1961) 229.

[10] A.L. Schawlow, C.H. Townes, Phys. Rev. 112 (1958) 1940.

[11] P.E. Powers, J.W. Haus, Fundamentals of Nonlinear Optics, CRC Press, New York, 2017.

[12] J.A. Armstrong, N. Bloembergen, J. Ducuing, P.S. Pershan, Phys. Rev. 127 (1962) 1918.

[13] E. Garmire, Opt. Express 21 (2013) 30532.

[14] P. Günter, Nonlinear Optical Effects and Materials, Springer, New York, 2000. 
[15] P.F. Bordui, M.M. Fejer, Ann. Rev. Mater. Sci. 23 (1993) 321.

[16] G. Grelaud, M.P. Cifuentes, F. Paul, M.G. Humphrey, J. Organomet. Chem. 751 (2014) 181.

[17] D.J. Williams, Nonlinear Optical Properties of Organic and Polymeric Materials, ACS, Washington, D.C., 1983.

[18] D. Bloor, Organic Materials for Non-linear Optics: Yesterday, Today, and Tomorrow, in: R.A. Hann, D. Bloor (Eds.), Organic Materials for Nonlinear Optics II, RSC, Cambridge, UK, 1991: pp. 3-21.

[19] M.G. Humphrey, M.P. Cifuentes, M. Samoc, T. Isoshima, A. Persoons, Perspect. Organomet. Chem. 87 (2003) 100.

[20] P.A. Sullivan, L.R. Dalton, Acc. Chem. Res. 43 (2010) 10.

[21] L.R. Dalton, S.J. Benight, L.E. Johnson, D.B. Knorr, I. Kosilkin, B.E. Eichinger, B. H. Robinson, A.K.Y. Jen, and R.M. Overney, Chem. Mater. 23 (2011) 430.

[22] H.S. Nalwa, Appl. Organomet. Chem. 5 (1991) 349.

[23] B.F. Levine, C.G. Bethea, C.D. Thurmond, R.T. Lynch, J.L. Bernstein, J. Appl. Phys. 50 (1979) 2523.

[24] G.F. Lipscomb, J. Chem. Phys. 75 (1981) 1509.

[25] I.R. Whittall, A.M. McDonagh, M.G. Humphrey, M. Samoc, Adv. Organomet. Chem. 42 (1998) 291. 
[26] S. Di Bella, Chem. Soc. Rev. 30 (2001) 355.

[27] N.J. Long, Angew. Chem. Int. Ed. 34 (1995) 21.

[28] J.C. Calabrese, L.T. Cheng, J.C. Green, S.R. Marder, W. Tam, J. Am. Chem. Soc. 113 (1991) 7227.

[29] S.R. Marder, D.N. Beratan, B.G. Tiemann, L.-T. Cheng, W. Tam, Structure/Property Relationships for Organic and Organometallic Materials with Second-order Optical Non-linearities, in: R.A. Hann, D. Bloor (Eds.), Organic Materials for Nonlinear Optics II, RSC, Cambridge, UK, 1991: pp. 165-175.

[30] M.P. Cifuentes, M.G. Humphrey, J. Organomet. Chem. 689 (2004) 3968.

[31] C.E. Powell, M.G. Humphrey, Coord. Chem. Rev. 248 (2004) 725.

[32] J.P. Morrall, M.G. Humphrey, G.T. Dalton, M.P. Cifuentes, M. Samoc, NLO Properties of Metal Alkynyl and Related Complexes, in: M.G. Papadopoulos, J. Leszczynski, A.J. Sadlej, (Eds), Nonlinear Optical Properties of Matter: From Molecules to Condensed Phases, Springer, Dordrecht, The Netherlands, 2006: pp. 537569.

[33] J.P. Morrall, G.T. Dalton, M.G. Humphrey, M. Samoc, Adv. Organomet. Chem. 55 (2007) 61.

[34] J. Giordmaine, Phys. Rev. 138 (1965) A1599.

[35] C. Bosshard, M. Bösch, I. Liakatas, M. Jäger, P. Günter, Second-Order Nonlinear 
Optical Organic Materials: Recent Developments, in: P. Günter (Ed.), Nonlinear Optical Effects and Materials, Springer, New York, 2000: pp. 163-299.

[36] R.W. Terhune, P.D. Maker, C.M. Savage, Phys. Rev. Lett. 8 (1962) 404.

[37] R.S. Finn, J.F. Ward, Phys. Rev. Lett. 26 (1971) 285.

[38] B.F. Levine, C.G. Bethea, Appl. Phys. Lett. 24 (1974) 445.

[39] B.F. Levine, C.G. Bethea, J. Chem. Phys. 63 (1975) 2666.

[40] D.J. Williams, Second-Order Nonlinear Optical Processes in Molecules and Solids, in: S.R. Marder, J.E. Sohn, G.D. Stucky (Eds.), Materials for Nonlinear Optics: Chemical Perspectives, ACS, Washington, D.C., 1991: pp. 31-49.

[41] B.F. Levine, C.G. Bethea, J. Chem. Phys. 65 (1976) 2439.

[42] D.A. Kleinman, Phys. Rev. 126 (1962) 1977.

[43] A. Dulcic, C. Sauteret, J. Chem. Phys. 69 (1978) 3453.

[44] D.M. Burland, C.A. Walsh, J. Opt. Soc. Am. B 8 (1991) 2269.

[45] K.D. Singer, J. Chem. Phys. 75 (1981) 3572.

[46] P. Kaatz, D.P. Shelton, J. Chem. Phys. 105 (1996) 3918.

[47] C.S. Liu, R. Glaser, P. Sharp, J.F. Kauffman, J. Phys. Chem. A 101 (1997) 7176.

[48] L.T. Cheng, W. Tam, S.R. Marder, A.E. Stiegman, G. Rikken, C.W. Spangler, J. Phys. 
Chem. 95 (1991) 10643.

[49] K. Clays, A. Persoons, Phys. Rev. Lett. 66 (1991) 2980.

[50] K. Clays, A. Persoons, Rev. Sci. Instrum. 63 (1992) 3285.

[51] R.W. Terhune, P.D. Maker, C.M. Savage, Phys. Rev. Lett. 14 (1965) 681.

[52] S. Kielich, J.R. Lalanne, F.B. Martin, Phys. Rev. Lett. 26 (1971) 1295.

[53] S. J. Cyvin, J. E. Rauch, J. C. Decius, J. Chem. Phys. 43 (1965) 4083.

[54] R. Bersohn, Y. Pao, H. L. Frisch, J. Chem. Phys. 45 (1966) 3184.

[55] S. Brasselet, J. Zyss, J. Opt. Soc. Am. B. 15 (1998) 257.

[56] I.R. Whittall, M.G. Humphrey, S. Houbrechts, J. Maes, A. Persoons, S. Schmid, D.C.R. Hockless, J. Organomet. Chem. 544 (1997) 277.

[57] M. Quintiliani, J. Pérez-Moreno, I. Asselberghs, P. Vázquez, K. Clays, T. Torres, J. Phys. Chem. B. 114 (2010) 6309.

[58] J. Zyss, I. Ledoux, Chem. Rev. 94 (1994) 77.

[59] W.M. Laidlaw, R.G. Denning, T. Verbiest, E. Chauchard, A. Persoons, Nature 363 (1993) 58 .

[60] U. Behrens, H. Brussaard, U. Hagenau, J. Heck, E. Hendrickx, J. Körnich, J.G.M. van der Linden, A. Persoons, A.L. Spek, N. Veldman, B. Voss, H. Wong, Chem. Eur. J. 2 
(1996) 98.

[61] C. Dhenaut, I. Ledoux, I.D.W. Samuel, J. Zyss, M. Bourgault, H. Le Bozec, Nature $374(1995) 339$.

[62] B.J. Coe, S.P. Foxon, M. Helliwell, D. Rusanova, B.S. Brunschwig, K. Clays, G. Depotter, M. Nyk, M. Samoc, D. Wawrzynczyk, J. Garin, J. Orduna, Chem. Eur. J. 19 (2013) 6613.

[63] G.J.T. Heesink, A.G.T. Ruiter, N.F. Van Hulst, B. Bölger, Phys. Rev. Lett. 71 (1993) 999.

[64] T. Verbiest, M. Kauranen, A. Persoons, J. Chem. Phys. 101 (1994) 1745.

[65] S.J. Cyvin, J.E. Rauch, J.C. Decius, J. Chem. Phys. 43 (1965) 4083.

[66] R. Bersohn, Y. Pao, H.L. Frisch, J. Chem. Phys. 45 (1966) 3184.

[67] E. Hendrickx, K. Clays, A. Persoons, Acc. Chem. Res. 31 (1998) 675.

[68] M.A. Pauley, H.-W. Guan, C.H. Wang, A.K.-Y. Jen, J. Chem. Phys. 104 (1996) 7821.

[69] S. Stadler, G. Bourhill, C. Bräuchle, J. Phys. Chem. 100 (1996) 6927.

[70] B.J. Orr, J.F. Ward, Mol. Phys. 20 (1971) 513.

[71] J.F. Ward, Rev. Mod. Phys. 37 (1965) 18.

[72] A. Willetts, J.E. Rice, D.M. Burland, D.P. Shelton, J. Chem. Phys. 97 (1992) 7590. 
[73] D.R. Kanis, M.A. Ratner, T.J. Marks, Chem. Rev. 94 (1994) 195.

[74] D.R. Kanis, M.A. Ratner, T.J. Marks, J. Am. Chem. Soc. 114 (1992) 10338.

[75] I.R. Whittall, M.G. Humphrey, D.C.R. Hockless, B.W. Skelton, A.H. White, Organometallics 14 (1995) 3970.

[76] A.M. McDonagh, I.R. Whittall, M.G. Humphrey, D.C.R. Hockless, B.W. Skelton, A.H. White, J. Organomet. Chem. 523 (1996) 33.

[77] A.M. McDonagh, I.R. Whittall, M.G. Humphrey, B.W. Skelton, A.H. White, J. Organomet. Chem. 519 (1996) 229.

[78] I.R. Whittall, M.G. Humphrey, A. Persoons, S. Houbrechts, Organometallics 15 (1996) 1935.

[79] R.H. Naulty, A.M. McDonagh, I.R. Whittall, M.P. Cifuentes, M.G. Humphrey, S. Houbrechts, J. Maes, A. Persoons, G.A. Heath, D.C.R. Hockless, J. Organomet. Chem. $563(1998) 137$.

[80] I.R. Whittall, M.P. Cifuentes, M.G. Humphrey, B. Luther-Davies, M. Samoc, S. Houbrechts, A. Persoons, G.A. Heath, D.C.R. Hockless, J. Organomet. Chem. 549 (1997) 127.

[81] E. Kulasekera, S. Petrie, R. Stranger, M.G. Humphrey, Organometallics 33 (2014) 2434.

[82] B.A. Babgi, A. Al-Hindawi, G.J. Moxey, F.I. Abdul Razak, M.P. Cifuentes, E. 
Kulasekera, R. Stranger, A. Teshome, I. Asselberghs, K. Clays, M.G. Humphrey, J. Organomet. Chem. 730 (2013) 108.

[83] D. Wei, M.S. Kodikara, M. Morshedi, G.J. Moxey, H. Wang, G. Wang, C. Quintana, C. Zhang, R. Stranger, M.P. Cifuentes, M.G. Humphrey, ChemPlusChem 81 (2016) 621.

[84] T.J.L. Silva, P.J. Mendes, A.M. Santos, M.H. Garcia, M.P. Robalo, J.P.P. Ramalho, A.J.P. Carvalho, M. Büchert, C. Wittenberg, J. Heck, Organometallics 33 (2014) 4655.

[85] P.J. Mendes, T.J.L. Silva, A.J.P. Carvalho, J.P.P. Ramalho, J. Mol. Struct. (THEOCHEM) 946 (2010) 33.

[86] P.J. Mendes, A.J.P. Carvalho, J.P.P. Ramalho, J. Mol. Struct. (THEOCHEM) 900 (2009) 110.

[87] J.L. Oudar, J. Chem. Phys. 67 (1977) 446.

[88] J.L. Oudar, D.S. Chemla, J. Chem. Phys. 66 (1977) 2664.

[89] I.R. Whittall, M.G. Humphrey, S. Houbrechts, A. Persoons, D.C.R. Hockless, Organometallics 15 (1996) 5738.

[90] C.E. Powell, M.P. Cifuentes, A.M. McDonagh, S.K. Hurst, N.T. Lucas, C.D. Delfs, R. Stranger, M.G. Humphrey, S. Houbrechts, I. Asselberghs, A. Persoons, D.C.R. Hockless, Inorg, Chim. Acta 352 (2003) 9.

[91] B. Babgi, L. Rigamonti, M.P. Cifuentes, T.C. Corkery, M.D. Randles, T. Schwich, S. 
Petrie, R. Stranger, A. Teshome, I. Asselberghs, K. Clays, M. Samoc, M.G. Humphrey, J. Am. Chem. Soc. 131 (2009) 10293.

[92] C.H. Wang, J. Chem. Phys. 112 (2000) 1917.

[93] J. Campo, W. Wenseleers, E. Goovaerts, M. Szablewski, G.H. Cross, J. Phys. Chem. C. $112(2008) 287$.

[94] A.M. Moran, D.S. Egolf, M. Blanchard-Desce, A.M. Kelley, J. Chem. Phys. 116 (2002) 2542.

[95] M.P. Robalo, A.P.S. Teixeira, M.H. Garcia, M.F. Minas da Piedade, M.T. Duarte, A.R. Dias, J. Campo, W. Wenseleers, E. Goovaerts, Eur. J. Inorg. Chem. 2006 (2006) 2175.

[96] C.R. Moylan, R.J. Twieg, V.Y. Lee, S.A. Swanson, K.M. Betterton, R.D. Miller, J. Am. Chem. Soc. 115 (1993) 12599.

[97] D.H. Bale, B.E. Eichinger, W. Liang, X. Li, L.R. Dalton, B.H. Robinson, P.J. Reid, J. Phys. Chem. B 115 (2011) 3505.

[98] T. Yoshimura, Phys. Rev. B 40 (1989) 6292.

[99] H.D. Cohen, C. Roothaan, J. Chem. Phys. 43 (1965) S34.

[100] H. Kurtz, D. Dudis, Rev. Comput. Chem. 12 (1998) 241.

[101] D.P. Shelton, J.E. Rice, Chem. Rev. 94 (1994) 3. 
[102] I.D.L. Albert, T.J. Marks, M.A. Ratner, Effect of Higher Excited Configurations on the Linear and Nonlinear Optical Properties of Organic Molecules, in: S.P. Karna, A.T. Yeates (Eds.), Nonlinear Optical Materials, ACS, Washington, D.C., 1996: pp. 116132.

[103] R.J. Bartlett, H. Sekino, Can Quantum Chemistry Provide Reliable Molecular Hyperpolarizabilities?, in: S.P. Karna, A.T. Yeates (Eds.), Nonlinear Optical Materials, ACS, Washington, D.C., 1996: pp. 23-57.

[104] M. Jaszunski, Chem. Phys. Lett. 140 (1987) 130.

[105] F. Aiga, K. Sasagane, R. Itoh, Chem. Phys. 167 (1992) 277.

[106] P. Pulay, Mol. Phys. 17 (1969) 197.

[107] J. Gerratt, I.M. Mills, J. Chem. Phys. 49 (1968) 1719.

[108] C.E. Dykstra, P.G. Jasien, Chem. Phys. Lett. 109 (1984) 388.

[109] C.E. Dykstra, J. Chem. Phys. 82 (1985) 4120.

[110] S.J.A. Van Gisbergen, J.G. Snijders, E.J. Baerends, J. Chem. Phys. 109 (1998) 10644.

[111] H. Sekino, R.J. Bartlett, J. Chem. Phys. 85 (1986) 976.

[112] J.E. Rice, R.D. Amos, S.M. Colwell, N.C. Handy, J. Sanz, J. Chem. Phys. 93 (1990) 8828.

[113] S.P. Karna, M. Dupuis, J. Comput. Chem. 12 (1991) 487. 
[114] H. Sekino, R.J. Bartlett, Int. J. Quantum Chem. 43 (1992) 119.

[115] J.E. Rice, N.C. Handy, J. Chem. Phys. 94 (1991) 4959.

[116] J.E. Rice, N.C. Handy, Int. J. Quantum Chem. 43 (1992) 91.

[117] K. Sasagane, F. Aiga, R. Itoh, J. Chem. Phys. 99 (1993) 3738.

[118] C. Beno1t, B. Kirtman, Chem. Phys. 245 (1999) 213.

[119] A. Saal, O. Ouamerali, J. Comput. Methods Sci. Eng. 4 (2004) 333.

[120] W. Bartkowiak, T. Misiaszek, Chem. Phys. 261 (2000) 353.

[121] M. Garcia-Borràs, M. Solà, J.M. Luis, B. Kirtman, J. Chem. Theory Comput. 8 (2012) 2688.

[122] G.J.M. Velders, D. Feil, J. Phys. Chem. 96 (1992) 10725.

[123] G.D. Purvis, R.J. Bartlett, Phys. Rev. A. 23 (1981) 1594.

[124] R.J. Bartlett, G.D. Purvis, Phys. Rev. A. 20 (1979) 1313.

[125] G. Maroulis, A.J. Thakkar, J. Chem. Phys. 93 (1990) 4164.

[126] E. Perrin, P.N. Prasad, P. Mougenot, M. Dupuis, J. Chem. Phys. 91 (1989) 4728.

[127] H. Sekino, R.J. Bartlett, J. Chem. Phys. 94 (1991) 3665.

[128] H. Sekino, R.J. Bartlett, J. Chem. Phys. 98 (1993) 3022. 
[129] K. Ohta, T. Sakaguchi, K. Kamada, T. Fukumi, Chem. Phys. Lett. 274 (1997) 306.

[130] K. V. Mikkelsen, Y. Luo, H. Ågren, P. Jorgensen, J. Chem. Phys. 100 (1994) 8240.

[131] B. Champagne, E.A. Perpète, S.J.A. Van Gisbergen, E.J. Baerends, J.G. Snijders, C. Soubra-Ghaoui, K.A. Robins, J. Chem. Phys. 109 (1998) 10489.

[132] H.C.B. De Oliveira, T.L. Fonseca, M.A. Castro, O.A.V. Amaral, S. Cunha, J. Chem. Phys. 119 (2003) 8417.

[133] D. Jacquemin, B. Champagne, J.-M. André, Int. J. Quantum Chem. 65 (1997) 679.

[134] D. Jacquemin, B. Champagne, J.-M. André, J. Mol. Struct. (THEOCHEM) 425 (1998) $69-79$.

[135] D. Jacquemin, E.A. Perpète, J. André, Int. J. Quantum Chem. 105 (2005) 553.

[136] M. Stähelin, C.R. Moylan, D.M. Burland, A. Willetts, J.E. Rice, D.P. Shelton, E.A. Donley, J. Chem. Phys. 98 (1993) 5595.

[137] G. Maroulis, C. Makris, U. Hohm, U. Wachsmuth, J. Phys. Chem. A 103 (1999) 4359.

[138] R. McWeeny, Int. J. Quantum Chem. 23 (1983) 405.

[139] B. Fernández, S. Coriani, A. Rizzo, Chem. Phys. Lett. 288 (1998) 677.

[140] H.J.A. Jensen, P. Jørgensen, H. Hettema, J. Olsen, Chem. Phys. Lett. 187 (1991) 387.

[141] M.J. Packer, E.K. Dalskov, S.P.A. Sauer, J. Oddershede, Theor. Chim. Acta. 89 (1994) 
323.

[142] E.K. Dalskov, S.P.A. Sauer, J. Phys. Chem. A. 102 (1998) 5269.

[143] H. Larsen, J. Olsen, C. Hattig, P. Jørgensen, O. Christiansen, J. Gauss, J. Chem. Phys. $111(1999) 1917$.

[144] H. Larsen, C. Hättig, J. Olsen, P. Jørgensen, Chem. Phys. Lett. 291 (1998) 536.

[145] H. Sekino, R.J. Bartlett, Chem. Phys. Lett. 234 (1995) 87.

[146] J.F. Stanton, R.J. Bartlett, J. Chem. Phys. 99 (1993) 5178.

[147] F. Sim, S. Chin, M. Dupuis, J. Rice, J. Phys. Chem. 97 (1993) 1158.

[148] D. Davis, K. Sreekumar, Y. Sajeev, S. Pal, J. Phys. Chem. B. 109 (2005) 14093.

[149] M. de Wergifosse, B. Champagne, J. Chem. Phys. 134 (2011) 74113.

[150] H.A. Kurtz, J.J.P. Stewart, K.M. Dieter, J. Comput. Chem. 11 (1990) 82-87.

[151] D. Avci, Spectrochim. Acta A: Mol. Biomol. Spectrosc. 82 (2011) 37.

[152] D. Avci, Spectrochim. Acta: A Mol. Biomol. Spectrosc. 77 (2010) 665.

[153] A.B. Zakharov, V. V Ivanov, L. Adamowicz, Optical Parameters of $\pi$-Conjugated Oligomer Chains from the Semiemperical Local Coupled-Cluster Theory, in: J. Leszczynski, M.K. Shukla (Eds.), Practical Aspects of Computational Chemistry IV, Springer, New York, 2016: pp. 57-102. 
[154] T.A. Klimenko, V. V. Ivanov, L. Adamowicz, Mol. Phys. 107 (2009) 1729.

[155] A.B. Zakharov, V. V. Ivanov, J. Struct. Chem. 52 (2011) 645.

[156] A.B. Zakharov, V. V. Ivanov, L. Adamowicz, J. Phys. Chem. C. 118 (2014) 8111.

[157] P. Hohenberg, W. Khon, Phys. Rev. 136 (1964) B864.

[158] W. Kohn, L.J. Sham, Phys. Rev. 140 (1965) A1133.

[159] W. Koch, M.C. Holthausen, A Chemist's Guide to Density Functional Thoery, Wiley, New York, 2001.

[160] C.J. Cramer, Essentials of Computational Chemistry Theories and Models, Wiley, Chichester, U.K., 2004.

[161] M.A.L. Marques, E.K.U. Gross, Annu. Rev. Phys. Chem. 2004, 55, 427-455.

[162] M.E. Casida, in Recent Advances in Density-Functional Methods, Part I (Ed.: D.P. Chong), World Scientific, Singapore, 1995, pp. 155-19.

[163] E. Runge, E.K.U. Gross, Phys. Rev. Lett. 52 (1984) 997.

[164] A. Dreuw, M. Head-Gordon, J. Am. Chem. Soc. 126 (2004) 4007.

[165] R.G. Parr, W. Yang, Density-Functional Theory of Atoms and Molecules, Oxford University Press, Oxford, 1989.

[166] T. Yanai, D.P. Tew, N.C. Handy, Chem. Phys. Lett. 393 (2004) 51. 
[167] M.E. Casida, C. Jamorski, K.C. Casida, D.R. Salahub, J. Chem. Phys. 108 (1998) 4439.

[168] D.J. Tozer, N.C. Handy, J. Chem. Phys. 109 (1998) 10180.

[169] A. Dreuw, J.L. Weisman, M. Head-Gordon, J. Chem. Phys. 119 (2003) 2943.

[170] D.J. Tozer, R.D. Amos, N.C. Handy, B.O. Roos, L. Serrano-Andrés, Mol. Phys. 97 (1999) 859.

[171] L. Bernasconi, M. Sprik, J. Hutter, J. Chem. Phys. 119 (2003) 12417.

[172] P.R.T. Schipper, O.V. Gritsenko, S.J.A. van Gisbergen, E.J. Baerends, J. Chem. Phys. $112(2000) 1344$.

[173] R. Van Leeuwen, E.J. Baerends, Phys. Rev. A. 49 (1994) 2421.

[174] H. Iikura, T. Tsuneda, T. Yanai, K. Hirao, J. Chem. Phys. 115 (2001) 3540.

[175] Y. Tawada, T. Tsuneda, S. Yanagisawa, T. Yanai, K. Hirao, J. Chem. Phys. 120 (2004) 8425 .

[176] H. Sekino, Y. Maeda, M. Kamiya, Mol. Phys. 103 (2005) 2183.

[177] D. Jacquemin, E.A. Perpète, M. Medved, G. Scalmani, M.J. Frisch, R. Kobayashi, C. Adamo, J. Chem. Phys. 126 (2007) 191108.

[178] M. Kamiya, H. Sekino, T. Tsuneda, K. Hirao, J. Chem. Phys. 122 (2005) 234111. 
[179] J.D. Chai, M. Head-Gordon, J. Chem. Phys. 128 (2008) 844106.

[180] O.A. Vydrov, G.E. Scuseria, J. Chem. Phys. 125 (2006) 234109.

[181] O.A. Vydrov, J. Heyd, A.V. Krukau, G.E. Scuseria, J. Chem. Phys. 125 (2006) 74106.

[182] B. Champagne, E.A. Perpète, D. Jacquemin, S.J.A. van Gisbergen, E.-J. Baerends, C. Soubra-Ghaoui, K.A. Robins, B. Kirtman, J. Phys. Chem. A. 104 (2000) 4755.

[183] L.E. Johnson, L.R. Dalton, B.H. Robinson, Acc. Chem. Res. 47 (2014) 3258.

[184] F. Castet, B. Champagne, J. Chem. Theory Comput. 8 (2012) 2044.

[185] M.S. Kodikara, R. Stranger, M.G. Humphrey, ChemPhysChem, in press, cphc. 201701052 .

[186] S.M. Colwell, C.W. Murray, N.C. Handy, R.D. Amos, Chem. Phys. Lett. 210 (1993) 261.

[187] S.M. Colwell, N.C. Handy, Chem. Phys. Lett. 217 (1994) 271.

[188] S. Muhammad, H. Xu, Z. Su, K. Fukuda, R. Kishi, Y. Shigeta, M. Nakano, Dalton Trans. 42 (2013) 15053.

[189] B.J. Coe, S.P. Foxon, E.C. Harper, M. Helliwell, J. Raftery, C.A. Swanson, B.S. Brunschwig, K. Clays, E. Franz. J. Garin, J. Orduna, P.N. Horton, M.B. Hursthouse, J. Am. Chem. Soc. 132 (2010) 1706.

[190] N.N. Ma, G.C. Yang, S.L. Sun, C.G. Liu, Y.Q. Qiu, J. Organomet. Chem. 696 (2011) 2380. 
[191] H.-B. Zhao, S.-L. Sun, Y.-Q. Qiu, C.-G. Liu, Z.-M. Su, Int. J. Quantum Chem. 110 (2010) 1863.

[192] C. Tu, G. Yu, G. Yang, X. Zhao, W. Chen, S. Li, X. Huang, Phys. Chem. Chem. Phys. $16(2014) 1597$.

[193] I.C. de Silva, R.M. de Silva, K.M. Nalin de Silva, J. Mol. Struct. (THEOCHEM) 728 (2005) 141

[194] N. Ma, C. Liu, Y. Qiu, S. Sun, Z. Su, J. Comput. Chem. 33 (2012) 211.

[195] B.J. Coe, L.A. Jones, J.A. Harris, B.S. Brunschwig, I. Asselberghs, K. Clays, A. Persoons, J. Garin, J. Orduna, J. Am. Chem. Soc. 126 (2004) 3880.

[196] X. Chen, K. Wu, J.G. Snijders, C. Lin, Inorg. Chem. 42 (2003) 532.

[197] D.M. Tian, N.N. Ma, W.Y. Wang, J. Wang, C.L. Zhu, Y.Q. Qiu, J. Organomet. Chem. $772(2014) 100$.

[198] M.R.S.A. Janjua, M. Amin, M. Ali, B. Bashir, M.U. Khan, M.A. Iqbal, W. Guan, L. Yan, Z.-M. Su, Eur. J. Inorg. Chem. (2012) 705.

[199] C. Liu, X.-H. Guan, Z.-M. Su, J. Phys. Chem. C 115 (2011) 6024.

[200] C.H. Wang, N.N. Ma, X.X. Sun, S.L. Sun, Y.Q. Qiu, P.J. Liu, J. Phys. Chem. A. 116 (2012) 10496.

[201] M. Medved, Š. Budzák, T. Pluta, Chem. Phys. Lett. 515 (2011) 78. 
[202] C. Yao, L.K. Yan, W. Guan, C.G. Liu, P. Song, Z.M. Su, J. Cluster Sci. 21 (2010) 69.

[203] Q. Li, K. Wu, R. Sa, Y. Wei, Chem. Phys. Lett. 471 (2009) 229.

[204] N. Ma, L. Yan, W. Guan, Y. Qiu, Z. Su, Phys. Chem. Chem. Phys. 14 (2012) 5605.

[205] D. Jacquemin, J. André, E.A. Perpète, J. Chem. Phys. 121 (2004) 4389.

[206] S.J.A. van Gisbergen, J.G. Snijders, E.J. Baerends, J. Chem. Phys. 103 (1995) 9347.

[207] S.J.A. van Gisbergen, J.G. Snijders, E.J. Baerends, Phys. Rev. Lett. 78 (1997) 3097.

[208] S.J.A. van Gisbergen, J.G. Snijders, E.J. Baerends, Comput. Phys. Commun. 118 (1999) 119.

[209] S. Tretiak, V. Chernyak, J. Chem. Phys. 119 (2003) 8809.

[210] X. Andrade, S. Botti, M.A.L. Marques, A. Rubio, J. Chem. Phys. 126 (2007) 184106.

[211] P. Romaniello, M.C. D'Andria, F. Lelj, J. Phys. Chem. A. 114 (2010) 5838.

[212] Q. Li, R. Sa, C. Liu, K. Wu, J. Phys. Chem. A. 111 (2007) 7925.

[213] K. Wu, R. Sa, C. Lin, New J. Chem. 29 (2005) 362.

[214] K. Garrett, X.S. Vazquez, S.B. Egri, J. Wilmer, L.E. Johnson, B.H. Robinson, C.M. Isborn, J. Chem. Theory Comput. 10 (2014) 3821.

[215] S. Sen, P. Seal, S. Chakrabarti, J. Cluster Sci. 21 (2010) 591. 
[216] J.M. André, J. Delhalle, Chem. Rev. 91 (1991) 843.

[217] S. Liu, C.E. Dykstra, J. Phys. Chem. 91 (1987) 1749.

[218] G.J.B. Hurst, M. Dupuis, E. Clementi, J. Chem. Phys. 89 (1988) 385.

[219] D. Jacquemin, B. Champagne, C. Hättig, Chem. Phys. Lett. 319 (2000) 327.

[220] T.H. Dunning, J. Chem. Phys. 90 (1989) 1007.

[221] E. Kulasekera, DFT/TD-DFT, Optical and Electrochemical Studies of Transition Metal Alkynyl Complexes for Nonlinear Optics, Ph.D. Thesis, Australian National University, Australia, 2014.

[222] G. te Velde, F.M. Bickelhaupt, E.J. Baerends, C. Fonseca Guerra, S.J.A. van Gisbergen, J.G. Snijders, T. Ziegler, J. Comput. Chem. 22 (2001) 931.

[223] E.J. Baerends, T. Ziegler, A.J. Atkins, J. Autschbach, O. Baseggio, D. Bashford, A. Bérces, F.M. Bickelhaupt, C. Bo, P.M. Boerrigter, L. Cavallo, C. Daul, D.P. Chong, D.V. Chulhai, L. Deng, R.M. Dickson, J.M. Dieterich, D.E. Ellis, M. van Faassen, L. Fan, T.H. Fischer, C. Fonseca Guerra, M. Franchini, A. Ghysels, A. Giammona, S.J.A. van Gisbergen, A. Goez, A.W. Götz, J.A. Groeneveld, O.V. Gritsenko, M. Grüning, S. Gusarov, F.E. Harris, P. van den Hoek, Z. Hu, C.R. Jacob, H. Jacobsen, L. Jensen, L. Joubert, J.W. Kaminski, G. van Kessel, C. König, F. Kootstra, A. Kovalenko, M.V. Krykunov, E. van Lenthe, D.A. McCormack, A. Michalak, M. Mitoraj, S.M. Morton, J. Neugebauer, V.P. Nicu, L. Noodleman, V.P. Osinga, S. Patchkovskii, M. Pavanello, C.A. Peeples, P.H.T. Philipsen, D. Post, C.C. Pye, H. Ramanantoanina, P. Ramos, W. Ravenek, J.I. Rodríguez, P. Ros, R. Rüger, P.R.T. Schipper, D. Schlüns, H. van Schoot, 
G. Schreckenbach, J.S. Seldenthuis, M. Seth, J.G. Snijders, M. Solà, M. Stener, M. Swart, D. Swerhone, V. Tognetti, G. te Velde, P. Vernooijs, L. Versluis, L. Visscher, O. Visser, F. Wang, T.A. Wesolowski, E.M. van Wezenbeek, G. Wiesenekker, S.K. Wolff, T.K. Woo, A.L. Yakovlev, ADF2017, SCM, Theoretical Chemistry, Vrije Universiteit, Amsterdam, The Netherlands, http://www.scm.com.

[224] D.R. Kanis, M.A. Ratner, T.J. Marks, J. Am. Chem. Soc. 112 (1990) 8203.

[225] D.R. Kanis, M.A. Ratner, T.J. Marks, J. Am. Chem. Soc. 114 (1992) 10338.

[226] H. Sahnoune, N. Gauthier, K.A. Green, K. Costuas, F. Paul, J.-F. Halet, Aust. J. Chem. $68(2015) 1352$.

[227] G.T. Dalton, M.P. Cifuentes, L.A. Watson, S. Petrie, R. Stranger, M. Samoc, M.G. Humphrey, Inorg. Chem. 48 (2009) 6534.

[228] L. Rigamonti, B. Babgi, M.P. Cifuentes, R.L. Roberts, S. Petrie, R. Stranger, S. Righetto, A. Teshome, I. Asselberghs, K. Clays, M.G. Humphrey, Inorg. Chem. 48 (2009) 3562.

[229] J.E. McGrady, T. Lovell, R. Stranger, M.G. Humphrey, Organometallics 16 (1997) 4004.

[230] C.D. Delfs, R. Stranger, M.G. Humphrey, A.M. McDonagh, J. Organomet. Chem. 607 (2000) 208.

[231] M.G. Humphrey, A.M. McDonagh, S. Houbrechts, I. Asselberghs, A. Persoons, T. Wada, H. Sasabe, M. Samoc, B. Luther-Davies, in: H. Sasabe (Ed.), Hyper-Structured 
Molecules III, Gordon and Breach, Reading, UK, 2002: pp. 90-99.

[232] K. Costuas, F. Paul, L. Toupet, J.-F. Halet, C. Lapinte, Organometallics. 23 (2004) 2053.

[233] F. Paul, L. Toupet, J.Y. Thépot, K. Costuas, J.-F. Halet, C. Lapinte, Organometallics $24(2005) 5464$.

[234] F. Paul, B.G. Ellis, M.I. Bruce, L. Toupet, T. Roisnel, K. Costuas, J.-F. Halet, C. Lapinte, Organometallics 25 (2006) 649.

[235] M.H. Garcia, M.P. Robalo, A.R. Dias, M.T. Duarte, W. Wenseleers, G. Aerts, E. Goovaerts, M.P. Cifuentes, S. Hurst, M.G. Humphrey, M. Samoc, B. Luther-Davies, Organometallics 21 (2002) 2107.

[236] F. Paul, K. Costuas, I. Ledoux, S. Deveau, J. Zyss, J.-F. Halet, C. Lapinte, Organometallics 21 (2002) 5229.

[237] A.M. McDonagh, M.P. Cifuentes, M.G. Humphrey, S. Houbrechts, J. Maes, A. Persoons, M. Samoc, B. Luther-Davies, J. Organomet. Chem. 610 (2000) 71.

[238] S.K. Hurst, M.P. Cifuentes, J.P.L. Morrall, N.T. Lucas, I.R. Whittall, M.G. Humphrey, I. Asselberghs, A. Persoons, M. Samoc, B. Luther-Davies, A.C. Willis, Organometallics 20 (2001) 4664.

[239] A.M. McDonagh, N.T. Lucas, M.P. Cifuentes, M.G. Humphrey, S. Houbrechts, A. Persoons, J. Organomet. Chem. 605 (2000) 193. 
[240] I.R. Whittall, M.G. Humphrey, S. Houbrechts, A. Persoons, D.C.R. Hockless, Organometallics 15 (1996) 5738.

[241] S.K. Hurst, M.P. Cifuentes, A.M. McDonagh, M.G. Humphrey, M. Samoc, B. LutherDavies, I. Asselberghs, A. Persoons, J. Organomet. Chem. 642 (2002) 259.

[242] I.R. Whittall, M.P. Cifuentes, M.G. Humphrey, B. Luther-Davies, M. Samoc, S. Houbrechts, A. Persoons, G.A. Heath, D. Bogsányi, Organometallics 16 (1997) 2631.

[243] S. Di Bella, C. Dragonetti, M. Pizzotti, D. Roberto, F. Tessore, R. Ugo, Coordination and Organometallic Complexes as Second-Order Nonlinear Optical Molecular Materials, in: H. Le Bozec, V. Guerchais (Eds.), Molecular Organometallic Materials for Optics, Springer, New York, 2010: pp. 1-55.

[244] E. Kulasekera, S. Petrie, R. Stranger, M.P. Cifuentes, M.G. Humphrey, J. Organomet. Chem. 748 (2013) 21.

[245] M. Parthey, J.B.G. Gluyas, M.A. Fox, P.J. Low, M. Kaupp, Chem. Eur. J. 20 (2014) 6895.

[246] M. Parthey, J.B.G. Gluyas, P.A. Schauer, D.S. Yufit, J.A.K. Howard, M. Kaupp, P.J. Low, Chem. Eur. J. 19 (2013) 9780.

[247] S. Marqués-González, M. Parthey, D.S. Yufit, J.A.K. Howard, M. Kaupp, P.J. Low, Organometallics 33 (2014) 4947.

[248] S. Houbrechts, K. Clays, A. Persoons, I.R. Whittall, M.G. Humphrey, Proc. SPIE-Int. Soc. Opt. Eng. 2852 (1996) 97. 
[249] H. Zhang, M. Morshedi, M.S. Kodikara, G.J. Moxey, G. Wang, H. Wang, C. Quintana, R. Stranger, C. Zhang, M.P. Cifuentes, M.G. Humphrey, ChemPlusChem 81 (2016) 613.

[250] J. Du, M.S. Kodikara, G.J. Moxey, M. Morshedi, A. Barlow, C. Quintana, G. Wang, R. Stranger, C. Zhang, M.P. Cifuentes, M.G. Humphrey, Dalton Trans., in press, DTART-01-2018-000155. 


\section{Figure captions}

Figure 1. Metallocenyl complex $(\mathrm{M}=$ metal (commonly Fe)).

Figure 2. Dipolar metal alkynyl complex $\left(\mathrm{L}_{\mathrm{n}} \mathrm{M}=\right.$ ligated metal $)$.

Figure 3. Second-harmonic generation ( $\mathrm{SHG}$, top), sum frequency generation (SFG, middle), and difference frequency generation (DFG, bottom).

Figure 4. Phase mismatch for SHG. $\mathrm{k}_{1}$ and $\mathrm{k}_{2}$ are the angular wavenumbers of the fundamental and second-harmonic waves. If phase matching is satisfied $(\Delta \mathrm{k}=0)$, momentum is also conserved $\left(\mathrm{k}_{2}=2 \mathrm{k}_{1}\right)$

Figure 5. Third-harmonic generation (THG).

Figure 6. Laboratory coordinate system in the HRS experiment; in this particular case, the wavelength of the incident laser beam is $1064 \mathrm{~nm}$.

Figure 7. Effect of varying $\mu_{\mathrm{eg}}$ and $\Delta \mu$ on $\beta$ (Reprinted with permission from T. Yoshimura, Phys. Rev. B, 1989, 40, 6293. Copyright 1989 by the American Physical Society.)

Figure 8. Static first hyperpolarizabilities $\left(\beta_{0}, 10^{-30}\right.$ esu $)$ of $\mathrm{Ru}\left(\mathrm{C} \equiv \mathrm{C}-4-\mathrm{C}_{6} \mathrm{H}_{4}-1-\mathrm{NO}_{2}\right)\left(\kappa^{2}-\right.$ dppe $)\left(\eta^{5}-\mathrm{C}_{5} \mathrm{H}_{5}\right)$ and trans $-\left[\mathrm{Ru}\left(\mathrm{C} \equiv \mathrm{C}-4-\mathrm{C}_{6} \mathrm{H}_{4}-1-\mathrm{NO}_{2}\right) \mathrm{Cl}\left(\kappa^{2}-\mathrm{dppm}\right)_{2}\right]$ as a function of basis set. Adapted from M.S. Kodikara, R. Stranger, M.G. Humphrey, ChemPhysChem, in press, cphc.201701052. Copyright Wiley-VCH Verlag \& Co. KGaA. Reproduced with permission.

Figure 9. Complexes 21a-c, 22a-c, 23a-d, and 25a-b. 
Figure 10. Variation of static $\beta_{\text {tot }}\left(10^{-27} \mathrm{esu}\right)$ as a function of $\mathrm{n}$. The calculations were carried out at the SAOP/TZP level of theory in the gas phase. Adapted with permission from E. Kulasekera, DFT/TD-DFT, Optical and Electrochemical Studies of Transition Metal Alkynyl Complexes for Nonlinear Optics, PhD Thesis, Australian National University, Australia, 2014.

Figure 11. Complexes 42 and 43. $[\mathrm{Ru}]=$ trans $-\mathrm{Ru}(\mathrm{dppe})_{2}$.

Figure 12. Complexes 28, 47, 49, 54, 57. 
(a)

\section{IHD-J}

WR

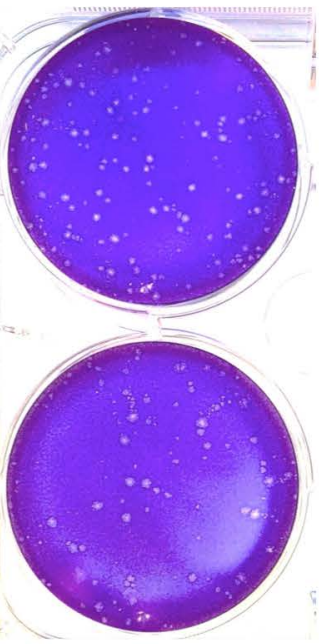

virus+ heparin (b)

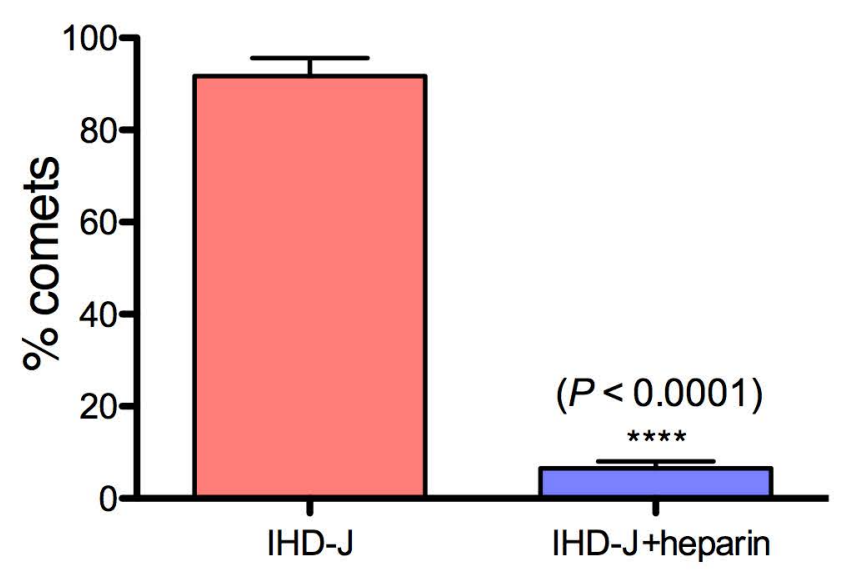

(d)

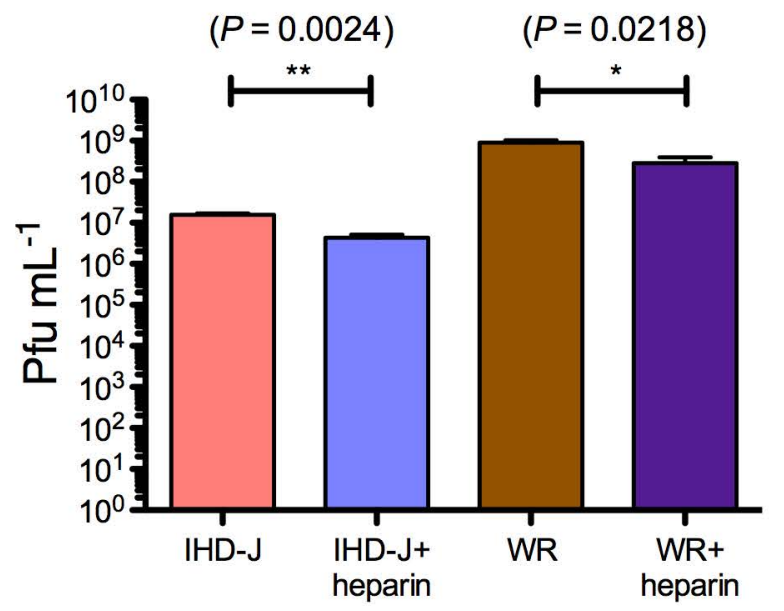


(a)
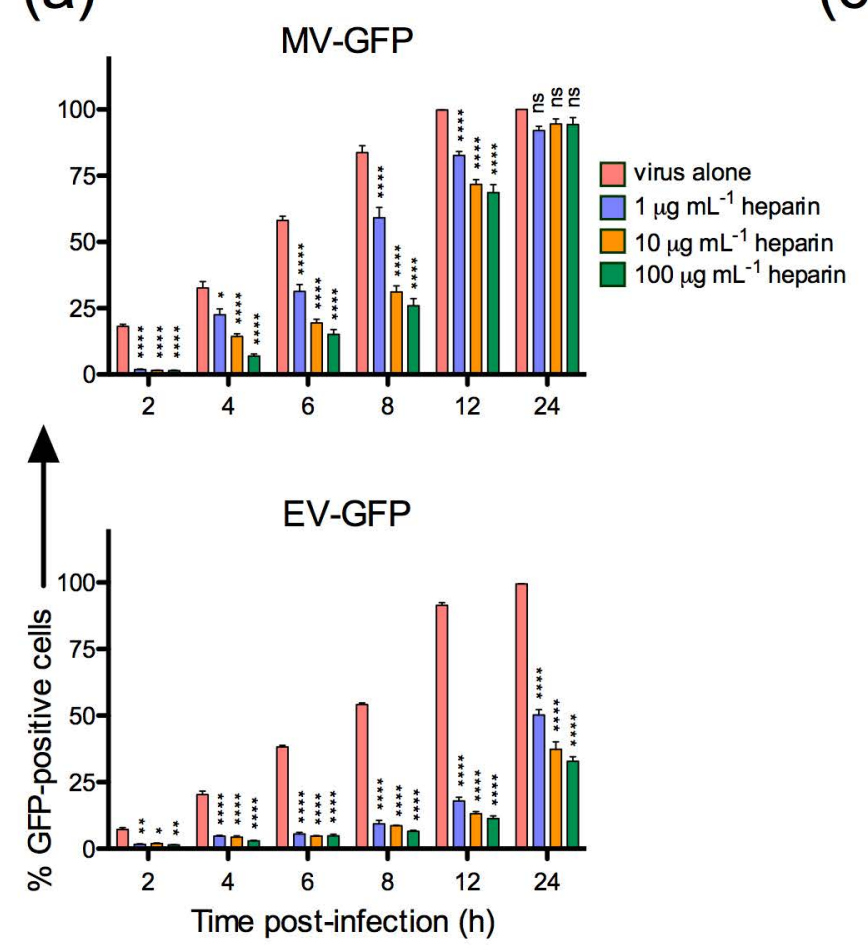

(b)

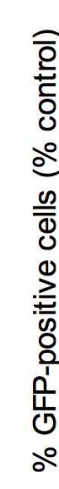

흥

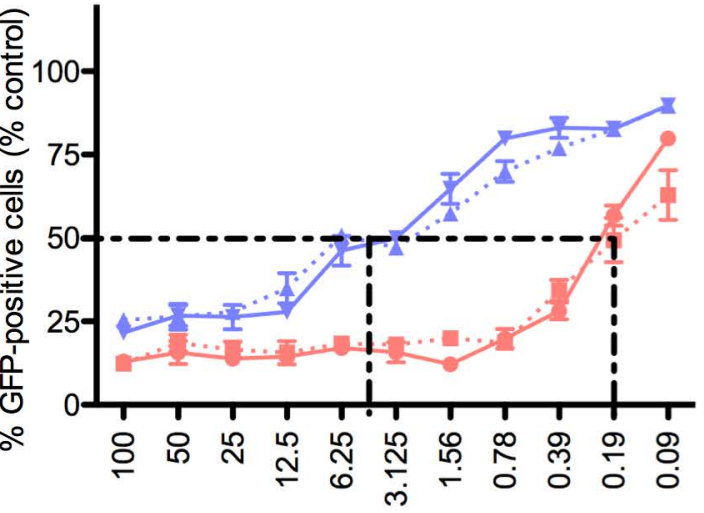

Heparin concentration $\left(\mu \mathrm{g} \mathrm{mL}^{-1}\right)$ (c)
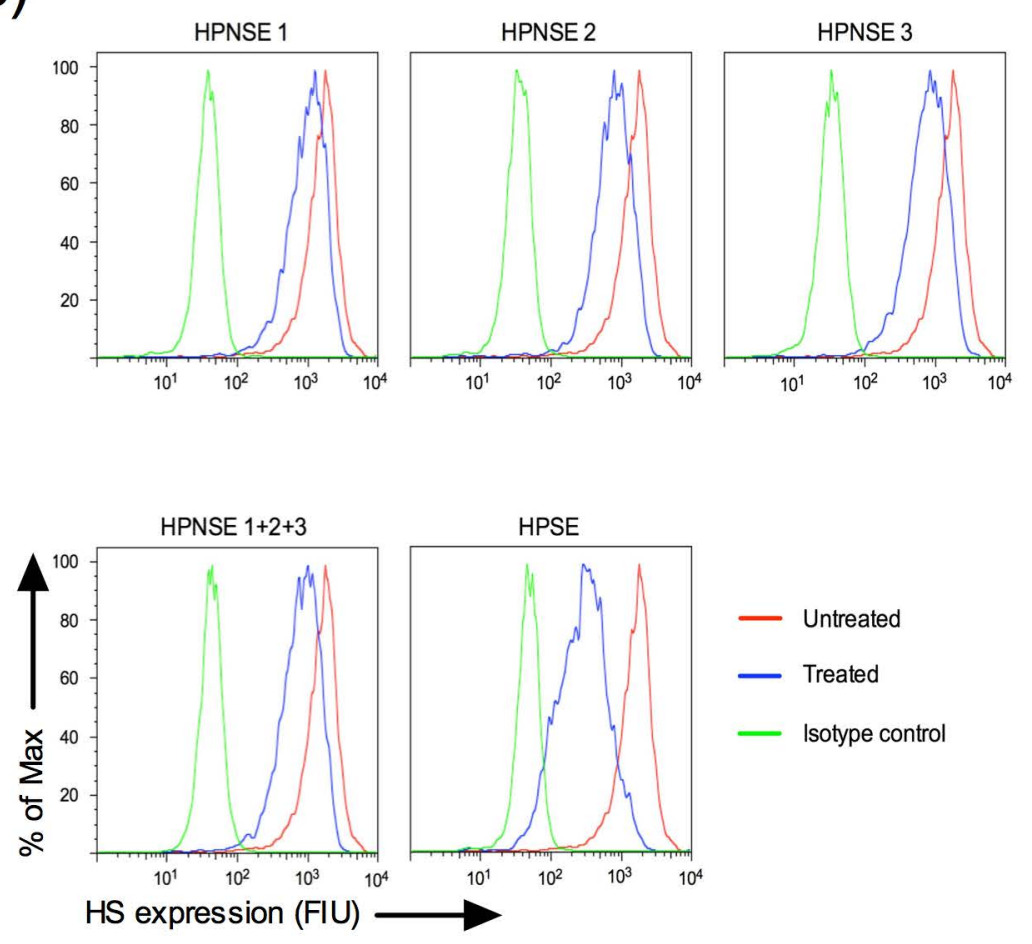

- Untreated

- Treated

— Isotype control (e)
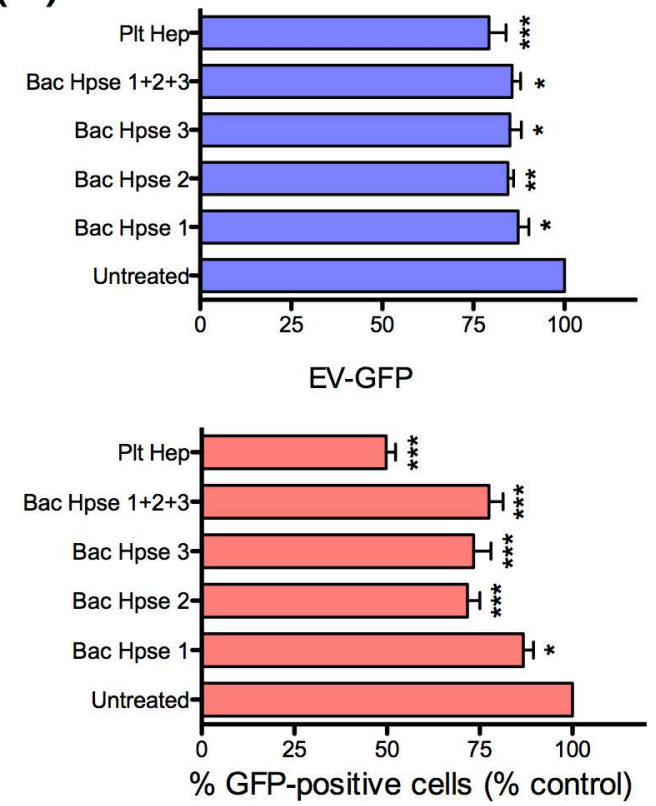

(d)

$\because$ MV-WR

--A- MV-IHD-J

$\rightarrow$ EV-IHD-J

- EV-WR

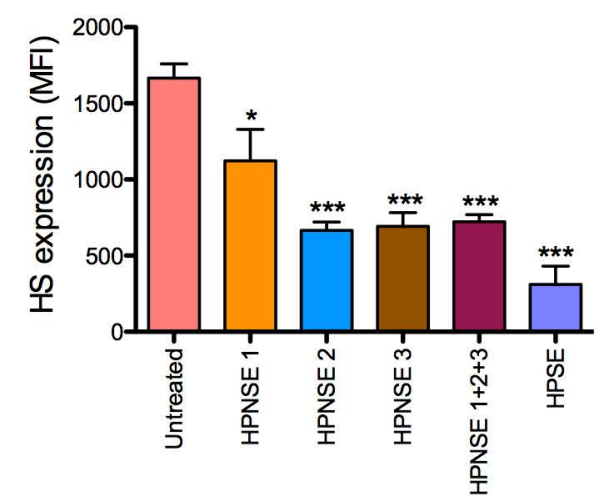

MV-GFP (f)

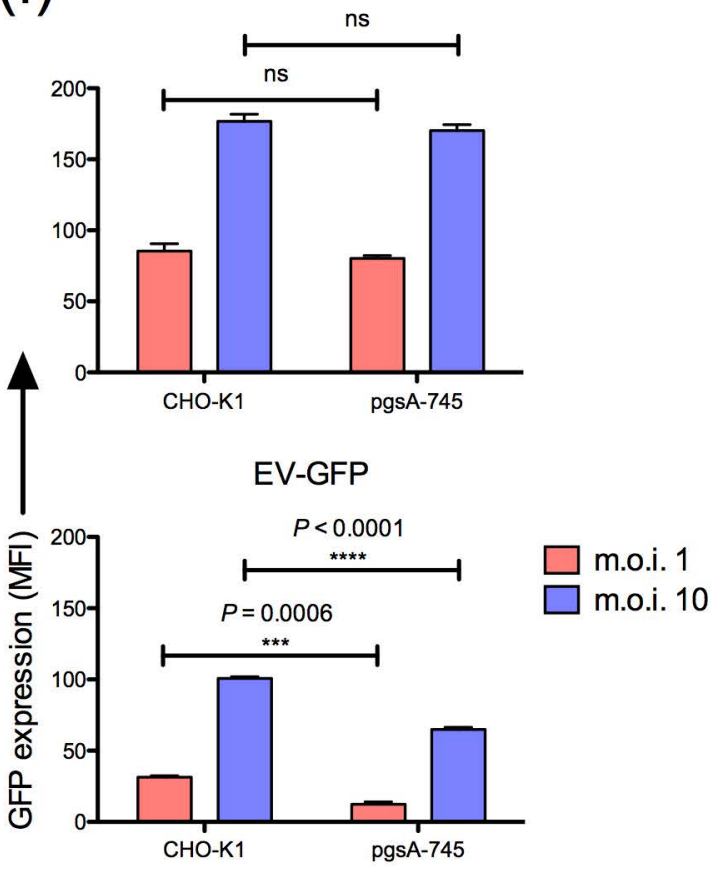


(a)

MV-GFP

$\mathrm{HS}^{\text {hi }}$ and $H \mathrm{~S}^{\text {low }}$

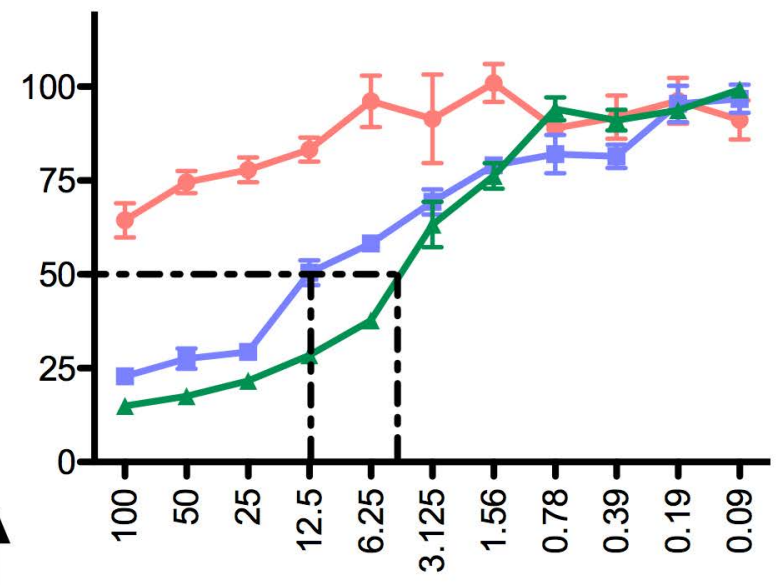

$\rightarrow$ MV-HS low

$-\mathrm{MV}_{-} \mathrm{SS}^{\mathrm{hi}}$

- MV-heparin

(b)

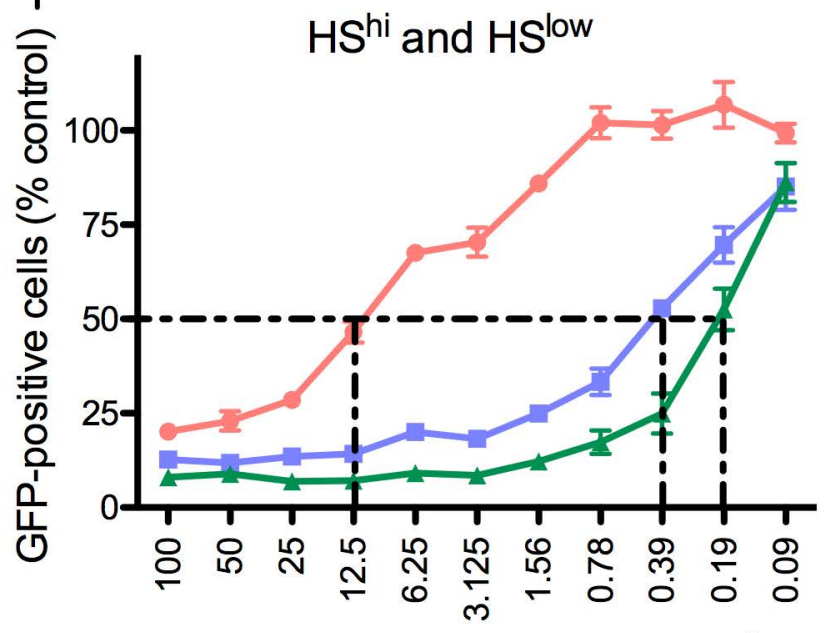

EV-GFP

$\mathrm{HS}^{\text {hi }}$ and $\mathrm{HS}^{\text {low }}$

Inhibitor concentration ( $\mu \mathrm{g} \mathrm{mL}^{-1}$ ) 
(a)

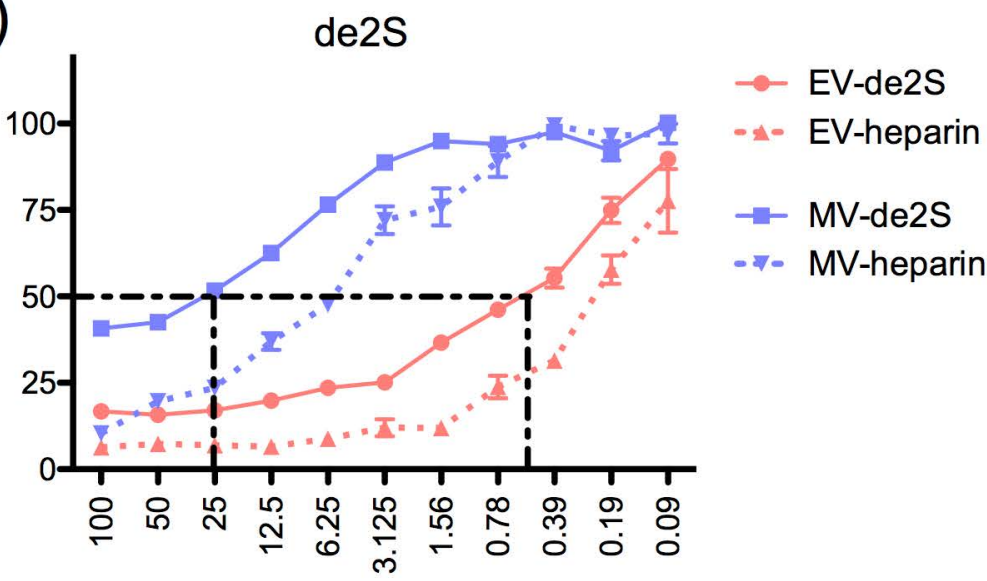

(b)

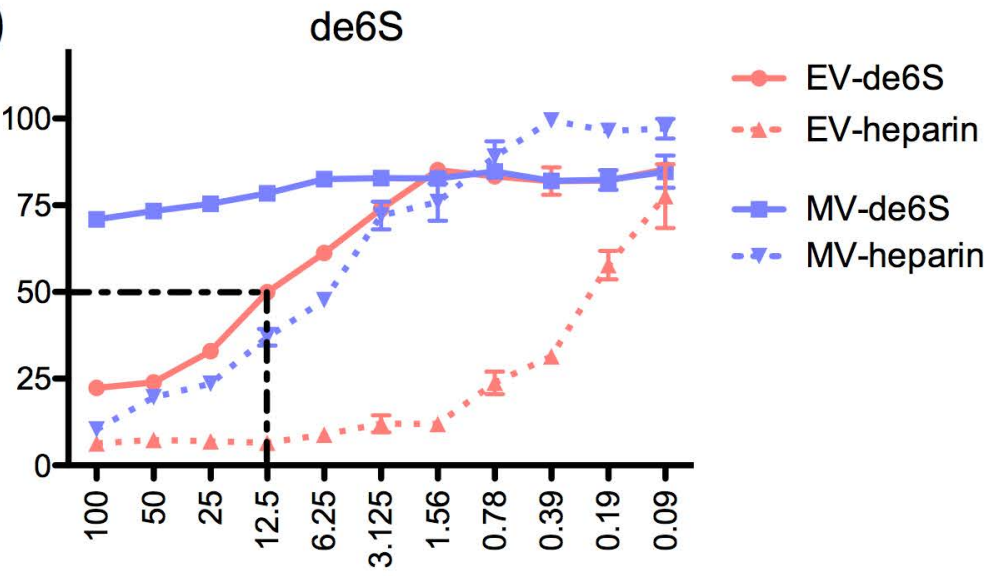

(c)

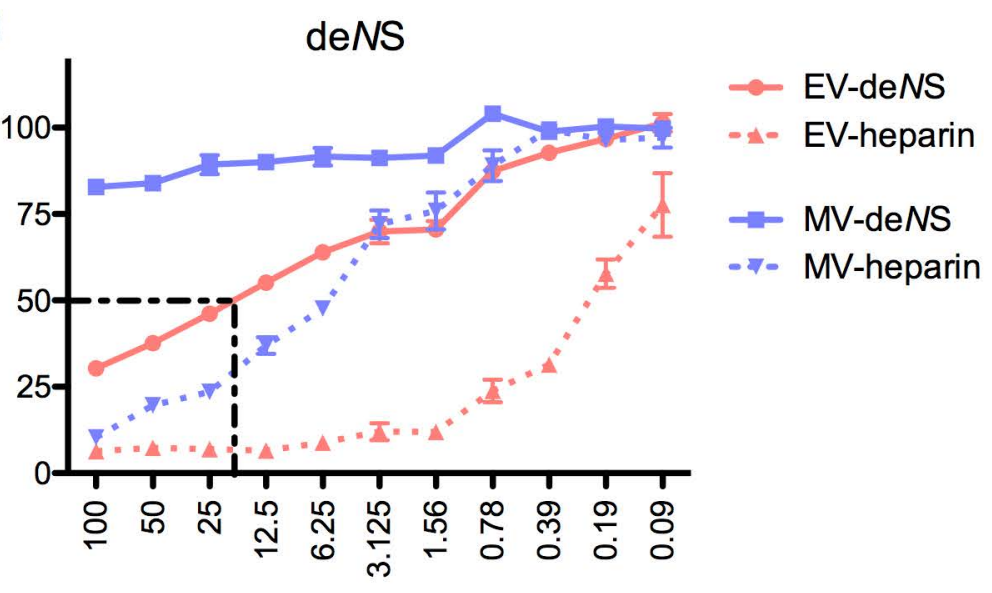

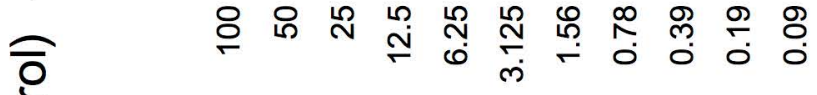

¿ (d)

$\frac{\partial}{0}$

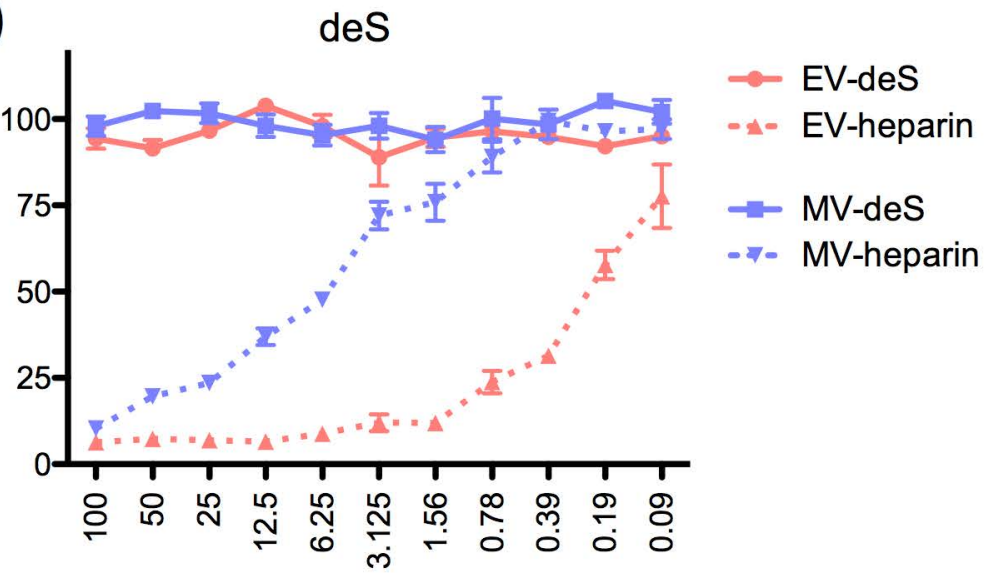

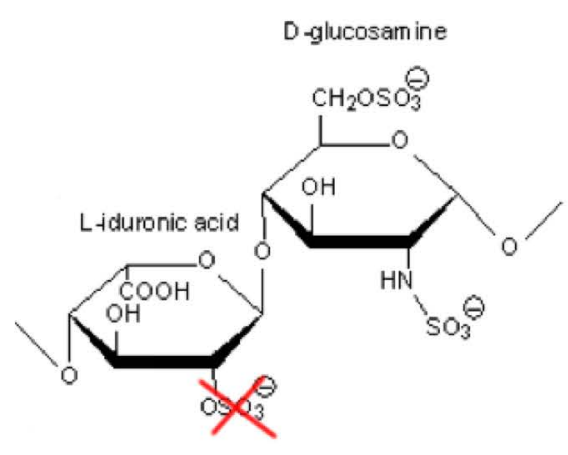
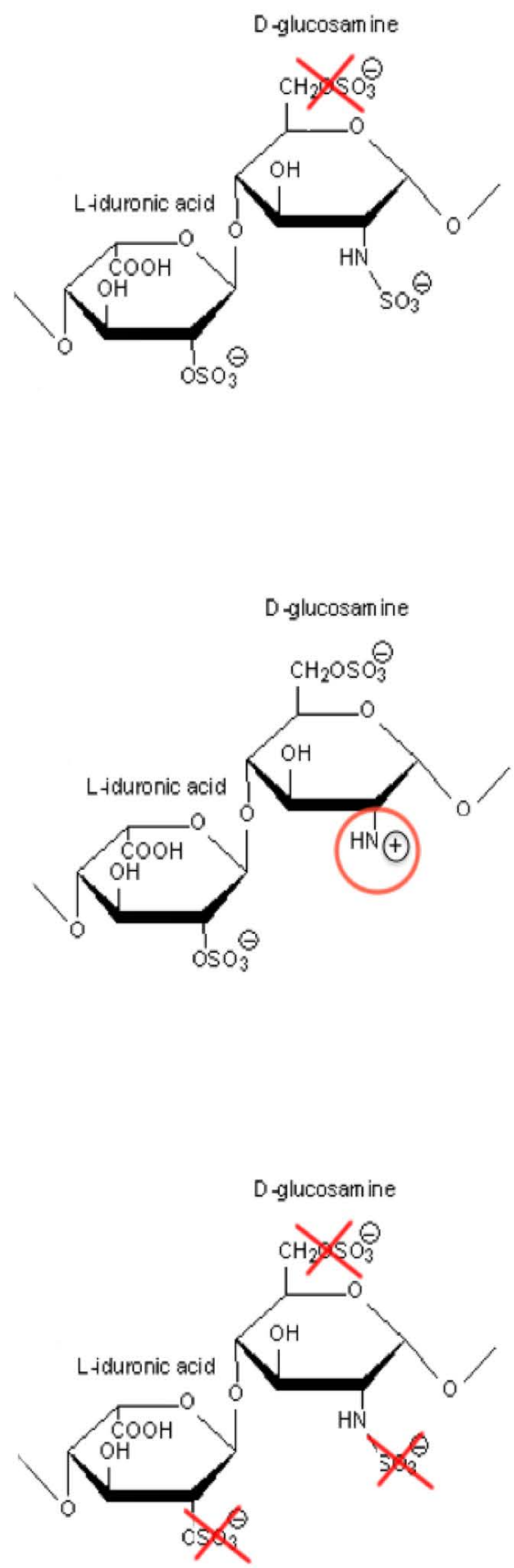

Inhibitor concentration ( $\mu \mathrm{g} \mathrm{mL}^{-1}$ ) 
(a)

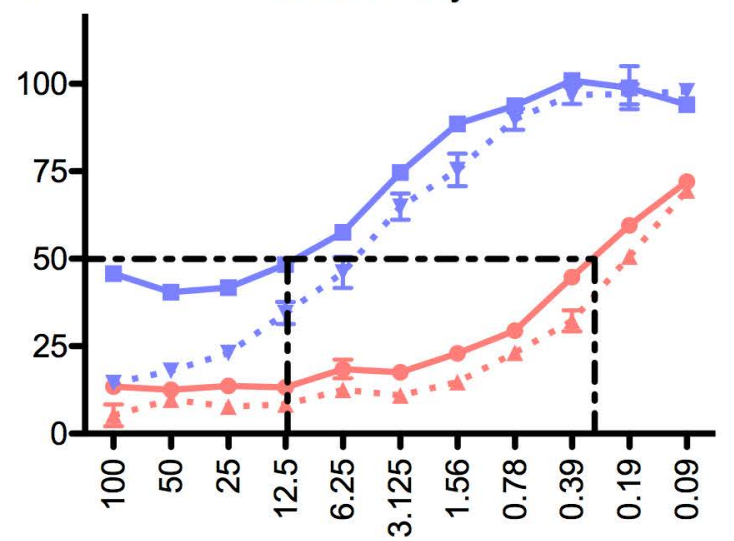

(b)

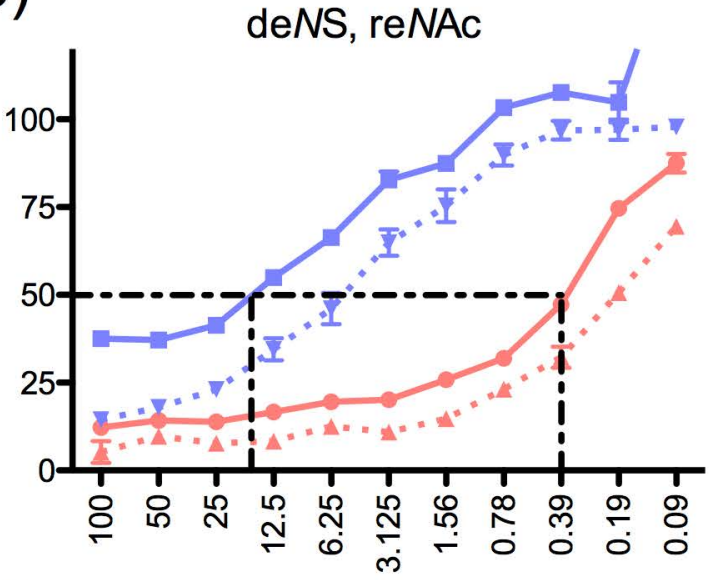

(c)

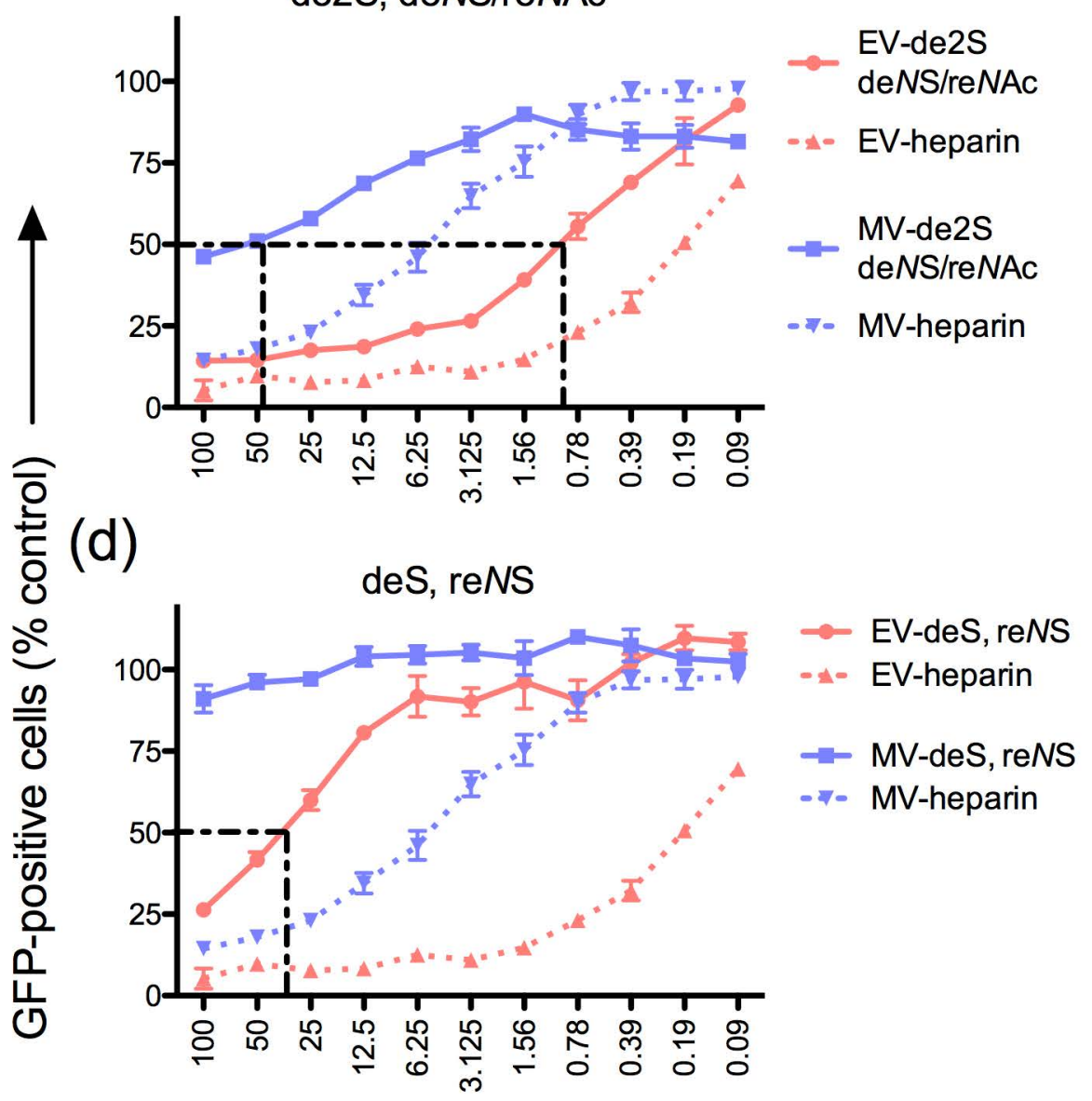

$\rightarrow$ EV-deNS, reNAc

- - EV-heparin

- MV-deNS, reNAc

- অ- MV-heparin
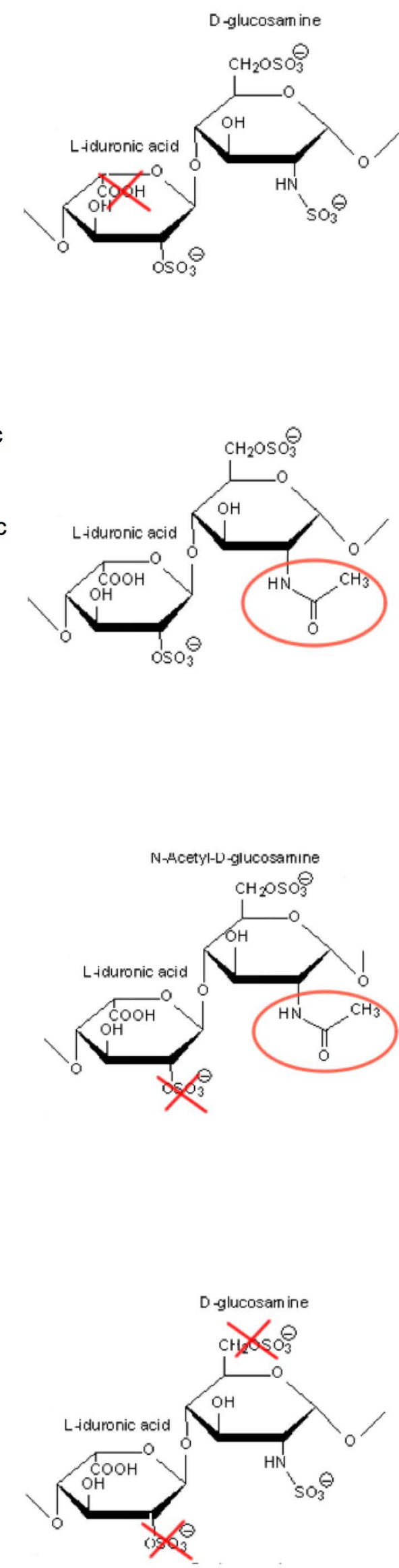
(a)

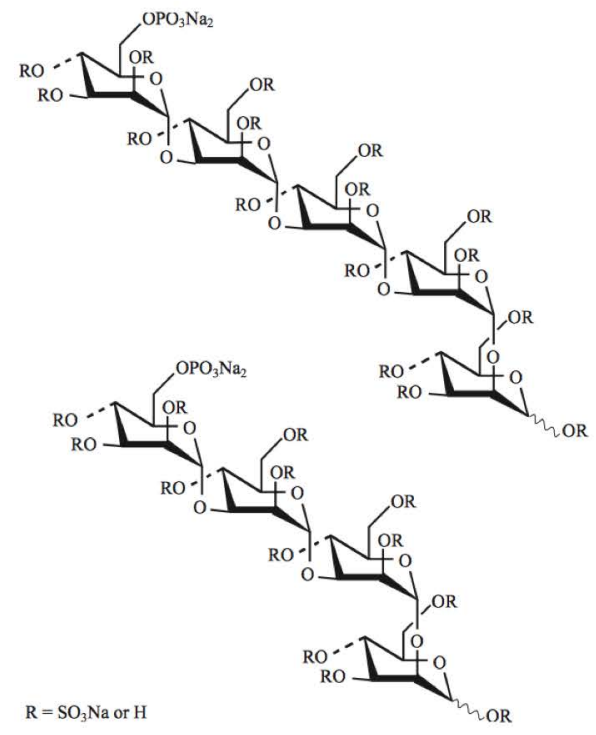

(b)

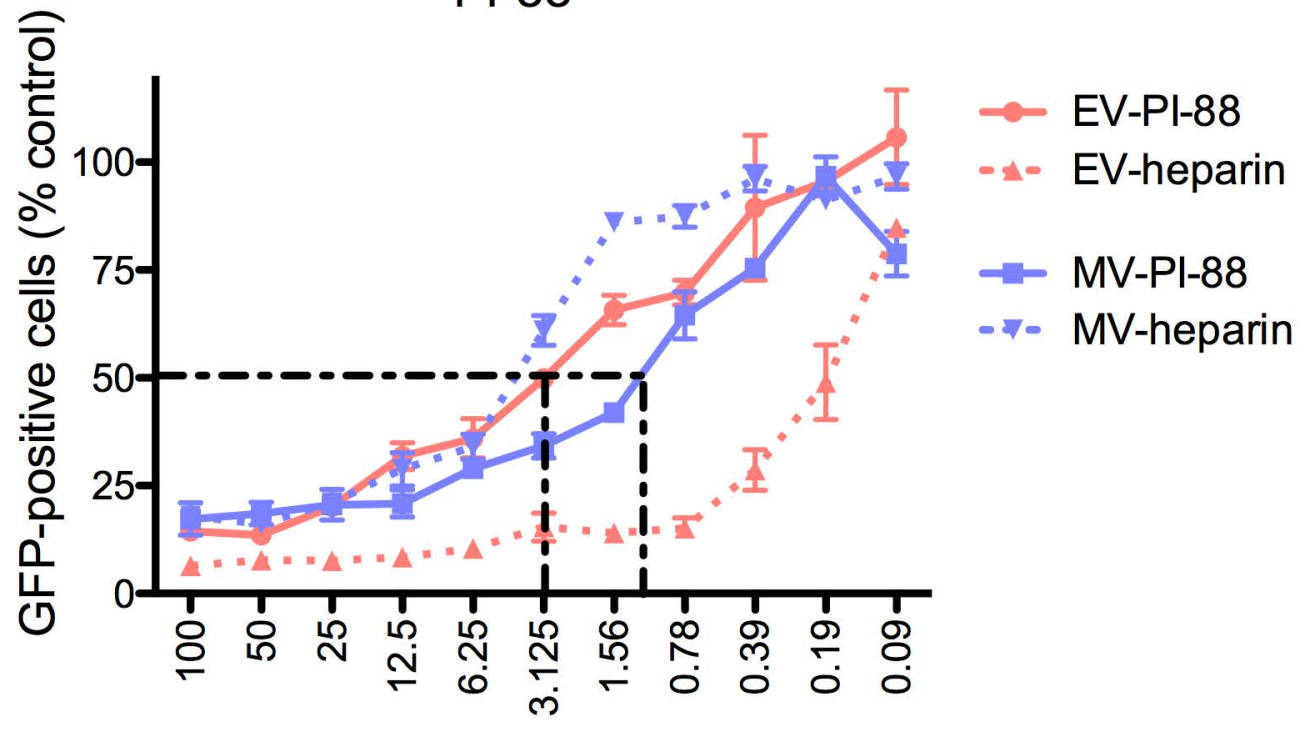

$\mathrm{Pl}-88$ concentration $\left(\mu \mathrm{g} \mathrm{mL}^{-1}\right)$ 


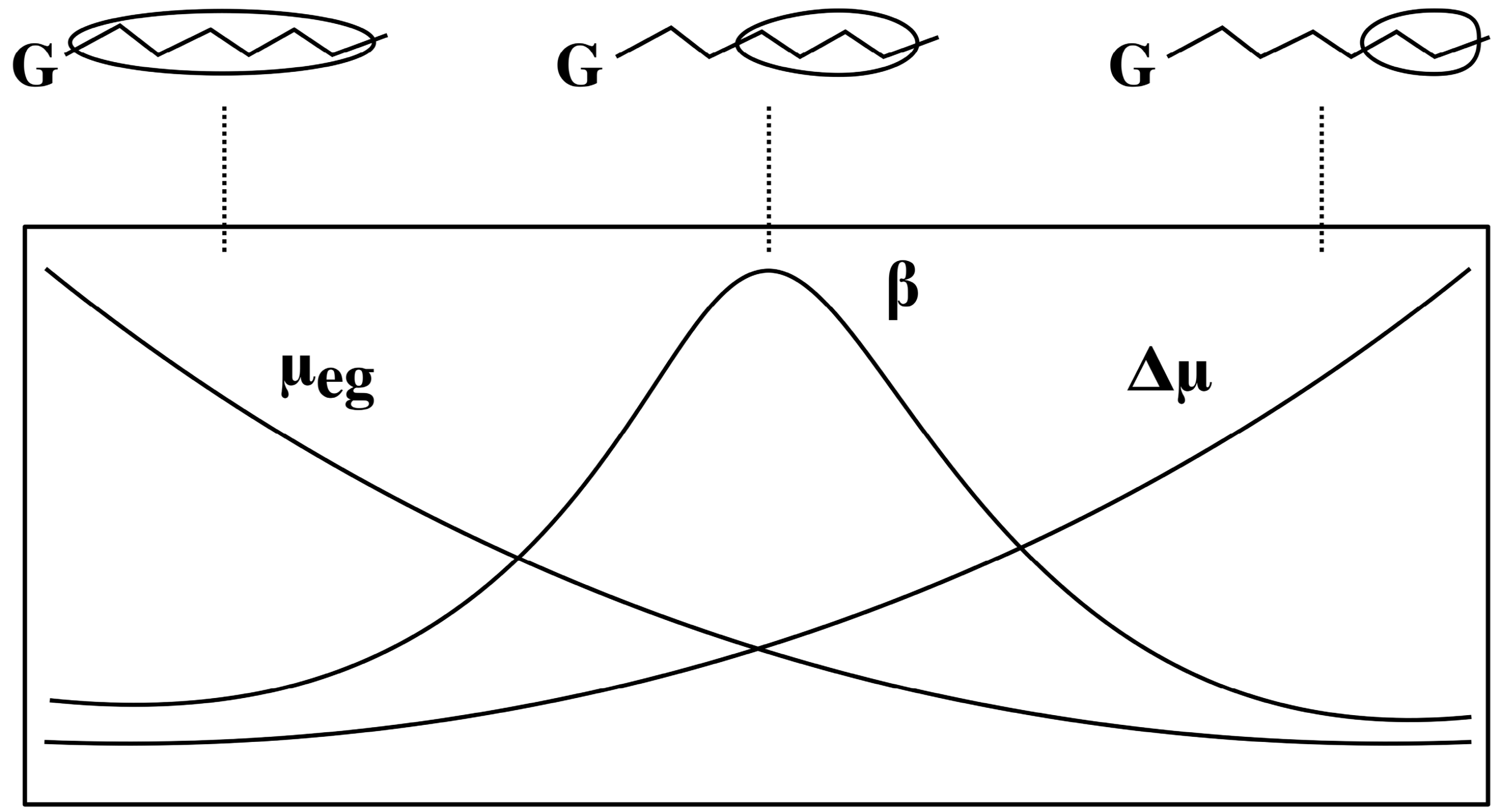

E: Excited State $\quad$ G: Ground State 


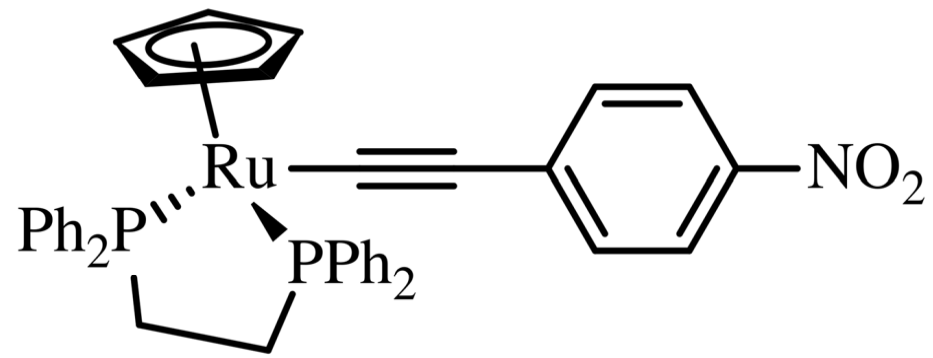

$\diamond$ BLYP $\triangle$ PBEO $\diamond$ LC-BLYP
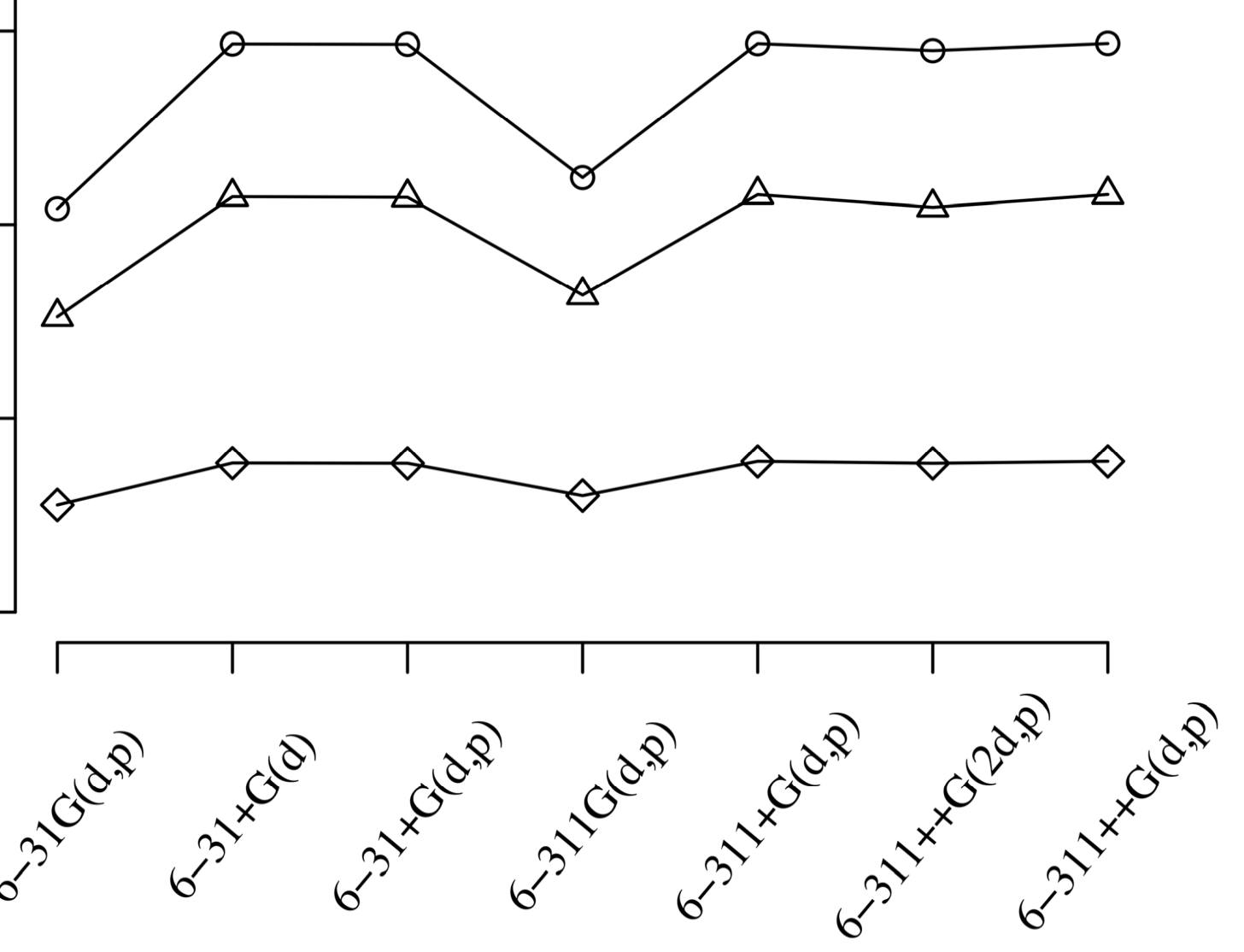
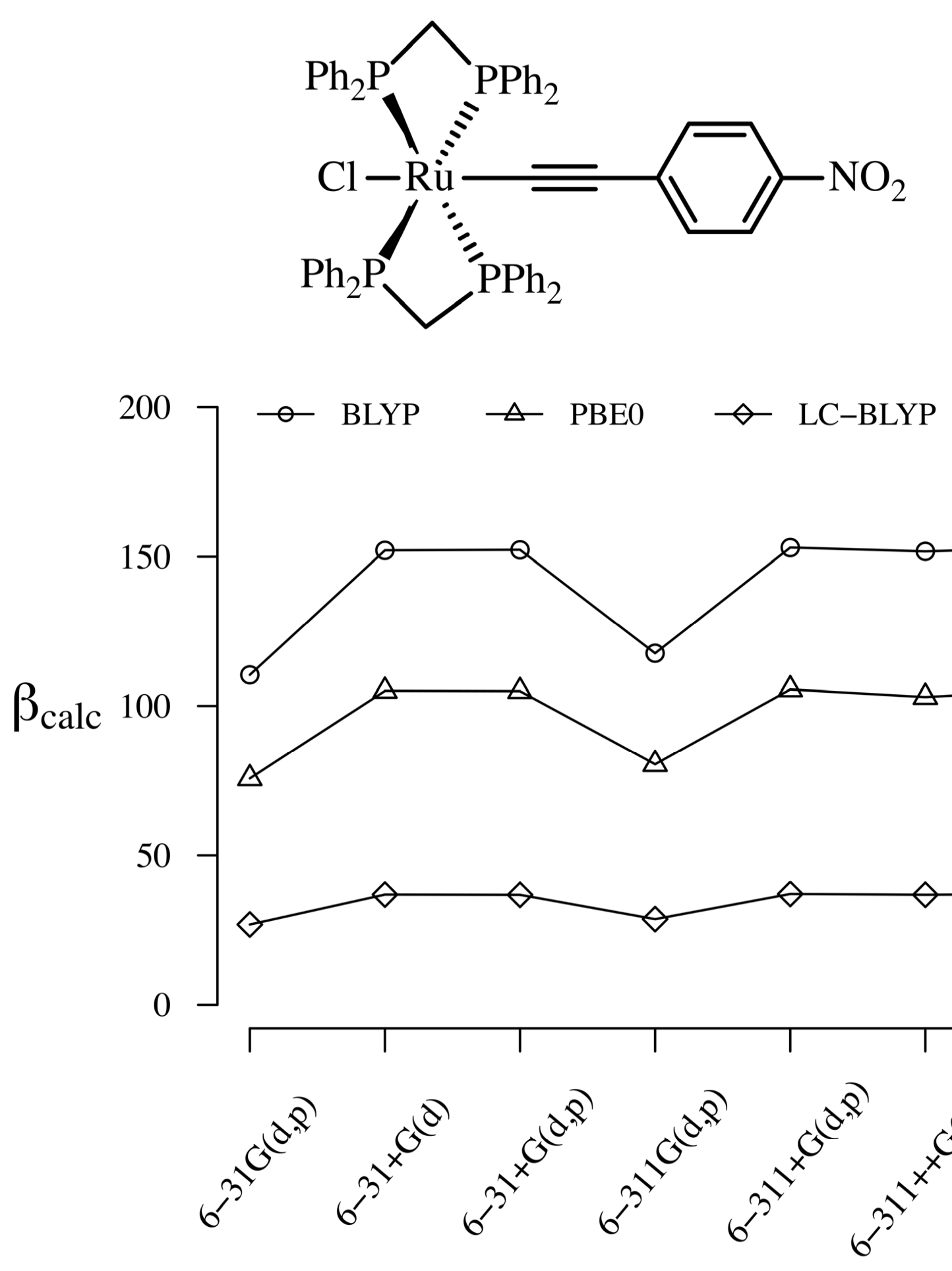

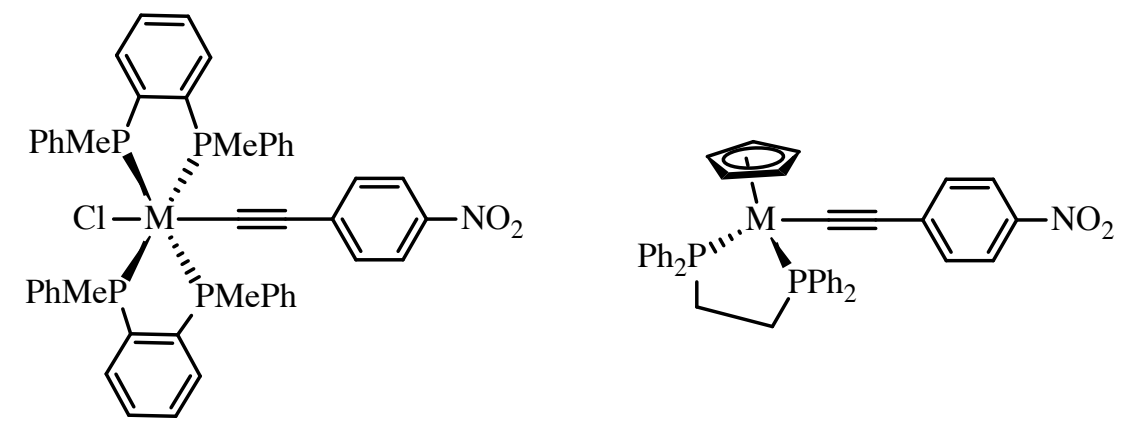

$M=F e(21 a), R u(21 b)$, Os (21c) $\quad M=F e(22 a), R u(22 b)$, Os (22c)
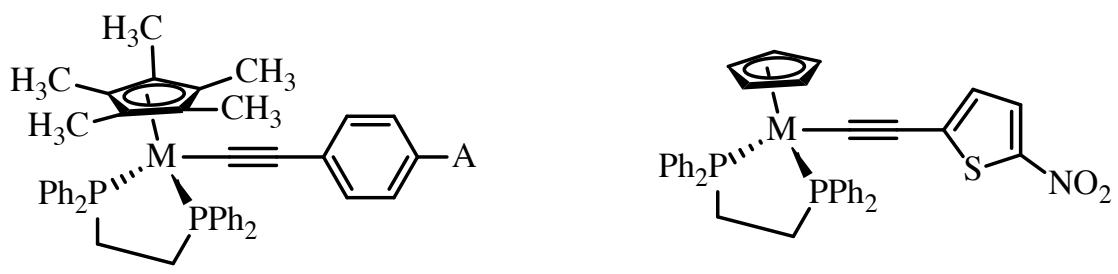

$$
\begin{aligned}
& M=F e ; A=N_{2}(\mathbf{2 3 a}), C N(\text { 23b) } \quad M=F e(25 a), R u(25 b) \\
& M=R u ; A=N O_{2}(\text { 23c), } C N(\text { 23d })
\end{aligned}
$$




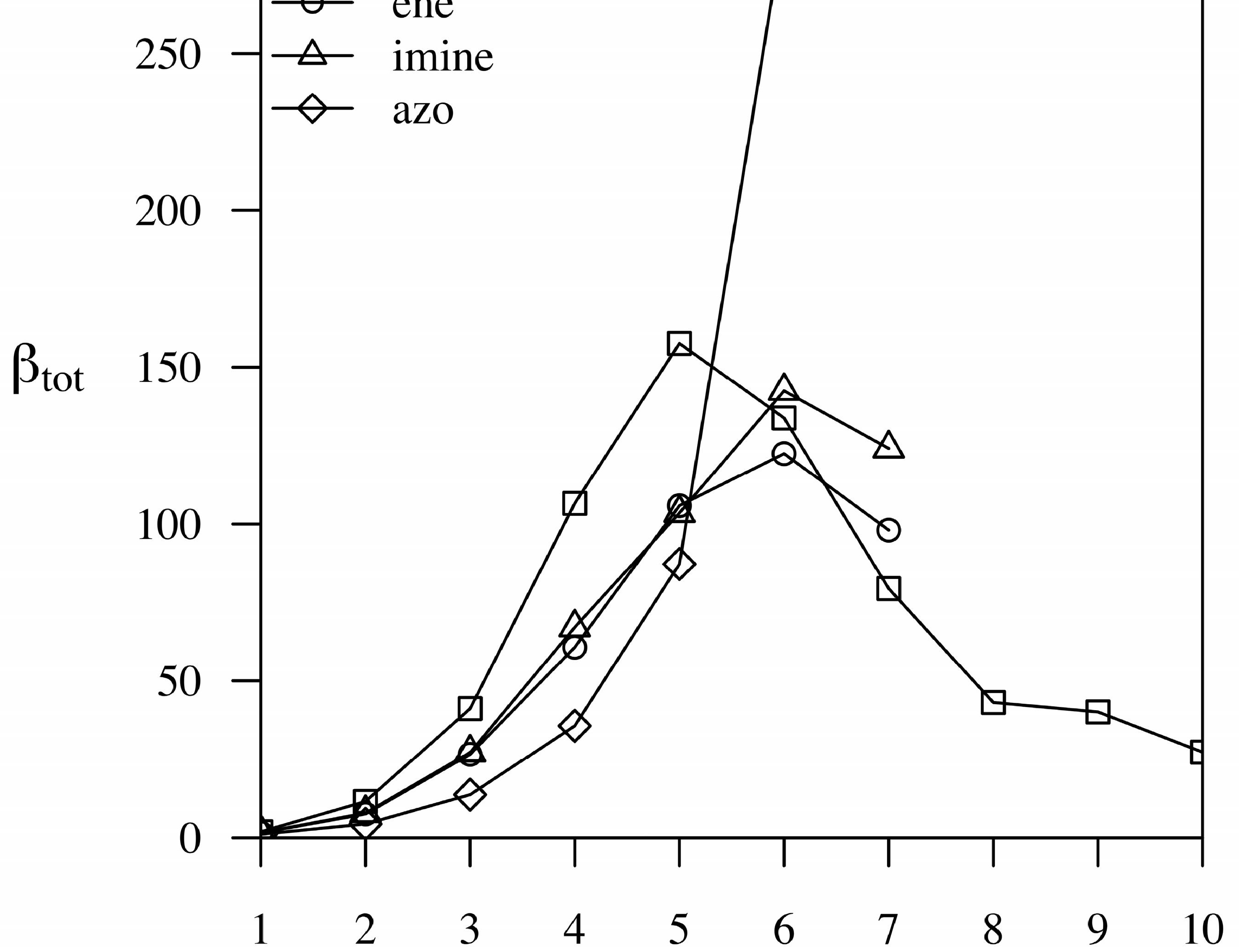




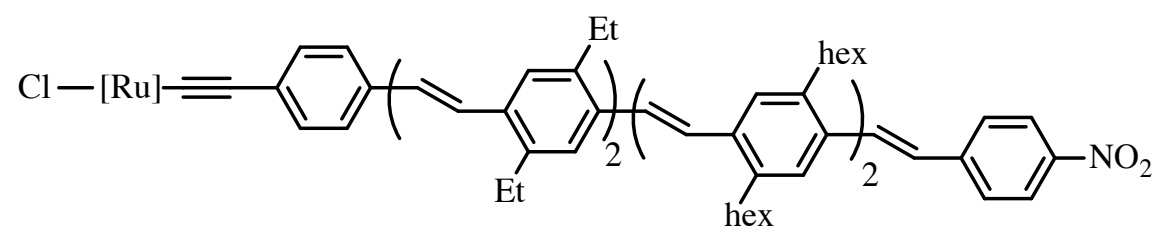

$44\left(\lambda_{\max }=419 \mathrm{~nm}, \beta_{\mathrm{exp}}=(940 \pm 240) \times 10^{-30}\right.$ esu, $\beta_{\mathrm{TLM}}=302 \times 10^{-30}$ esu $)$

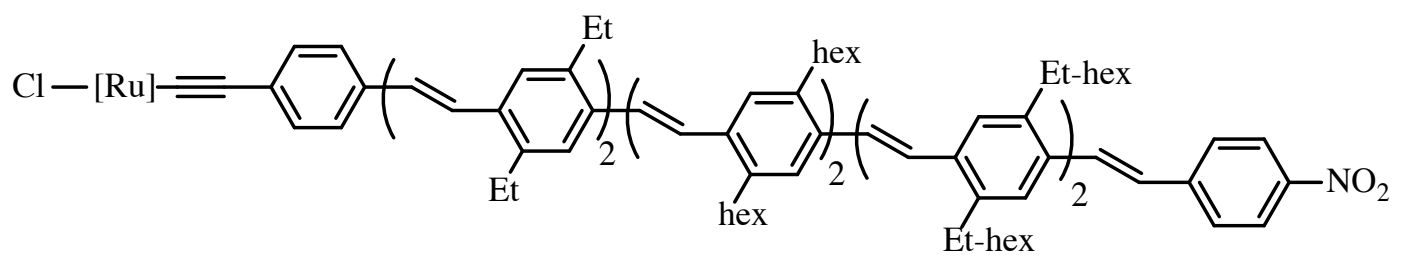

$45\left(\lambda_{\max }=423 \mathrm{~nm}, \beta_{\mathrm{exp}}=(890 \pm 220) \times 10^{-30}\right.$ esu, $\beta_{\mathrm{TLM}}=277 \times 10^{-30}$ esu $)$ 


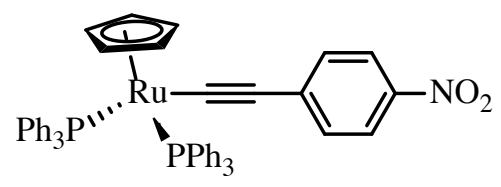

28

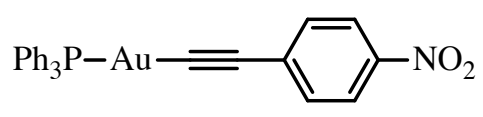

49

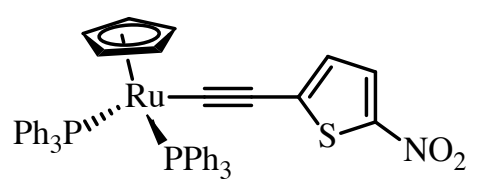

47

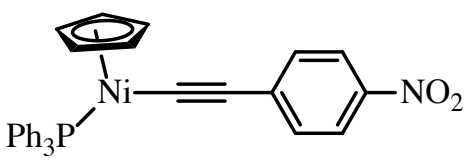

54

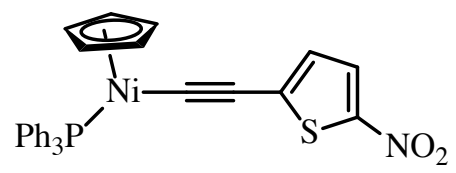

57 